\title{
Numerical modeling of cold flow and hot gas desulfurization in a circulating fluidized bed
}

Neeraj N. Pugalia

West Virginia University

Follow this and additional works at: https://researchrepository.wvu.edu/etd

\section{Recommended Citation}

Pugalia, Neeraj N., "Numerical modeling of cold flow and hot gas desulfurization in a circulating fluidized bed" (2001). Graduate Theses, Dissertations, and Problem Reports. 1163.

https://researchrepository.wvu.edu/etd/1163

This Thesis is protected by copyright and/or related rights. It has been brought to you by the The Research Repository @ WVU with permission from the rights-holder(s). You are free to use this Thesis in any way that is permitted by the copyright and related rights legislation that applies to your use. For other uses you must obtain permission from the rights-holder(s) directly, unless additional rights are indicated by a Creative Commons license in the record and/ or on the work itself. This Thesis has been accepted for inclusion in WVU Graduate Theses, Dissertations, and Problem Reports collection by an authorized administrator of The Research Repository @ WVU. For more information, please contact researchrepository@mail.wvu.edu. 
Numerical Modeling of Cold Flow and Hot Gas Desulfurization in a Circulating Fluidized bed.

\begin{abstract}
Neeraj Pugalia
Thesis submitted to the College of Engineering and Mineral Resources at West Virginia University in partial fulfillment of the requirements for the degree
\end{abstract}

\author{
Master of Science \\ in \\ Chemical Engineering
}

\author{
Aubrey L. Miller. Ph.D., Chair \\ Eung H. Cho, Ph.D. \\ Madhava Syamlal, Ph.D.
}

Department of Chemical Engineering

Morgantown, West Virginia.

2001

Keywords: Hot Gas Desulfurization, Grain Model, Unreacted Shrinking Core Model, CFB Riser, Boundary Condition at the Wall.

Copyright 2001 Neeraj Pugalia 


\section{ABSTRACT \\ Numerical Modeling of Cold Flow and Hot Gas Desulfurization in a Circulating Fluidized bed.}

Neeraj Pugalia.

SECTION I

This work was carried out to understand the behavior of the solid and gas phases in a CFB riser. Only the riser is modeled as a straight pipe. A model with linear algebraic approximation to solids viscosity of the form, $\mu_{\mathrm{s}}=5.34 \varepsilon_{\mathrm{s}}$, ( $\varepsilon_{\mathrm{s}}$ is the solids volume fraction) with an appropriate boundary condition at the wall obtained by approximate momentum balance solution at the wall to account for the solids recirculation is tested against experimental results. The work done was to predict the flow patterns in the CFB risers from available experimental data, including data from a 7.5-cm-ID CFB riser at the Illinois Institute of Technology and data from a 20.0-cm-ID CFB riser at the Particulate Solid Research, Inc., facility .

\section{SECTION II}

This research aims at modeling the removal of hydrogen sulfide from hot coal gas using zinc oxide as the sorbent in a circulating fluidized bed and in the process identifying the parameters that affect the performance of the sulfidation reactor. Two different gas-solid reaction models, the unreacted shrinking core (USC) and the grain model were applied to take into account chemical reaction resistances. Also two different approaches were used to affect the hydrodynamics of the process streams. The first model takes into account the effect of micro-scale particle clustering by adjusting the gasparticle drag law and the second one assumes a turbulent core with pseudo-steady state boundary condition at the wall. A comparison is made with experimental results 


\section{ACKNOWLEDGEMENTS}

I would like express my sincere gratitude and appreciation to my advisor Dr. A. L. Miller for his advice, encouragement and support but above all his belief in me through out the course of this work.

I would like to thank my committee members, Dr. E. Cho and Dr. M Syamlal for their guidance, invaluable suggestions and sharing their experiences with me.

Many thanks to Mr. D. Berry and Mr. C. Guenther from NETL, Morgantown for sharing some of experimental data, operating conditions for hot gas desulfurization and important inputs and valuable tips regarding working of MFIX.

I would like to acknowledge the faculty and graduate students, Department of Chemical Engineering, WVU, who have been kind, helpful and supportive .

Special thanks to Ms. L. Rogers and Ms B. Helmick for their co-operation and timely help with the paper work .

I would like to thank my friends Dharmarajan Hariharan, Ganesh Kumar, Rahul Shukla, Swamy Vaddey and Ramesh Gali for their motivation, support and important inputs throughout my research. I learned some new values from them and I am thankful for that.

Last but not the least I would like to thank my family for their never ending support and faith in me and I dedicate this work to my grandmother. 


\section{TABLE OF CONTENTS}

$\begin{array}{ll}\text { Acknowledgements } & \text { ii }\end{array}$

$\begin{array}{ll}\text { Abstract. } & \text { iii }\end{array}$

Table of Contents.

List of Tables. vii

List of Figures. viii

$\begin{array}{ll}\text { Nomenclature } & \text { xiii }\end{array}$

\section{SECTION I.}

CHAPTER I. INTRODUCTION 1

1.1 Introduction to CFB 1

1.2 Objective 2

CHAPTER II. REVIEW OF LITERATURE

2.1 Introduction 4

2.2 Hydrodynamic Models

2.3 Most Recent Work $\quad 8$

CHAPTER III. MODEL DESCRIPTION 12

3.1 Introduction 12

3.2 Boundary Condition at the Wall. 14

3.3 Modeling conditions and experimental data used for comparison 16

CHAPTER IV. RESULTS AND DISCUSSION 18

$\begin{array}{lll}\text { 4.1 PSRI riser } & 18\end{array}$

4.1.1 Effect of Inlet Specifications $\quad 19$ 
4.1.3 Comparison of results 22

$\begin{array}{ll}4.2 \text { IIT riser } & 25\end{array}$

4.2.1 Comparison of results 26

4.3 Effect of varying the solids viscosity and particle diameter on flow profiles 31

CHAPTER V. CONCLUSION 34

REFERENCES

APPENDIX A. MFIX Sample Subroutines 41

\section{SECTION II.}

CHAPTER I. INTRODUCTION

1.1 Introduction to Hot Gas Desulfurization 54

$\begin{array}{ll}1.2 \text { Objective } & 56\end{array}$

CHAPTER II. LITERATURE SURVEY

$\begin{array}{ll}2.1 \text { Introduction } & 57\end{array}$

2.2 Gas Solid Reaction Models $\quad 58$

2.2.1 Unreacted Shrinking Core Model $\quad 58$

2.2.2 The Grain Model

2.2.3 Overlapping Grain Model

2.3 Modeling of Hot Gas Desulfurization $\quad 59$

2.4 Details of the Grain Model 67

CHAPTER III. IMPLEMENTATION OF THE GRAIN MODEL IN MFIX 72

$\begin{array}{ll}3.1 \text { Introduction } & 72\end{array}$

3.2 Rate expression for the Control Volume 73 
3.4 Geometry and Operating Conditions $\quad 81$

CHAPTER IV. RESULTS AND DISCUSSION 83

$\begin{array}{ll}\text { 4.1 Setup A results. } & 83\end{array}$

$\begin{array}{ll}\text { 4.2 Setup B results } & 87\end{array}$

$\begin{array}{ll}4.3 \text { Setup C results } & 90\end{array}$

4.3.1 Effect of pressure drop across the reactor on the sulfur capture. 90

4.3.2 Effect of boundary condition and solids viscosity on the sulfur capture 94

4.3.3 Effect of the gas-solid reaction model on the sulfur capture. 98

CHAPTER V. CONCLUSION 101

$\begin{array}{ll}\text { REFERENCES } & 103\end{array}$

$\begin{array}{ll}\text { APPENDIX A. Summary Of Equations } & 107\end{array}$

APPENDIX B. MFIX Sample Subroutines 109 


\section{LIST OF TABLES}

\section{SECTION I.}

Table I. List of Equations in the Hydrodynamic Model ............................................. 13

Table II. Modeling Conditions for PSRI CFB riser. ..................................................... 18

Table III. Parameters of air/fcc system of IIT CFB riser. ...........................................225

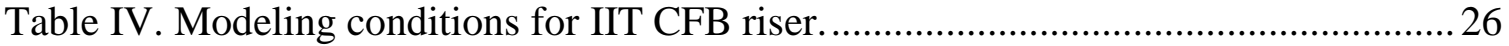

SECTION II.

Table I. Reactor setup and parameters................................ 82 


\section{SECTION I.}

\section{LIST OF FIGURES}

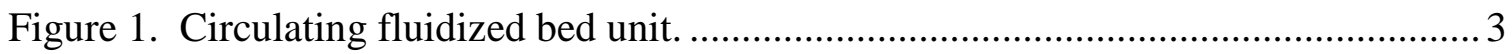

Figure 2. Cell arrangement at a characteristic wall.................................................... 15

Figure 3. Riser modeled as a straight pipe with reduced inlet. ........................................ 19

Figure 4. Effect of inlet volume fraction specifications. [superficial gas velocity $=5.2 \mathrm{~m} / \mathrm{s}$,

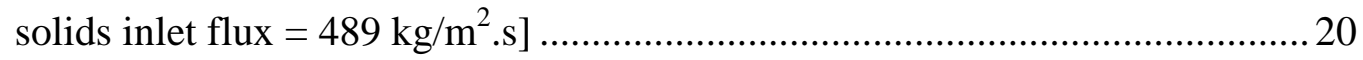

Figure 5. Effect of inlet volume fraction specifications .[superficial gas velocity $=5.2$ $\mathrm{m} / \mathrm{s}$, solids inlet flux $\left.=489 \mathrm{~kg} / \mathrm{m}^{2} . \mathrm{s}\right]$

Figure 6. Effect of friction factor $\mathrm{f}_{\mathrm{s}}$ [gas inlet velocity $=5.2 \mathrm{~m} / \mathrm{s}$ solids inlet flux $=489$

$\mathrm{kg} / \mathrm{m}^{2} . \mathrm{s}, \mu_{\mathrm{s}}=5.34 \varepsilon{ }_{\mathrm{s}}$ poise $]$

Figure 7. Effect of friction factor $\mathrm{f}_{\mathrm{s}}$ [gas inlet velocity $=5.2 \mathrm{~m} / \mathrm{s}$ solids inlet flux $=489$

$\mathrm{kg} / \mathrm{m}^{2} . \mathrm{s}, \mu_{\mathrm{s}}=5.34 \varepsilon{ }_{\mathrm{s}}$ poise $]$

Figure 8. Radial profile of solid volume fraction at $3.9 \mathrm{~m}$ in the PSRI CFB riser. [superficial gas velocity $=7.6 \mathrm{~m} / \mathrm{s} ;$ solids feed flux $\left.=489.0 \mathrm{~kg} / \mathrm{m}^{2} . \mathrm{s}\right]$

Figure 9. Radial profile of solid flux at $3.9 \mathrm{~m}$ in the PSRI CFB riser.[superficial gas velocity $=7.6 \mathrm{~m} / \mathrm{s} ;$ solids feed flux $\left.=489.0 \mathrm{~kg} / \mathrm{m}^{2} . \mathrm{s}\right]$

Figure 10. Radial profile of solid volume fraction at $3.9 \mathrm{~m}$ in the PSRI CFB riser. $\left[\right.$ superficial gas velocity $=11.0 \mathrm{~m} / \mathrm{s}$; solids feed flux $\left.=489.0 \mathrm{~kg} / \mathrm{m}^{2} . \mathrm{s}\right] \ldots \ldots .24$

Figure 11. Radial profile of solid volume fraction at $3.9 \mathrm{~m}$ in the PSRI CFB riser. $\left[\right.$ superficial gas velocity $=11.0 \mathrm{~m} / \mathrm{s}$; solids feed flux $\left.=489.0 \mathrm{~kg} / \mathrm{m}^{2} . \mathrm{s}\right] \ldots \ldots .24$ 
Figure 12. Radial profile of solid volume fraction at $1.86 \mathrm{~m}$ in the IIT CFB riser. $\left[\right.$ superficial gas velocity $=2.89 \mathrm{~m} / \mathrm{s}$; solids feed flux $\left.=20.4 \mathrm{~kg} / \mathrm{m}^{2} . \mathrm{s}\right] \ldots .26$

Figure 13. Radial profile of solid flux at $1.86 \mathrm{~m}$ in the IIT CFB riser.[superficial gas velocity $=2.89 \mathrm{~m} / \mathrm{s} ;$ solids feed flux $\left.=20.4 \mathrm{~kg} / \mathrm{m}^{2} . \mathrm{s}\right]$

Figure 14. Radial profile of solid volume fraction at $1.86 \mathrm{~m}$ in the IIT CFB riser. $\left[\right.$ superficial gas velocity $=2.89 \mathrm{~m} / \mathrm{s} ;$ solids feed flux $\left.=12.0 \mathrm{~kg} / \mathrm{m}^{2} . \mathrm{s}\right] \ldots .27$

Figure 15. Radial profile of solid flux at $1.86 \mathrm{~m}$ in the IIT CFB riser.[superficial gas velocity $=2.89 \mathrm{~m} / \mathrm{s} ;$ solids feed flux $\left.=12.0 \mathrm{~kg} / \mathrm{m}^{2} . \mathrm{s}\right]$ 28

Figure 16. Radial profile of solid volume fraction at $1.86 \mathrm{~m}$ in the IIT CFB riser. $\left[\right.$ superficial gas velocity $=2.89 \mathrm{~m} / \mathrm{s} ;$ solids feed flux $=32.8 \mathrm{~kg} / \mathrm{m}^{2} . \mathrm{s}$ ] $\ldots 28$

Figure 17. Radial profile of solid flux at $1.86 \mathrm{~m}$ in the IIT CFB riser.[superficial gas velocity $=2.89 \mathrm{~m} / \mathrm{s} ;$ solids feed flux $\left.=32.8 \mathrm{~kg} / \mathrm{m}^{2} . \mathrm{s}\right]$

Figure 18. Radial profile of solid volume fraction at $1.86 \mathrm{~m}$ in the IIT CFB riser. $\left[\right.$ superficial gas velocity $=2.61 \mathrm{~m} / \mathrm{s} ;$ solids feed flux $\left.=20.4 \mathrm{~kg} / \mathrm{m}^{2} . \mathrm{s}\right] \ldots .29$

Figure 19. Radial profile of solid flux at $1.86 \mathrm{~m}$ in the IIT CFB riser. [superficial gas velocity $=2.61 \mathrm{~m} / \mathrm{s} ;$ solids feed flux $\left.=20.4 \mathrm{~kg} / \mathrm{m}^{2} . \mathrm{s}\right]$ 30

Figure 20. Effect of ' $n$ ' in $\mu_{\mathrm{s}}=\mathrm{n} \varepsilon_{\mathrm{s}}$ model, gas inlet velocity $=5.2 \mathrm{~m} / \mathrm{s}$ solids inlet $\ldots \ldots \ldots . . .31$

$$
\text { Flux }=489 \mathrm{~kg} / \mathrm{m}^{2} . \mathrm{s}
$$

Figure 21. Effect of ' $n$ ' in $\mu_{\mathrm{s}}=\mathrm{n} \varepsilon_{\mathrm{s}}$ model, gas inlet velocity $=5.2 \mathrm{~m} / \mathrm{s}$ solids inlet

$$
\text { Flux }=489 \mathrm{~kg} / \mathrm{m}^{2} . \mathrm{s}
$$

Figure 22. Effect of particle diameter. Gas inlet vel. $5.2 \mathrm{~m} / \mathrm{s}$ solids inlet

$$
\text { Flux }=489 \mathrm{~kg} / \mathrm{m}^{2} . \mathrm{s}
$$


Figure 23. Effect of particle diameter. Gas inlet vel. $5.2 \mathrm{~m} / \mathrm{s}$ solids inlet Flux $=489$

$\mathrm{kg} / \mathrm{m}^{2}$.s.

\section{SECTION II.}

Figure2.1 Time conversion data intermediate temperatures. (Gibson and Harrison, 1980)

Figure2.2 Experimental Sulfidation Profiles of $\mathrm{ZnO}$ at $500{ }^{\circ} \mathrm{C}$ Reacted in 1, 2 and $3 \% \mathrm{H}_{2} \mathrm{~S}$ Vs. calculated profiles from the overlapping grain model. ( Susan Lew, Adel Sarofim, Flytzani-Stephanopoulos, 1992 ............

Figure2.3 Experimental Sulfidation Profiles of $\mathrm{ZnO}$ at $400-700{ }^{\circ} \mathrm{C}, 2 \% \mathrm{H}_{2} \mathrm{~S}$ Vs. calculated profiles from the overlapping grain model. (Susan Lew, Adel Sarofim, Flytzani-Stephanopoulos, 1992).......................

Figure2.4 Fit of Unreacted Shrinking Core (USC) and Overlapping Grain (OG) models into TGA data with sorbent A $12000 \mathrm{ppmv}_{2} \mathrm{~S}$ at 400, 500 and $600{ }^{\circ}$ C. ( J.T Konttinen, C. A. P. Zevenhoven and M. M. Hupa, 1997).

Figure2.5 USC and OG models fit into life-cycle fluidized bed sulfidation data of sorbent B at high pressure during cycles 1,17 and $30\left(\mathrm{H}_{2} \mathrm{~S} 1\right.$ vol. \%). ( J.T Konttinen, C. A. P. Zevenhoven and M. M. Hupa, 1997)......

Figure2.6 Fit of USC and OG models into solid conversion rate data produced in fluidized bed at high pressure with sorbent B.200, 1500 ppmv $\mathrm{H}_{2} \mathrm{~S}$. ( J.T Konttinen, C. A. P. Zevenhoven and M. M. Hupa, 1997)...........

Figure 2.7 Variable size grain model. .68

Figure 4.1. Variation of solids volume fraction with radial distance. [Setup A] .84 
Figure 4.2. Variation of solids and gas velocity with radial distance. [Setup A] ............. 84

Figure 4.3. Variation of solid flux with radial distance. [Setup A] .............................. 85

Figure 4.4. Effect of cluster correction on the radial gas and solids velocities. [SetupA] 85

Figure 4.5. Effect of cluster correction on solids volume fraction. [Setup A] .................86

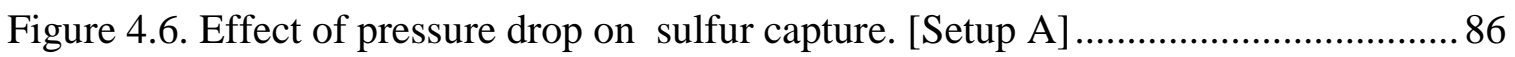

Figure 4.7. Effect of initial specific surface area and sorbent purity on the sulfur capture

[Setup B]

Figure 4.8. Variation of solids volume fraction with radial distance. [Setup B] 88

Figure 4.9. Variation of gas and solid velocity with radial distance. [Setup B] 88

Figure 4.10. Variation of solid flux with radial distance. [Setup B]....

Figure 4.11. Effect of Pressure drop on sulfur capture. [Setup C] .91

Figure 4.12. Variation of sulfur capture with solids volume fraction. [Setup C] ............91

Figure 4.13.Variation of sulfur capture with slip velocity. [Setup C] ............................ 92

Figure 4.14. Variation of solids volume fraction with radial distance. [Setup C] ...........92

Figure 4.15. Variation of gas and solid velocity with radial distance. [Setup C] ...........93

Figure 4.16. Variation of solids flux with radial distance. [Setup C] ........................... 93

Figure 4.17. Variation of gas and solid velocity with radial distance. Effect of gas solid boundary condition. [Setup C] 94

Figure 4.18. Variation of solids volume fraction with radial distance. [Setup C] ..........95

Figure 4.19. Variation of gas and solid velocity with radial distance. Effect of gas-solid boundary condition. $[$ Setup C] …................................................ 96

Figure 4.20. Variation of solids volume fraction with radial distance Effect of gas- solid boundary condition. [Setup C] 96 
Figure 4.21. Variation of solid volume fraction with radial distance. Effect of gas-solid boundary condition and solid viscosity. [Setup C]

Figure 4.22. Variation of gas and solid velocity with radial distance. Effect of gas solid boundary condition and solid viscosity. [Setup C] .98

Figure 4.23. Variation of solids volume fraction with radial distance. A comparison between the grain model and the unreacted shrinking core model. [Setup C] 99

Figure 4.24. Variation of hydrogen sulfide mass fraction along the height of the CFB. A comparison between the grain model and the unreacted shrinking core model. [Setup C] 99 


\section{NOMENCLATURE}

\section{SECTION I and II.}

$\mathrm{D}_{\mathrm{e}} \quad$ Product layer diffusivity. $\left(\mathrm{cm}^{2} / \mathrm{sec}.\right)$

$\rho_{\mathrm{s}} \quad$ Density of the solid particle. $\left(\mathrm{g} / \mathrm{cm}^{3}\right)$

$\varepsilon_{0} \quad$ Initial porosity of the sorbent particle.

$\mathrm{r}_{0} \quad$ I nitial radius of the grain. $(\mathrm{cm})$

$\mathrm{A}_{0, \mathrm{~s}} \quad$ Initial specific surface area of the sorbent. $\left(\mathrm{cm}^{2} / \mathrm{g}\right)$

$\mathrm{N}_{\mathrm{H}_{2} \mathrm{~S}} \quad$ Moles of hydrogen sulfide.

$\mathrm{C}_{\mathrm{H}_{2} \mathrm{~S}} \quad$ Concentration of hydrogen sulfide. $\left(\mathrm{gmole} / \mathrm{cm}^{3}\right)$

$\mathrm{A}_{\text {surf }} \quad$ Total external surface area of the grains based on the reaction surface in the control volume. $\left(\mathrm{cm}^{2}\right)$

$\varepsilon_{\mathrm{g}} \quad$ Gas Volume Fraction.

$\mathrm{V}_{\text {cell }} \quad$ Volume of the computational cell.

$\rho_{\text {spent }} \quad$ Density of the spent sorbent. $\left(\mathrm{g} / \mathrm{cm}^{3}\right)$

$\rho_{\text {fresh }} \quad$ Density of the fresh sorbent. $\left(\mathrm{g} / \mathrm{cm}^{3}\right)$

$\mathrm{V}_{\text {grain,spent }} \quad$ Volume of the spent grain. $\left(\mathrm{cm}^{3}\right)$

$\mathrm{V}_{\text {grain,fresh }} \quad$ Volume of the fresh grain. $\left(\mathrm{cm}^{3}\right)$

$\mathrm{X}_{\text {fresh }} \quad$ Mass fraction of fresh sorbent.

$\mathrm{M}_{\mathrm{H}_{2} \mathrm{~S}} \quad$ Mass of the Hydrogen Sulfide. (g)

$\mathrm{X}_{\mathrm{H}_{2} \mathrm{~S}} \quad$ Mass fraction of Hydrogen Sulfide. (g) 


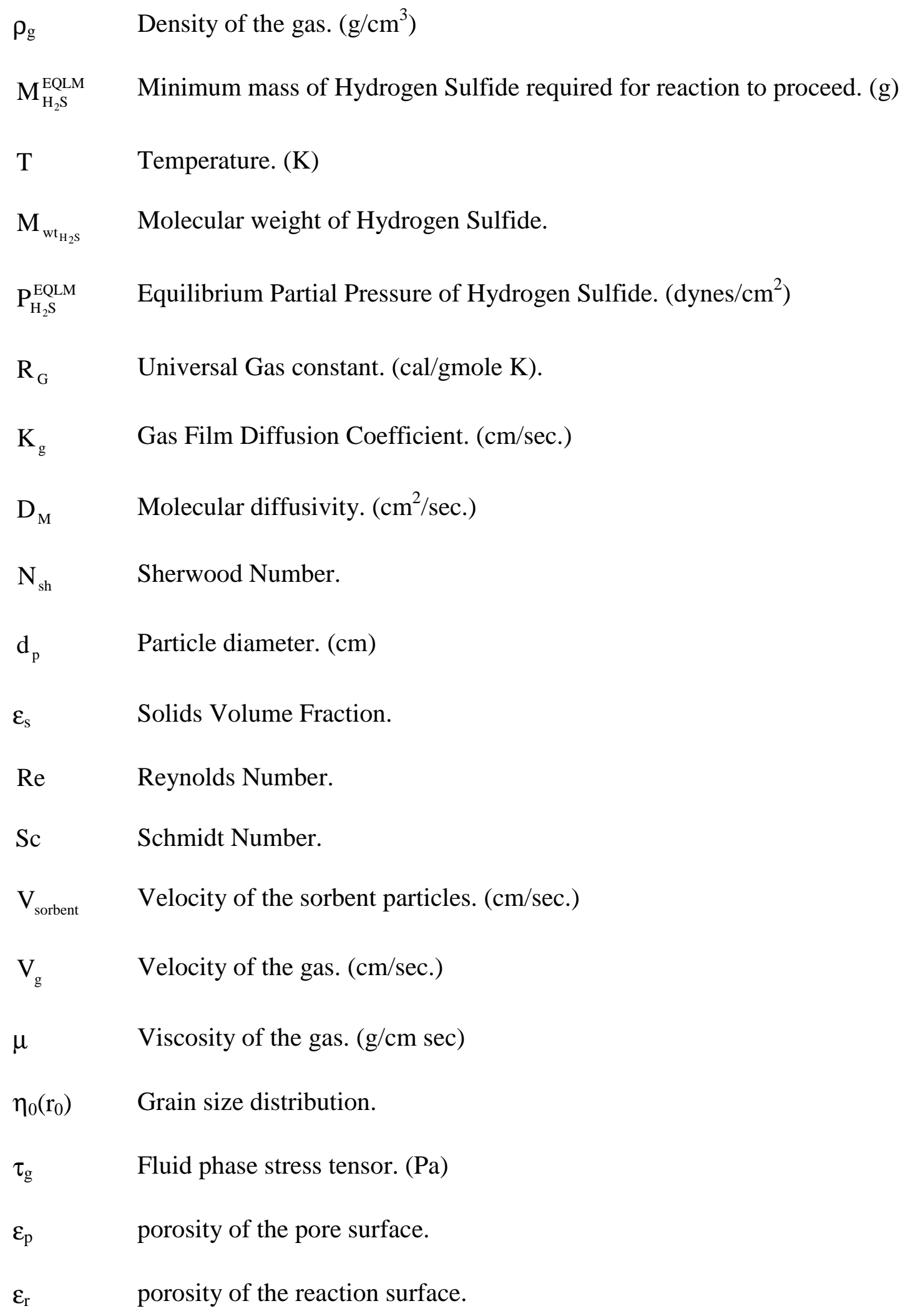


$\varepsilon_{\mathrm{sm}} \quad$ Solid volume fraction of $\mathrm{m}^{\text {th }}$ solid phase

$\rho_{\mathrm{sm}} \quad$ Material Density of $\mathrm{m}^{\text {th }}$ solid phase

$A_{p}, S_{p} \quad$ Pore surface area. $\left(\mathrm{cm}^{2}\right)$

$A_{r}, S_{r} \quad$ Reaction surface area. $\left(\mathrm{cm}^{2}\right)$

$\mathrm{A}_{\mathrm{x}} \quad$ Average cross-sectional diffusion area. $\left(\mathrm{cm}^{2}\right)$

$\mathrm{C}_{\mathrm{A} 0} \quad$ Concentration of the reactant gas in the bulk. $\left(\right.$ gmole $\left./ \mathrm{cm}^{3}\right)$

$\mathrm{C}_{\mathrm{AS}} \quad$ Concentration of the reacting gas at the surface. $\left(\mathrm{gmole} / \mathrm{cm}^{3}\right)$

$\mathrm{d}_{\mathrm{pm}} \quad$ Particle diameter for $\mathrm{m}^{\text {th }}$ solid phase. $(\mathrm{cm})$

f Geometric factor.

$\mathrm{F}_{\mathrm{g}} \quad$ Grain shape factor.

$F_{g m}, \beta \quad$ Coefficient for interphase force between fluid and solid phase. $\left(\mathrm{g} / \mathrm{cm}^{3} \mathrm{sec}\right)$

$\mathrm{k} \quad$ Intrinsic reaction rate constant. $(\mathrm{cm} / \mathrm{sec})$

$\mathrm{M}_{\text {fresh }} \quad$ Mass of the fresh sorbent. $(\mathrm{g})$

$\mathrm{M}_{\text {spent }} \quad$ Mass of the spent sorbent. (g)

$\mathrm{P}_{\mathrm{g}} \quad$ Pressure in the fluid phase. $(\mathrm{Pa})$

$\mathrm{R} \quad$ Radius of the sorbent particle. $(\mathrm{cm})$

$\mathrm{r}_{0, \max } \quad$ initial upper grain radius limit.

$\mathrm{r}_{0, \min } \quad$ initial lower grain radius limit.

$\mathrm{Re}_{\mathrm{m}} \quad \mathrm{m}^{\text {th }}$ solid phase particle Reynolds number.

$\mathrm{R}_{\mathrm{gn}} \quad$ Rate of production of $\mathrm{n}^{\text {th }}$ chemical species in the fluid phase. $\left(\mathrm{g} / \mathrm{cm}^{3} \mathrm{sec}\right)$

$\mathrm{r}_{\mathrm{p}} \quad$ Radius of the pore/product surface area. $(\mathrm{cm})$

$r_{\mathrm{r}} \quad$ Radius of the reaction surface area. $(\mathrm{cm})$

$\mathrm{R}_{\mathrm{s}} \quad$ Rate of disappearance of reactant A. ( gmoles/sec. $\mathrm{cm}^{2}$ ) 


\begin{tabular}{|c|c|}
\hline $\mathrm{R}_{\mathrm{smn}}$ & Rate of production of $n^{\text {th }}$ chemical species in the $\mathrm{m}^{\text {th }}$ solid phase. $\left(\mathrm{g} / \mathrm{cm}^{3} \mathrm{sec}\right)$ \\
\hline RXNA1F & Rate of reaction. (gmole/ $\left.\mathrm{cm}^{2} \mathrm{sec}\right)$ \\
\hline $\mathrm{S}_{\mathrm{s}}$ & Solid phase stress tensor. $(\mathrm{Pa})$ \\
\hline $\mathrm{V}_{\mathrm{g}}$ & Gas velocity. $(\mathrm{cm} / \mathrm{sec})$ \\
\hline $\mathrm{V}_{\mathrm{sm}}$ & $\mathrm{M}^{\text {th }}$ solid phase velocity vector \\
\hline $\mathrm{X}_{\mathrm{c}}, \mathrm{X}_{\mathrm{B}}$ & Fractional solid conversion. \\
\hline $\mathrm{X}_{\mathrm{gn}}$ & Mass fraction of $\mathrm{n}^{\text {th }}$ chemical species in the fluid phase \\
\hline $\mathrm{X}_{\mathrm{smn}}$ & Mass fraction of $\mathrm{n}^{\text {th }}$ chemical species in the $\mathrm{m}^{\text {th }}$ solid phase \\
\hline $\mathrm{Y}(\mathrm{t})$ & Lower active reactant grain radius limit. \\
\hline $\mathrm{Z}$ & Ratio of molar volume of the product to that of the reactant. \\
\hline $\mathrm{f}_{\mathrm{s}}$ & Friction Factor at the wall. \\
\hline$\tau_{\mathrm{rz}}$ & Radial Solid Shear stress due to flow in $\mathrm{z}$ direction. $(\mathrm{Pa})$ \\
\hline $\mathrm{V}_{\mathrm{sR}}$ & Solid Velocity at the Fictitious $(\mathrm{R})$ computational cell. $(\mathrm{cm} / \mathrm{sec})$ \\
\hline $\mathrm{V}_{\mathrm{SR}-1}$ & Solid Velocity at the $(\mathrm{R}-1)$ computational cell. $(\mathrm{cm} / \mathrm{sec})$ \\
\hline $\mathrm{v}_{\mathrm{sr}}$ & Solid Velocity at the wall. $(\mathrm{cm} / \mathrm{sec})=\left(\mathrm{v}_{\mathrm{sR}}+\mathrm{v}_{\mathrm{sR}-1}\right) / 2$ \\
\hline $\mathrm{C}(1)$ & Drag Cluster Correction Factor. \\
\hline
\end{tabular}




\section{SECTION I}




\section{CHAPTER I}

\section{INTRODUCTION}

\subsection{Introduction to CFB}

The circulating fluidized bed (CFB) is a transport reactor system. It consists of four major parts, the riser, the disengaging cyclone, the standpipe and the feeding system as shown in the figure 1 . The riser, where majority of conversion occurs in the core of the CFB reactor. CFB technology has many applications in fossil fuel processing. Originally developed for catalytic cracking in the petroleum industry, it has been extended to variety of uses including coal fired boilers for power generation.

A CFB is characterized by high superficial gas velocity and high solid recirculation rate through the bed. Squires et al.,1985,1986, have reviewed the subject of CFB application. The flow regimes in which the CFB is operated is termed as the fast fluidization regime. It is a regime between the bubbling/ slugging regime and the dilute phase transport regime (Yerushalmi, et al. 1986). It has been known that the axial and radial inhomogeneous distribution of solid particles and substantial back mixing of gas and solids exist in the fast fluidization regime. In dilute fast fluidization regime, solid particles tend to segregate in relatively large dense clusters. In dense fast fluidization regime, the gas and the solids move in a core-annulus type of flow patterns (Weisten, et al., 1986, Bader et al.,1988, Miller 1991). The core-annulus flow can be defined as a low density, upward, rapidly moving gas-solid core surrounded by a downward, relatively slower moving, high density annulus near the wall. Also gas-solid flows are a part of many chemical processes. Thus their study is of importance in design, improvement and 
scale up of new and old processes Therefore, the key to a quantitative understanding of the circulating fluidized beds is the prediction of the flow patterns of the gas and the solids in the riser. Numerical simulations of these phenomena represent an important part of this effort to better understand and hence improve these processes.

\subsection{Objective}

These trials represent the work done to better understand the behavior of the solid and gas phases at the wall of a CFB riser. Only the riser is modeled as a straight pipe.

The aim was also to test the linear algebraic approximation to solids viscosity of the form, $\mu_{\mathrm{s}}=\mathrm{n} \varepsilon_{\mathrm{s}}$, (Miller \& Gidaspow, 1992) with an oppropriate boundary condition at the wall and compare it with the experimental results. We used a two-phase fluid flow computational model to predict the gas-solids flow patterns in the riser of CFB. This two dimensional computational model consisted of a generalization of the Navier-Stoke`s equations for two phases (gas and solids). The axial solids boundary condition at the wall of the riser was modified by using the approximate momentum balance solution at the wall to account for the solids recirculation. The work done was to predict the flow patterns in the CFB risers from available experimental data, including data from a 7.5cm-ID CFB riser at the Illinois Institute of Technology (Miller, 1991) and data from a 20.0-cm-ID CFB riser at the Particulate Solid Research, Inc., facility (Knowlton, 1995). 


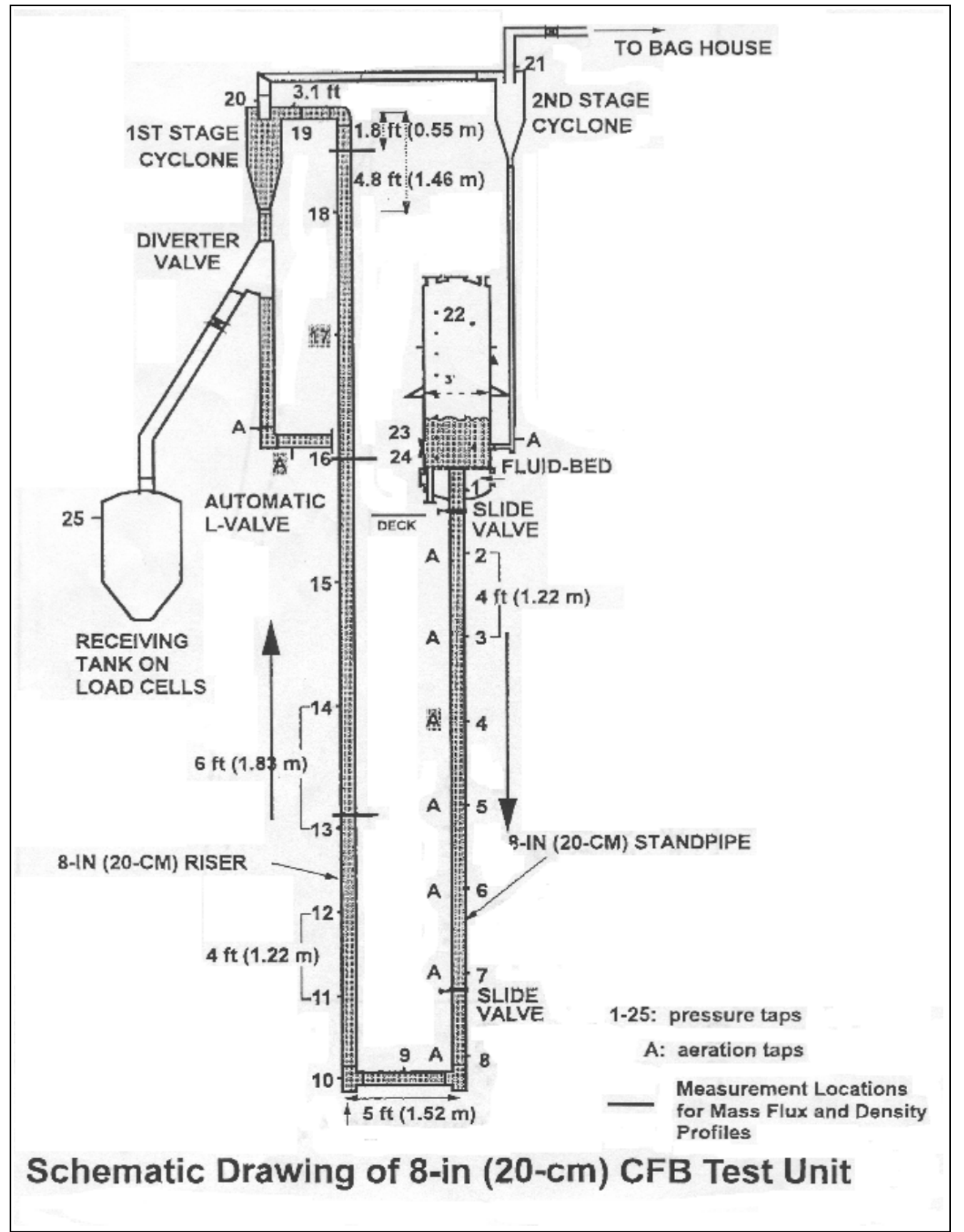

Figure 1. Circulating Fluidized bed unit. 


\section{CHAPTER II \\ REVIEW OF LITERATURE}

\subsection{Introduction}

This chapter covers some of the developments in the study of hydrodynamics of CFBs, and the progress in computational modeling of CFBs.

Many hydrodynamic models, based on fundamental laws of mass, momentum, energy and species conversion, have been proposed to characterize the relationship between solids hold-up and gas velocity, solids mass flux, riser geometry and particle characteristics in the CFB riser since the early 1970's. There are mainly three categories of models (Harris and Davison, 1994; Berruti et al., 1995). Type I models are onedimensional models, based on a mass or momentum balance, predicting only axial solids suspension density and velocity profiles. Type II models characterize both radial and axial solids hold-up and velocity profiles by using empirical approximations (such as clustering-annular flow model, core-annular flow model) for local flows at different axial locations. These are still one- dimensional models, based on a core ( or cluster) mass and annulus mass balances. Type III models are two-dimensional models, employing the fundamental equations of fluid dynamics to quantify rigorously twophase gas-solids flow. Type III models are classified as viscous models, turbulent models, and kinetic theory models. 


\subsection{Hydrodynamic Models}

Yerushalmi et al. (1976) carried out some of the important experimental work of the axial solids distribution in the CFB riser. They pointed out high concentration of solids at the bottom of the riser and discussed the importance of fast fluidization regime. Rhodes and Geldart (1986) proposed a model that combines existing entrainment and bed expansion correlations with a system pressure balance. They treated the dilute phase of a CFB riser as a long extended free board, and used an entrainment model to explain the observed trends in the variation of axial solids fraction profiles in the CFB riser when gas velocity and solids mass circulation flux were changed. Obviously, their approach neglected the contribution of the solids downflow at the wall, and this caused an underestimation of the solids concentration. Bolton and Davidson ( 1988) extended Rhodes's entrainment model by taking into account a film of particles falling near the walls. They also measured the downward solids mass flux by using small protruding scoops. The conclusion was that the downward solids flow rate, near the wall, declined exponentially with height through the riser and was consistent with turbulent diffusion of entrained particles from the center to the wall.

Type II models characterize the solids distribution both radially and axially. Yerushalmi et al. (1976) adopted the "clustering" concept, which referred to a larger pseudo-particle formed from solids agglomeration. The particle terminal velocity of the cluster is high enough to account for the large solids slip velocity in the experiment. Using an induced-cluster concept, Horio (1988) extended the model of Nakamura and Capes (1973) for pneumatic transport to explain the high slip velocity and the annular 
flow of solids in fast fluidized beds. Similar suggestions of the cluster formation have been made by Basu and Nag, (1987).Arastoopour and Gidaspow (1979) modeled fast fluidization using a cluster concept and a relative velocity model in one dimension.

An extension of the KFIX computer code (Syamlal, 1985) was used to survey the flow patterns in the CFB riser by Tsuo and Gidaspow ( 1990). Their results showed that in the less dense regime, the predicted flow consisted of centrally upward moving solids and downward moving clusters which agree with the experimental observations made by high speed movies. The model also predicted the radial nonuniformity of solid density due to the wall cluster. These wall clusters descend at the wall, while the solids are transported up in the center of the riser. Cluster density increases with an increasing solid flux, with a decreasing gas velocity, with a decreasing riser radius, or with a decreasing fine particles mixing.

Micro-scale particle clustering effects in the numerical simulation of a CFB riser were taken into account (O'Brien and Syamlal, 1994) by lumping drag and viscous effects together to get a correlation. The experimental observation of the particle hold-up was used to adjust the phenomenological gas-solids drag law in the region of low particle loading and low Reynolds number. These transient simulations were characterized by rapid formation and disintegration of particle strands. The strands move slowly downward near the wall, but often detach, only to be blown rapidly upward. This effect intensifies as the particles recycling rate is increased or the gas velocity is decreased. The net effect, when time averaged, is the development of radial and axial particle density profiles. 
Another kind of approximation is the core-annulus model. Hartge et al. (1986) adopted the Richardson-Zaki (1954) correlation to calculate the core and annular slip velocities. Berruti et al. (1989) assumed that the slip velocity in the center was equal to the particle terminal velocity and the density in the annulus was equal to that at minimum fluidization, also, the solids descended along the annulus at the particle terminal velocity. Their model could explain the high slip velocity. Solids velocity profiles and solids flux profiles across the cross-section of risers were measured by Grace (1990), and showed approximately a parabolic distribution radially, with negative solids velocity at the wall.

The major limitation of type II models is that they need empirical correlations or data for input, thus, they cannot be used for prediction of the flow structure of the riser.

As reviewed by Berruti et al. (1995), there are three critical points for the type III models: First, the modeling of the turbulent flow phenomena is very complex and requires some significant simplifying formulations. Secondly, no single, comprehensive model has been developed which is valid for all operating conditions and particle characteristics encountered in CFB risers. Finally, some of these models are limited to the fully developed flow regions of CFB risers only, thus, they give no insight into the fluid dynamic behavior in the region of developing flow near the riser base.

Sinclair and Jackson (1989) focused on the gas-particle and particle-particle interactions which did not arise directly from the effects of gas phase turbulence: the interactions between the mean particle and gas velocity fields, the mean particle velocity field, and the fluctuation particle velocity component. They assumed that the momentum of the moving particles was sufficient to carry them through the gas film 
and the interaction occurred by direct particle-particle collisions. They predicted qualitatively the effect of particle-particle collisions which was enough to generate the particle flow segregation in CFB experiments. Quantitative comparison of the prediction with the experimental data was done by Pita and Sundaresan ( 1991 ). Their work showed good agreement between the prediction and the experimental data, but the prediction were usually sensitive to the parameter coefficient of restitution.

The research carried out by Tsuo and Gidaspow (1990) revealed a different style of type III models that avoid the introduction of turbulence. The model consists of a generalization of the Navier-Stokes equations for two-phase flow. The formulation required a solid-viscosity term. Ding and Gidaspow (1990) provided a predictive twophase flow model which was derived starting with the Boltzmann equation for velocity distribution of particles for solids viscosities, and stresses were calculated by simultaneously solving a fluctuating energy equation for the particle phase. The method was based on the kinetic theory of granular solids, and the model showed a good agreement with the experimental data. The work of Gidaspow et al. provided a predictive method for calculating the solid viscosity based on the kinetic theory.

\subsection{Most Recent Work}

Experimental and computational study of multiphase gas and particles flow was carried in a CFB riser by Arastoopour et al (1999). Laser Doppler anemometry was applied to measure the flow behaviour of FCC catalysts. A typical core annulus flow with relative velocity between the particles of different size was obtained. A multi fluid computational fluid dynamics model was developed and verified against the 
experimental results. The flow model was based on the a Eulerian description of the phases where the kinetic theory of flow patterns forms the turbulence modeling in the solid phases.The model was generalized for one gas phase and $\mathrm{N}$ number of solid phases to provide a realistic description of particle-size distributions and non-uniform diameter in gas solid distribution. Each solid phase was characterized by a diameter, a form factor, density and restitution coefficient. Simulations with one gas and two solid phases agreed well with the measurements.

Gu (1999) determined an analytical expression of the cluster diameter as the function of solid fraction, gas-phase viscosity and density. Using this consitutive relationship, the gas-cluster model predicted the pressure drops along the risers of several commercial FCC units with reasonable accuracy.

In the paper by Herbert et al. (1999) important representative results have been presented from last 8 years of CFB study at the Institute of Process Engineering at ETH Zurich. The physics at work in CFB riser is very complex and is not fully understood yet so this information could be used by other groups so that the complex fluid dynamic behaviour of these systems can be better understood.

A predictive model was developed (Behie et al, 1997) for the fully developed zone in the circulating fluidized bed riser reactor operating in the fast fluidization regime. The model accounts for the upward flow of the gas and the solids in the core and downward flow of the two phases at the annulus.

Sinclair et al. (1997) developed a mathematical model that incorporates the two mechanisms that gives rise to lateral seggregation of solids : interactions associated with individual particles based on kinetic theory treatment and interactions associatedwith 
collection of particles based on anology with single phase turbulent flows. The effect of this treatment on the sensitivity of the model predictions to the in elasticity of the particle -particle collisions is explored. The resulting model can predict the expected segregation patterns for systems characterized by inelastic collisions, as well as many of the other salient features of vertical gas -solid flows.

Gidaspow and $\mathrm{Lu}$ (1996) measured the particle size distribution for a flow of 75 $\mu \mathrm{m}$ FCC particles in a CFB using video-digital camer technique. A random oscillating particel velocity was determined from the spread of the particle histograms. This random velocity was used to compute the powder viscosity with the help of dense-phase kinetic theory of granular flow. There was excellent agreement between this kinetic-theory measurement and previous macroscopic viscosity measurements.

Numerical computations were carried out by Ocone et al. (1995) to analyze the influence of the duct widths on the flow of the gas-solids system in vertical ducts. The model is also a two-phase model, with the particles being considered as a continuum characterized by bulk properties. The fluid phase is considered as Newtonian. The particles phase stress tensor is modeled considering the two phases interacting through a drag force, and particles interacting with each other through collisions and friction (rubbing). Also, similarities in the flow structure were analyzed to exploit the possibility of scaling up based on hydrodynamic analogies. Multiple steady states were observed when the duct width was increased.

Seu-Kim and Arastoopour (1995) used a modified kinetic theory model to simulate the FCC particles flow behavior in a CFB riser. They assumed that the shear stress at the wall to dissipate in the form of the collision of the cohesive particles with 
the wall. They found that as a result of inelastic collision of particles with the wall, FCC particles formed the larger agglomerates/clusters at the wall and particles having smaller size were found at the annular region.

The common feature amongst the above computational models was that they were limited to a narrow operating range and riser geometry and had some of the constituive relationship based on experiments performed by the researchers . In 1995, a benchmark modeling effort by ten research groups (Bernard; Sundaresan; Arastoopour and Kim; Gidaspow, Sun and Johnson; Chaouki, Godfroy and Patience; Pugsley and Berruti; Rhodes and Wang; O'Brien and Syamlal; and Chen) provided a good perspective of the state-of-the-art in CFB modeling. These ten groups comprised of either type II or type III modelers. Two experimental CFB units of different geometries were used. The predicted results of each group were compared with the experimental data, including axial pressure profiles, radial solids mass flux profiles, and radial solids density profiles. The conclusions were : 1) No single model could predict all the conditions and all the trends in the data; 2) Type II models showed better agreement with experimental data than type III models; 3) Most models couldn't properly represent radial solid density and flux profiles at the high solid mass flux conditions; 4) No model sufficiently predicted the increase in suspension density at the top of the risers. This benchmark modeling effort provided a fair representation of the accuracy and applicability of the hydrodynamic models and it indicated some direction for future development. 


\section{CHAPTER III MODEL DESCRIPTION}

\subsection{Introduction}

In the paper by Miller \& Gidaspow, 1992, the hydrodynamics of gas-solid flow was studied in a $7.5 \mathrm{~cm}$ acrylic riser with $75 \mu \mathrm{m}$ FCC catalyst particles. It was possible to determine the viscosity of the gas solid suspension from the data obtained. The viscosity was found to be a linear function of the volume fraction of the solids and the shear stress was directly proportional to shear strain rate.

In this study a multi phase fluid flow computational model called MFIX (Multi phase flow with Interphase exchange) is used to predict flow patterns in CFB risers. Linear correlation for the solids viscosity is used to match the experimental data and the same correlation is applied to other flow conditions based on the above investigation. Boundary condition at the riser wall for the axial solids momentum balance was modified to account for recirculation of solids in the riser.

MFIX (Syamlal 1994, www.mfix.org) is a general purpose hydrodynamic model that describes the chemical reactions and heat transfer in dense or dilute fluid-solids flows typically occurring in energy conversion and chemical processing reactors. The model is a generalization of the Navier- Stoke`s equations for two-phase fluid flow. All the solid particles were considered identical, characterized by a mean diameter and density. The gas pressure was considered to exist in the gas phase only and the riser operates at an isothermal condition. The governing conservation equations being used in the model are listed in Table I. 


\section{Table I. List of Equations in Hydrodynamic Model.}

\section{Gas Continuity :}

$\frac{\partial}{\partial t}\left(\varepsilon_{g} \rho_{g}\right)+\nabla \cdot\left(\varepsilon_{g} \rho_{g} \overrightarrow{v_{g}}\right)=0$

Solids Continuity :

$\frac{\partial}{\partial t}\left(\varepsilon_{s} \rho_{s}\right)+\nabla \cdot\left(\varepsilon_{s} \rho_{s} \overrightarrow{v_{s}}\right)=0$

Gas momentum balance :

$\frac{\partial}{\partial t}\left(\varepsilon_{g} \rho_{g} \overrightarrow{v_{g}}\right)+\nabla \cdot\left(\varepsilon_{g} \rho_{g} \overrightarrow{v_{g} v_{g}}\right)=-\nabla P_{g}+\nabla \cdot \overline{\overline{\tau_{g}}}+F_{g}\left(\overrightarrow{v_{s}}-\overrightarrow{v_{g}}\right)+\varepsilon_{g} \rho_{g} \vec{g}$

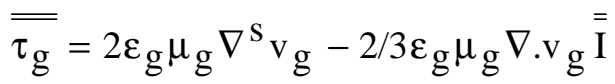

$\nabla \mathrm{v}_{\mathrm{g}}=\frac{1}{2}\left[\nabla \mathrm{v}_{\mathrm{g}}+\nabla \mathrm{v}_{\mathrm{g}}^{\mathrm{T}}\right]$

\section{$\underline{\text { Solid momentum balance : }}$}

$\frac{\partial}{\partial \mathrm{t}}\left(\varepsilon_{\mathrm{s}} \rho_{\mathrm{s}} \overrightarrow{\mathrm{v}_{\mathrm{s}}}\right)+\nabla \cdot\left(\varepsilon_{\mathrm{s}} \rho_{\mathrm{s}} \overrightarrow{\mathrm{v}_{\mathrm{s}}} \overrightarrow{\mathrm{v}_{\mathrm{s}}}\right)=\nabla \cdot \overline{\overline{S_{\mathrm{s}}}}+\varepsilon_{\mathrm{s}} \rho_{\mathrm{s}} \overrightarrow{\mathrm{g}}-\mathrm{F}_{\mathrm{g}}\left(\overrightarrow{\mathrm{v}_{\mathrm{s}}}-\overrightarrow{\mathrm{v}_{\mathrm{g}}}\right)$

$\overline{\overline{\mathrm{S}_{\mathrm{s}}}}=2 \mu_{\mathrm{s}} \nabla^{\mathrm{s}} \mathrm{v}_{\mathrm{s}}-2 / 3 \mu_{\mathrm{s}} \nabla \cdot \mathrm{v}_{\mathrm{s}} \overline{\overline{\mathrm{I}}} ; \mu_{\mathrm{s}}=5.34 \varepsilon_{\mathrm{s}}$ (poise)

$\nabla^{\mathrm{s}} \mathrm{v}_{\mathrm{s}}=\frac{1}{2}\left[\nabla \mathrm{v}_{\mathrm{s}}+\nabla \mathrm{v}_{\mathrm{s}}^{\mathrm{T}}\right]$

\section{Gas Solid Drag Law :}

$$
\begin{aligned}
& \mathrm{F}_{\mathrm{g}}=\frac{3 \varepsilon_{\mathrm{s}} \rho_{\mathrm{g}}}{4 \mathrm{~V}_{\mathrm{rm}}^{2} \mathrm{~d}_{\mathrm{pm}}}\left(0.63+4.8 \sqrt{\mathrm{V}_{\mathrm{rm}} / \operatorname{Re}_{\mathrm{m}}}\right)^{2}\left|\overrightarrow{\mathrm{v}}_{\mathrm{s}}-\overrightarrow{\mathrm{v}_{\mathrm{g}}}\right| \\
& \mathrm{V}_{\mathrm{rm}}=0.5\left(\mathrm{~A}-0.06 \operatorname{Re}_{\mathrm{m}}+\sqrt{\left(0.06 \operatorname{Re}_{\mathrm{m}}\right)^{2}+0.12 \mathrm{Re}_{\mathrm{m}}(2 \mathrm{~B}-\mathrm{A})+\mathrm{A}^{2}}\right)
\end{aligned}
$$

where $\mathrm{A}=\varepsilon_{\mathrm{g}}{ }^{4.14} ; \mathrm{B}=0.8 \varepsilon_{\mathrm{g}}{ }^{1.28}$ if $\varepsilon_{\mathrm{g}} \leq 0.85 \quad \& \mathrm{~B}=\varepsilon_{\mathrm{g}}{ }^{2.65}$ if $\varepsilon_{\mathrm{g}}>0.85$ 
MFIX code has the following characteristics: mass and momentum balance equations for gas and multiple solids phases; a gas phase and two solids phase energy equations; an arbitrary number of species balance equations for each phase; granular stress equations based on kinetic theory and frictional flow theory; a user-defined chemistry subroutine; three dimensional cartesian or cylindrical coordinate systems; nonuniform mesh size; impermeable and semi permeable internal surfaces; user-friendly input data files; multiple, single-precision, binary, direct access output files. In addition, two MFIX post- processor codes animate the results of the calculations and retrieve and manipulate data from the output files.

\subsection{Boundary Condition at the Wall.}

The work concerning the near wall behavior was studied with the aid of the model which arises from the solution of the reduced momentum equation for fully developed flow with negligible acceleration around the wall region.

$$
0=\frac{-1}{\mathrm{r}} \frac{\partial}{\partial \mathrm{r}}\left(\mathrm{r} \tau_{\mathrm{rz}}\right)+\beta\left(\mathrm{v}_{\mathrm{g}}-\mathrm{v}_{\mathrm{s}}\right)-\left(\rho_{\mathrm{s}}-\rho_{\mathrm{s}}\right) \varepsilon_{\mathrm{s}} \mathrm{g}
$$

On integrating this equation over the two cells at the wall, $((\mathrm{R})$ and $(\mathrm{R}-1))$, as shown in the figure 2. (For convenience of illustration the cell dimensions in the relevant direction are assumed constant.) 


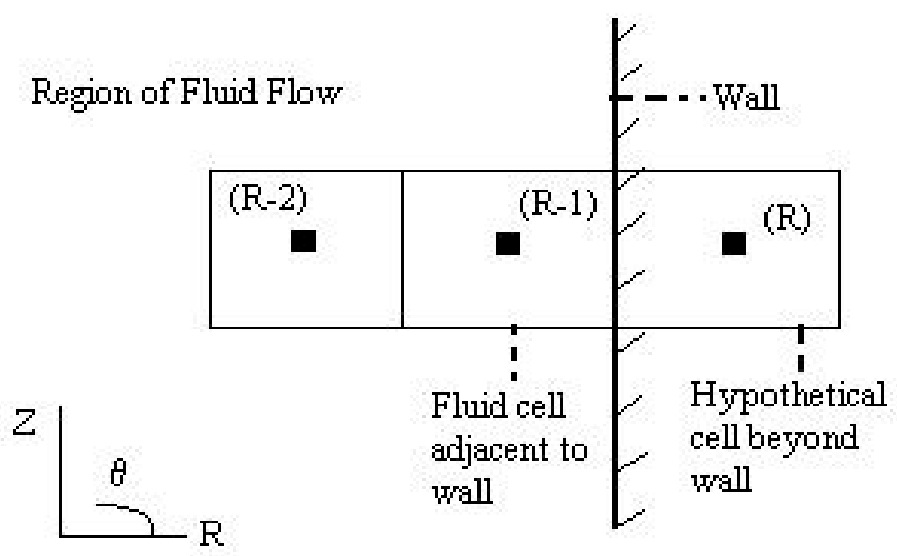

Figure 2. Cell Arrangement at a characteristic wall.

$\mathrm{R} \tau_{\mathrm{Rz}}-(\mathrm{R}-\Delta \mathrm{R}) \tau_{(\mathrm{R}-1) \mathrm{z}}=\mathrm{C}_{1}------(2)$

where,

$\mathrm{C}_{1}=\left[\Delta \mathrm{R}\left(\mathrm{R}-\frac{\Delta \mathrm{R}}{2}\right)\left(\beta\left(\mathrm{v}_{\mathrm{g}}-\mathrm{v}_{\mathrm{s}}\right)-\left(\rho_{\mathrm{s}}-\rho_{\mathrm{g}}\right) \varepsilon_{\mathrm{s}} \mathrm{g}\right)\right]_{(\mathrm{R}-1)}------(3)$

with the right hand side of the equation (3) evaluated at the fluid cell adjacent to the wall, (R-1).

This model approximates the stress terms for the two different cells differently, as shown below,

$$
\begin{aligned}
& \tau_{\mathrm{Rz}}=\mathrm{f}_{\mathrm{s}} \varepsilon_{\mathrm{s}} \rho_{\mathrm{s}} \mathrm{v}_{\mathrm{sr}}\left|\mathrm{v}_{\mathrm{sr}}\right| \\
& \tau_{(\mathrm{R}-1) \mathrm{z}}=\left(-\varepsilon_{\mathrm{s}} \mu_{\mathrm{s}}\right)\left(\frac{\mathrm{v}_{\mathrm{sR}-1}-\mathrm{v}_{\mathrm{sR}-2}}{\Delta \mathrm{R}}\right)
\end{aligned}
$$

from equation (2) we can write

$\mathrm{Rf}_{\mathrm{s}} \varepsilon_{\mathrm{s}} \rho_{\mathrm{s}} \mathrm{v}_{\mathrm{sr}}\left|\mathrm{v}_{\mathrm{sr}}\right|=(\mathrm{R}-\Delta \mathrm{R})\left(-\varepsilon_{\mathrm{s}} \mu_{\mathrm{s}}\right)\left(\frac{\mathrm{v}_{\mathrm{sR}-1}-\mathrm{v}_{\mathrm{sR}-2}}{\Delta \mathrm{R}}\right)+\mathrm{C}_{1}$ 
also, $\mathrm{v}_{\mathrm{sr}}=\left(\mathrm{v}_{\mathrm{sR}}+\mathrm{v}_{\mathrm{sR}-1}\right) / 2$.

Averaging the velocity term $\mathrm{v}_{\mathrm{s}}$ over $(\mathrm{R})$ and $(\mathrm{R}-1)$ cells and assuming the positive value only leads to the quadratic equation of the form,

$\mathrm{v}_{\mathrm{sR}}^{2}+2 \mathrm{v}_{\mathrm{sR}} \mathrm{v}_{\mathrm{s}(\mathrm{R}-1)}+\mathrm{v}_{\mathrm{s}(\mathrm{R}-1)}^{2}-\frac{4 \mathrm{C}_{2}}{\mathrm{Rf}_{\mathrm{s}} \varepsilon_{\mathrm{s}} \rho_{\mathrm{s}}}=0$

where $C_{2}=(R-\Delta R)\left(-\varepsilon_{s} \mu_{s}\right)\left(\frac{v_{s R-1}-v_{s R-2}}{\Delta R}\right)+C_{1}$

Solving the quadratic equation gives,

$\mathrm{v}_{\mathrm{sR}}=-\mathrm{v}_{\mathrm{s}(\mathrm{R}-1)} \pm \sqrt{\frac{4 \mathrm{C}_{2}}{\mathrm{Rf}_{\mathrm{s}} \varepsilon_{\mathrm{s}} \rho_{\mathrm{s}}}}-------(4)$

where, negative roots were used as unrealistic results were obtained with positive root.

\subsection{Modeling conditions and experimental data used for comparison}

Two different sets of CFB risers (IIT 7.5-cm-ID riser and PSRI 20.0-cm-ID riser) were simulated at different modeling conditions. The simulation results and comparison with the experimental data are presented in the next chapter.

An experimental study of the gas and solids flow patterns in a 7.5-cm-ID clear acrylic CFB riser with $75 \mu \mathrm{m}$ FCC catalyst (U.S.260 equilibrium catalyst) particles was conducted by Miller (1991) at the Illinois Institute of Technology (IIT), for various superficial gas velocities and solids feed fluxes. Core-annulus flow patterns were observed, which could be described as a dilute rising core surrounded by a dense descending annular region. Four distinct experimental conditions have been chosen for our modeling study. They are characterized by the following feed conditions:

1) Superficial gas velocity equals $2.89 \mathrm{~m} / \mathrm{s}$ and solids feed flux equals $12.0 \mathrm{~kg} / \mathrm{m}^{2}$-s. 
2) Superficial gas velocity equals $2.89 \mathrm{~m} / \mathrm{s}$ and solids feed flux equals $20.4 \mathrm{~kg} / \mathrm{m}^{2}-\mathrm{s}$.

3) Superficial gas velocity equals $2.89 \mathrm{~m} / \mathrm{s}$ and solids feed flux equals $32.8 \mathrm{~kg} / \mathrm{m}^{2-} \mathrm{s}$.

4) Superficial gas velocity equals $2.61 \mathrm{~m} / \mathrm{s}$ and solids feed flux equals $20.4 \mathrm{~kg} / \mathrm{m}^{2}$-s.

Another study in a CFB riser utilizing identical $75 \mu \mathrm{m}$ FCC catalyst (U.S.260 equilibrium catalyst) particles was conducted by Knowlton (1995) at the Particulate Solid Research, Inc. (PSRI), for various superficial gas velocities and solids feed fluxes. Coreannulus flow patterns were also observed in the experiments. Three distinct experimental cases have been chosen for our modeling study. They are characterized by the following feed conditions:

1) Superficial gas velocity equals $5.2 \mathrm{~m} / \mathrm{s}$ and solids feed flux equals $489.0 \mathrm{~kg} / \mathrm{m}^{2}-\mathrm{s}$;

2) Superficial gas velocity equals $7.6 \mathrm{~m} / \mathrm{s}$ and solids feed flux equals $489.0 \mathrm{~kg} / \mathrm{m}^{2}$-s;

3) Superficial gas velocity equals $11.0 \mathrm{~m} / \mathrm{s}$ and solids feed flux equals $489.0 \mathrm{~kg} / \mathrm{m}^{2}-\mathrm{s}$;

These two CFB risers are of different geometries and use different operating conditions. Their only similarity is that they use the same carrier gas and solids catalyst.

The modeling of these units using the same numerical technique, correlations, and equations etc. could be used to validate the model. Time averaged (40-60 sec.) radial profiles of solids flux, solids volume fraction and solids density, solids velocity were obtained after steady state was reached. 


\section{CHAPTER IV \\ RESULTS AND DISCUSSION}

The operating conditions for the test cases under study for the PSRI and IIT risers are listed along with the comparison of the simulated results with the experimental data in this chapter.

\subsection{PSRI Riser}

The riser is modeled as a $20-\mathrm{cm}$ inner diameter tube, which is $14.2 \mathrm{~m}$ high. The conditions for which the riser is modeled are listed below.

\section{Table II. Modeling Conditions for PSRI CFB Riser.}

\begin{tabular}{|c|c|c|c|}
\hline Operating conditions & 1 & 2 & 3 \\
\hline Operating pressure. ( $\mathrm{kPa})$ & 101.3 & 101.3 & 101.3 \\
\hline Operating temperature. $(\mathrm{K})$ & 298 & 298 & 298 \\
\hline Particle diameter. $(\mu \mathrm{m})$ & 75 & 75 & 75 \\
\hline Gas feed velocity. $(\mathrm{m} / \mathrm{s})$ & 5.2 & 7.6 & 11.0 \\
\hline Solids Flux. $\left(\mathrm{kg} / \mathrm{m}^{2}-\mathrm{s}\right)$ & 489 & 489 & 489 \\
\hline Void fraction at the inlet. & 0.9 & 0.9 & 0.9 \\
\hline Riser radius. (m) & 0.20 & 0.20 & 0.20 \\
\hline Particle Density. $\left(\mathrm{kg} / \mathrm{m}^{3}\right)$ & 1654.0 & 1654.0 & 1654.0 \\
\hline Gas Viscosity. (kg/m-s) & $1.8 \times 10^{-5}$ & $1.8 \times 10^{-5}$ & $1.8 \times 10^{-5}$ \\
\hline Jet radius. $(\mathrm{m})$ & 0.10 & 0.10 & 0.10 \\
\hline Riser height. (m) & 14.2 & 14.2 & 14.2 \\
\hline
\end{tabular}




\subsubsection{Effect of Inlet Specifications}

While most actual CFB risers would have some form of non-uniform distribution of solids at the inlet of the riser, the simulations do not account for these nonuniformities. In the studies conducted, remarkable differences in behavior were observed with few changes in the inlet configuration and inlet void fraction (solids-distribution). When the diameter of the inlet coincided with that of the riser, no down-flow was observed. For naturally occurring downflow, there are no simple outlet conditions that can be assigned (Tsuo and Gidaspow, 1990). Hence the diameter of the inlet was reduced to half the diameter of the riser, and the remaining section of the riser bottom, was specified such as to disable flow across it, as shown in the figure 3 . Also a change in the volume fraction in the region where there is no flow from 0.9 (Inlet Configuration 1) to 0.5 (Inlet Configuration 2) affected the flow profiles significantly as shown in Figures 4 and 5 respectively.

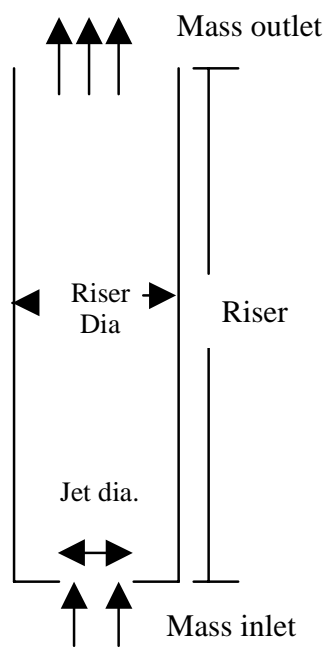

Figure 3. Riser modeled as a straight pipe with reduced inlet. 


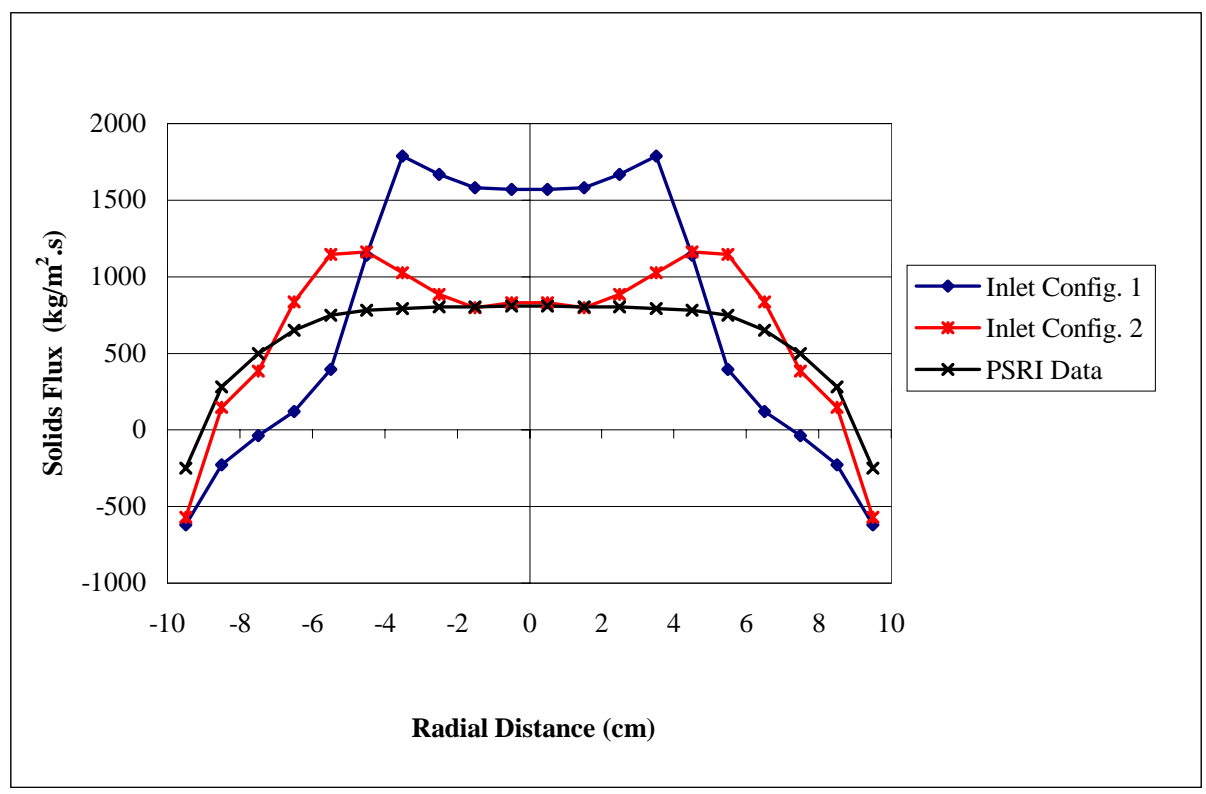

Figure 4. Effect of inlet volume fraction specifications.[Superficial gas velocity $=5.2$ $\mathrm{m} / \mathrm{s}$, solids inlet flux $\left.=489 \mathrm{~kg} / \mathrm{m}^{2} . \mathrm{s}\right]$

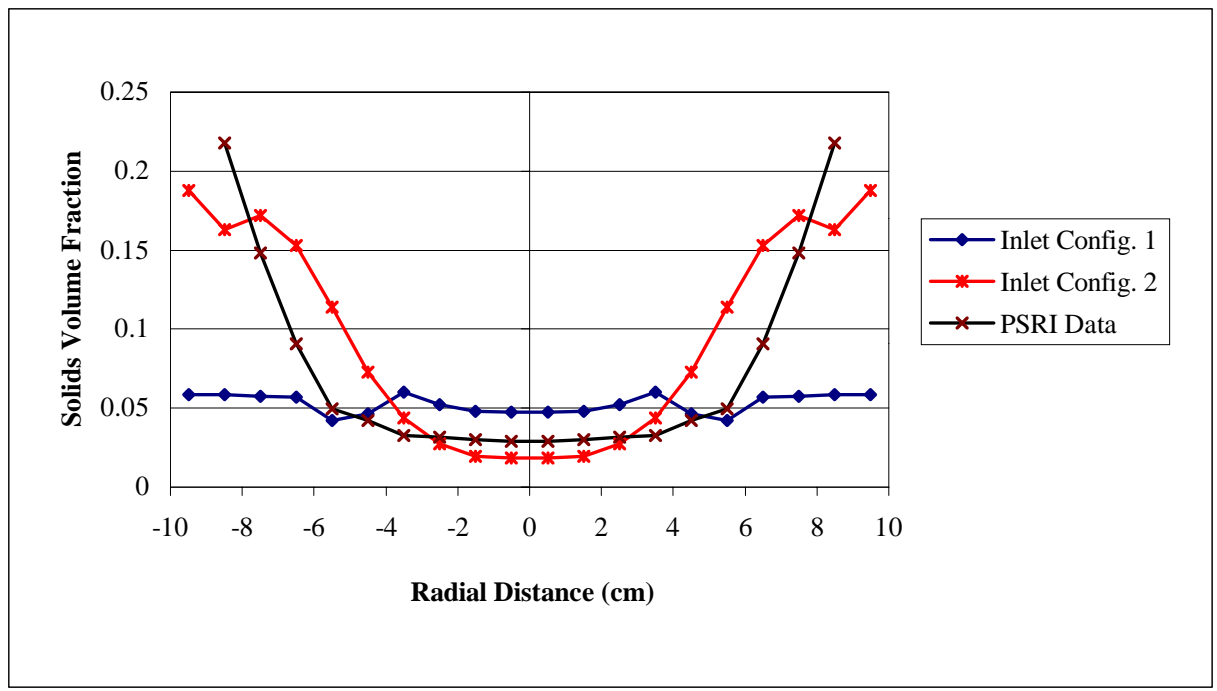

Figure 5. Effect of inlet volume fraction specifications .[Superficial gas velocity $=\mathbf{5 . 2}$ $\mathrm{m} / \mathrm{s}$, solids inlet flux $=489 \mathrm{~kg} / \mathrm{m}^{2} . \mathrm{s}$ 


\subsubsection{Determination of Friction factor at the wall}

With the first test case ( Superficial gas velocity equals $5.2 \mathrm{~m} / \mathrm{s}$ and solids feed flux equals $489.0 \mathrm{~kg} / \mathrm{m}^{2}$-s.) we matched the downflow at the wall obtained from experimental data by varying the friction factor. Once that value of friction factor was obtained we used the same value for modeling all the other conditions and also the same value of volume fraction (0.5-0.6) was used in the disabled region. The flux and the volume fraction profiles at height of $3.9 \mathrm{~m}$ is shown in figures 6 and 7 respectively. It is seen that as $f_{s}$ is increased the downflow at the wall decreases but there is hardly any change in the flux profiles except at the wall. Again as seen in the volume fraction profiles the solids concentration at the wall increases with the decrease in $\mathrm{f}_{\mathrm{s}}$.

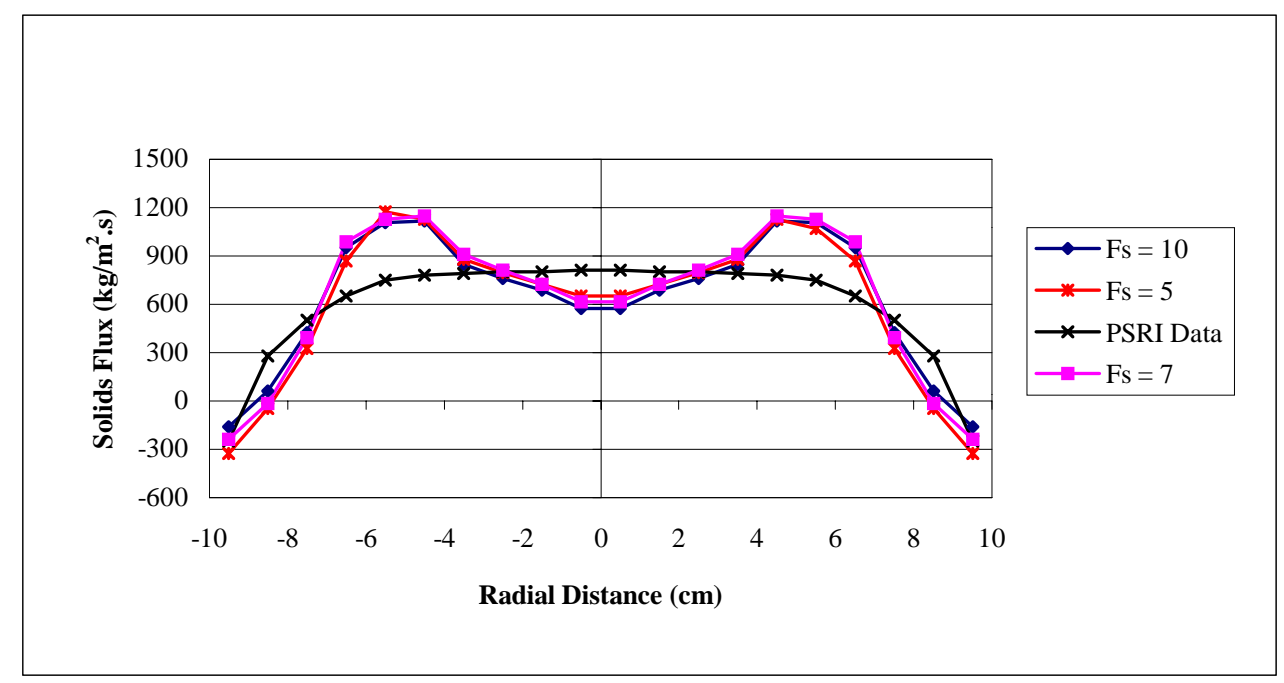

Figure 6. Effect of friction factor $\mathrm{f}_{\mathrm{S}}[$ Gas inlet velocity $=5.2 \mathrm{~m} / \mathrm{s}$ solids inlet flux $=$ $489 \mathrm{~kg} / \mathrm{m}^{2} . \mathrm{s}, \mu_{\mathrm{s}}=5.34 \varepsilon_{\mathrm{s}}$ poise $]$ 


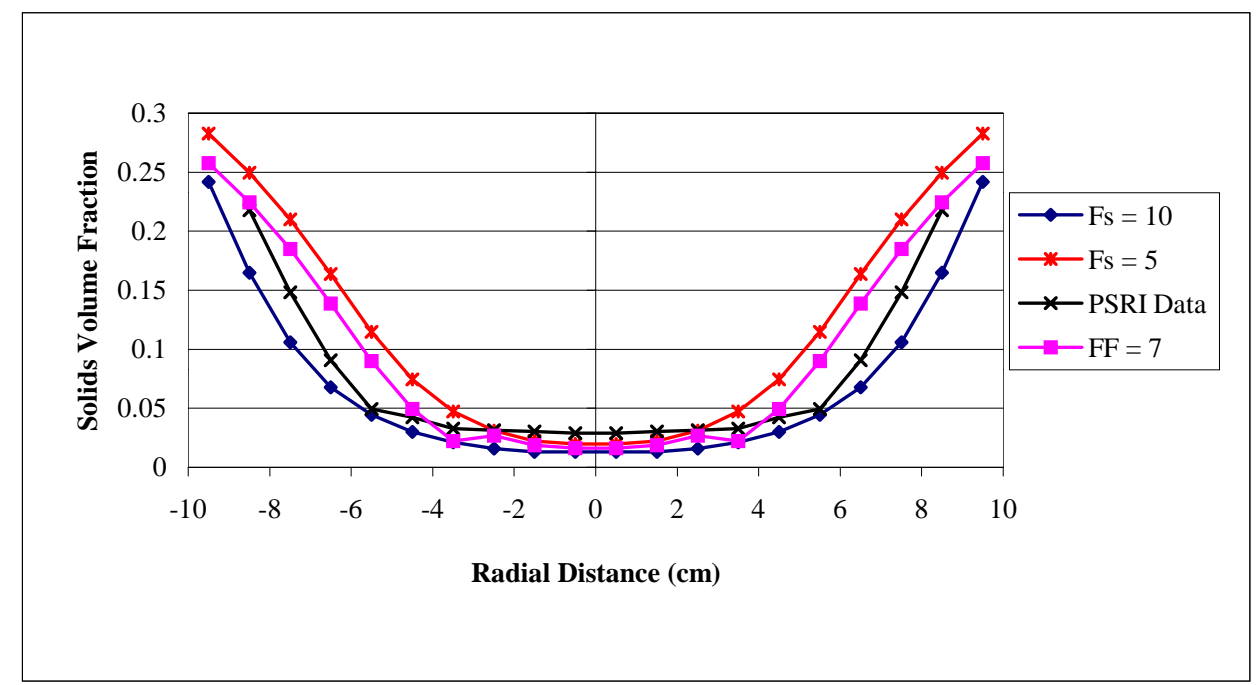

Figure 7. Effect of friction factor $f_{S}$ [Gas inlet velocity $=5.2 \mathrm{~m} / \mathrm{s}$ solids inlet flux $=$ $489 \mathrm{~kg} / \mathrm{m}^{2} . \mathrm{s}, \mu_{\mathrm{s}}=5.34 \varepsilon$ s poise]

Thus with $\mathrm{f}_{\mathrm{s}}=7$ the flux at the wall matches the experimental data and this value will be used for subsequent modeling.

\subsubsection{Comparison of results}

For the test case 2 (Superficial gas velocity equals $7.6 \mathrm{~m} / \mathrm{s}$, and solids feed flux equals $489.0 \mathrm{~kg} / \mathrm{m}^{2}$-s) with $\mathrm{f}_{\mathrm{s}}=7$, and $\mu_{\mathrm{s}}=5.34 \varepsilon_{\mathrm{s}}$ (poise), the results are shown in Figures 8 and 9 respectively. Exact match for the solids flux at the wall is observed for value of $\mathrm{f}_{\mathrm{s}}$ determined for the first case. The flux and the volume fraction are under predicted in the center and there is over prediction around the wall. 


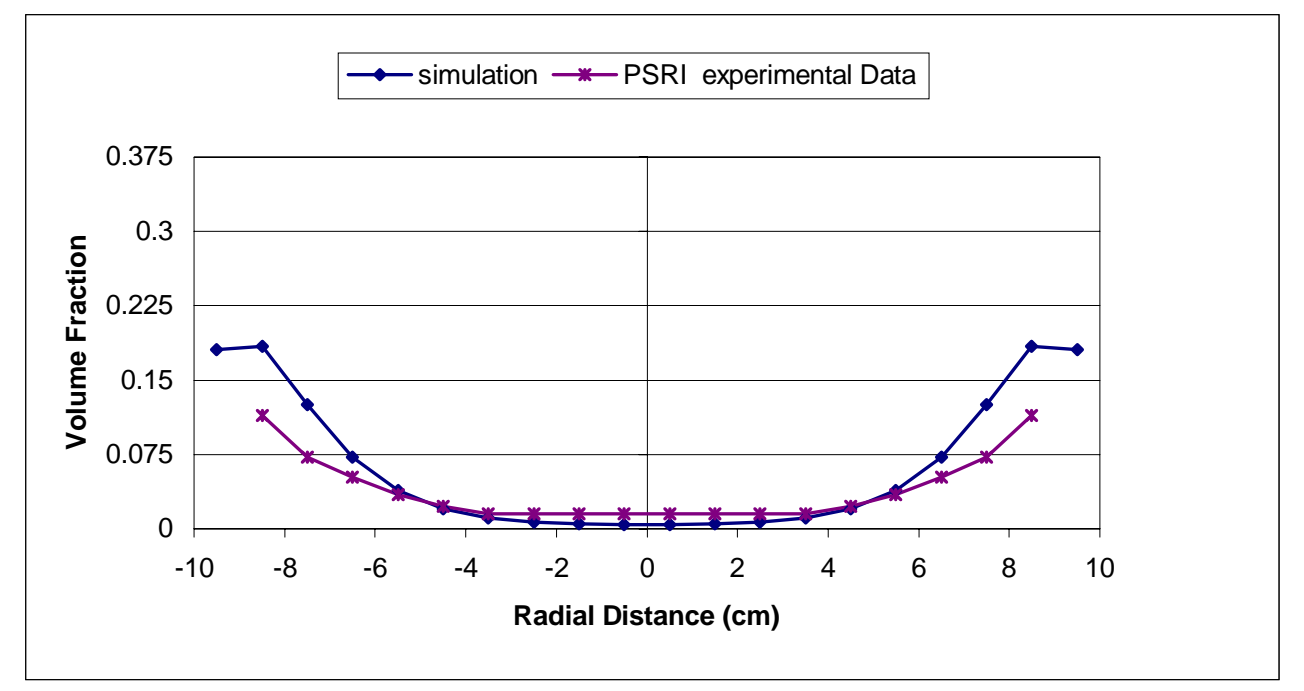

Figure 8. Radial Profile of Solid Volume Fraction at $3.9 \mathrm{~m}$ in the PSRI CFB riser. [Superficial Gas velocity $=7.6 \mathrm{~m} / \mathrm{s}$; Solids feed flux $=489.0 \mathrm{Kg} / \mathrm{m}^{2} . \mathrm{s}$ ]

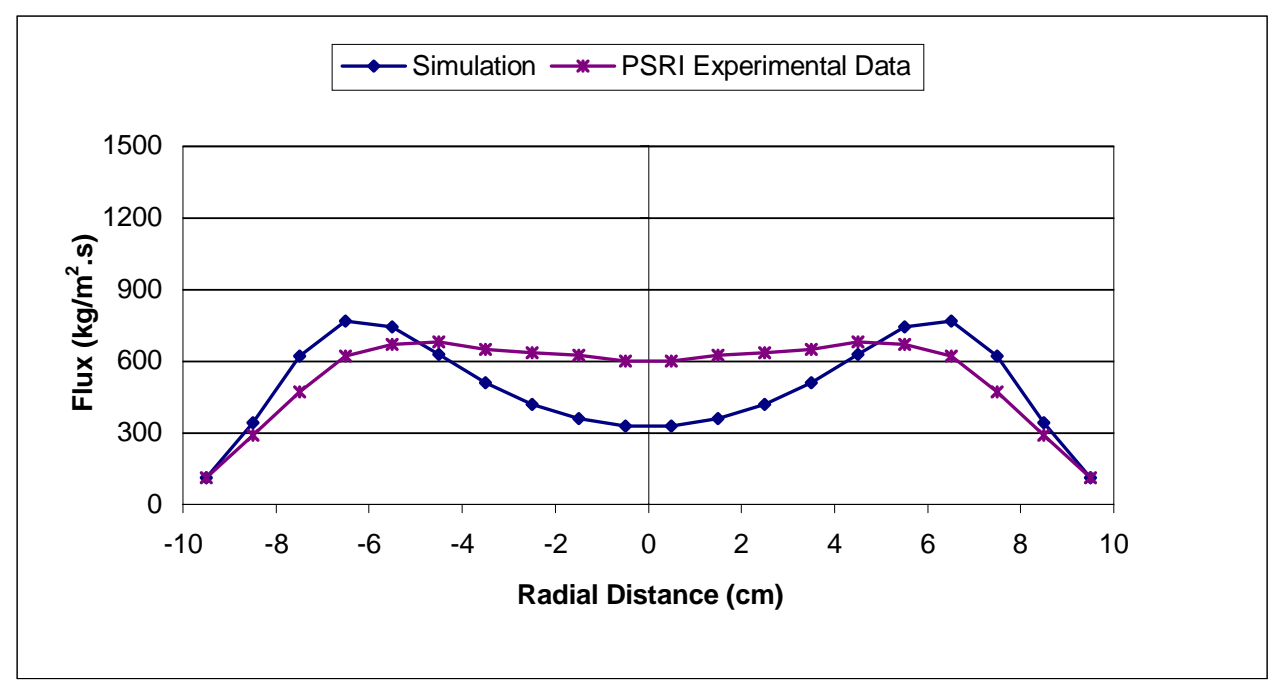

Figure 9. Radial Profile of Solid Flux at $3.9 \mathrm{~m}$ in the PSRI CFB riser.[Superficial Gas velocity $=7.6 \mathrm{~m} / \mathrm{s}$; Solids feed flux $\left.=489.0 \mathrm{Kg} / \mathrm{m}^{2} . \mathrm{s}\right]$

For the test case 3 (Superficial gas velocity equals $11.0 \mathrm{~m} / \mathrm{s}$, and solids feed flux equals $489.0 \mathrm{~kg} / \mathrm{m}^{2}$-s) with $\mathrm{f}_{\mathrm{s}}=7$, and $\mu_{\mathrm{s}}=5.34 \varepsilon_{\mathrm{s}}$ (poise), the flux and the solids volume fraction profiles are shown in figures 10 and 11 respectively. 


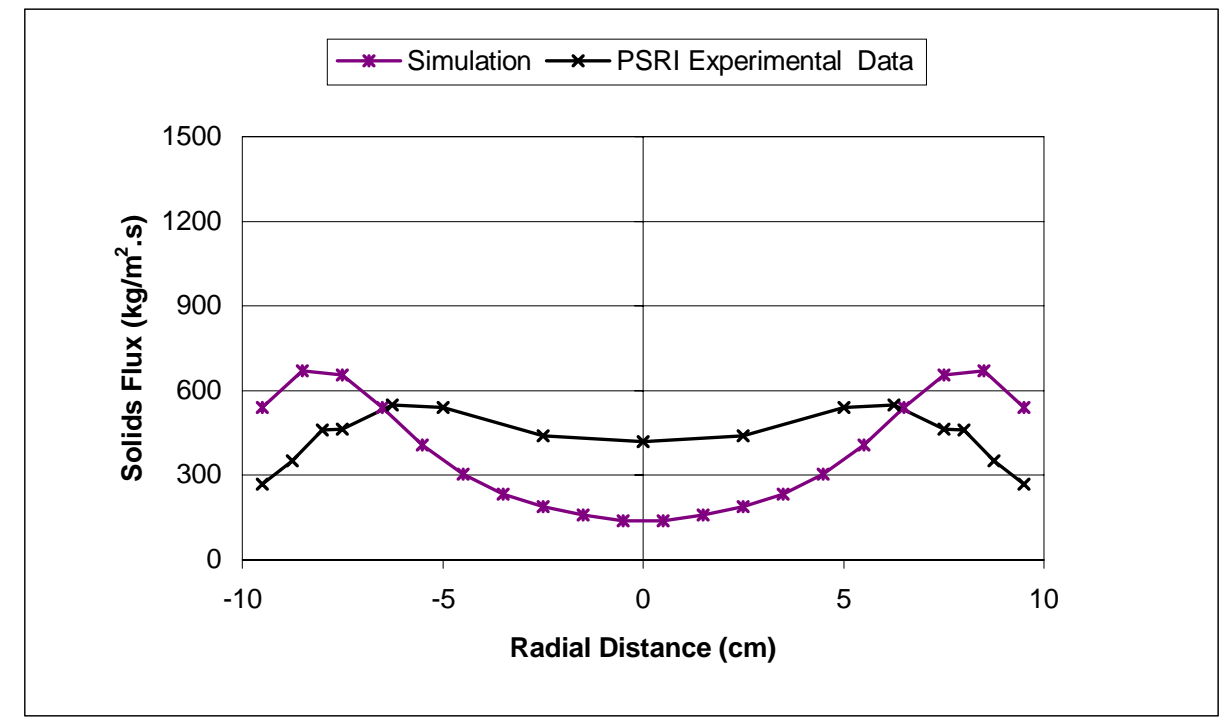

Figure 10. Radial Profile of Solid Volume Fraction at $3.9 \mathrm{~m}$ in the PSRI CFB riser.[Superficial Gas velocity $=\mathbf{1 1 . 0} \mathrm{m} / \mathrm{s}$; Solids feed flux $=489.0 \mathrm{Kg} / \mathrm{m}^{2} . \mathrm{s}$ ]

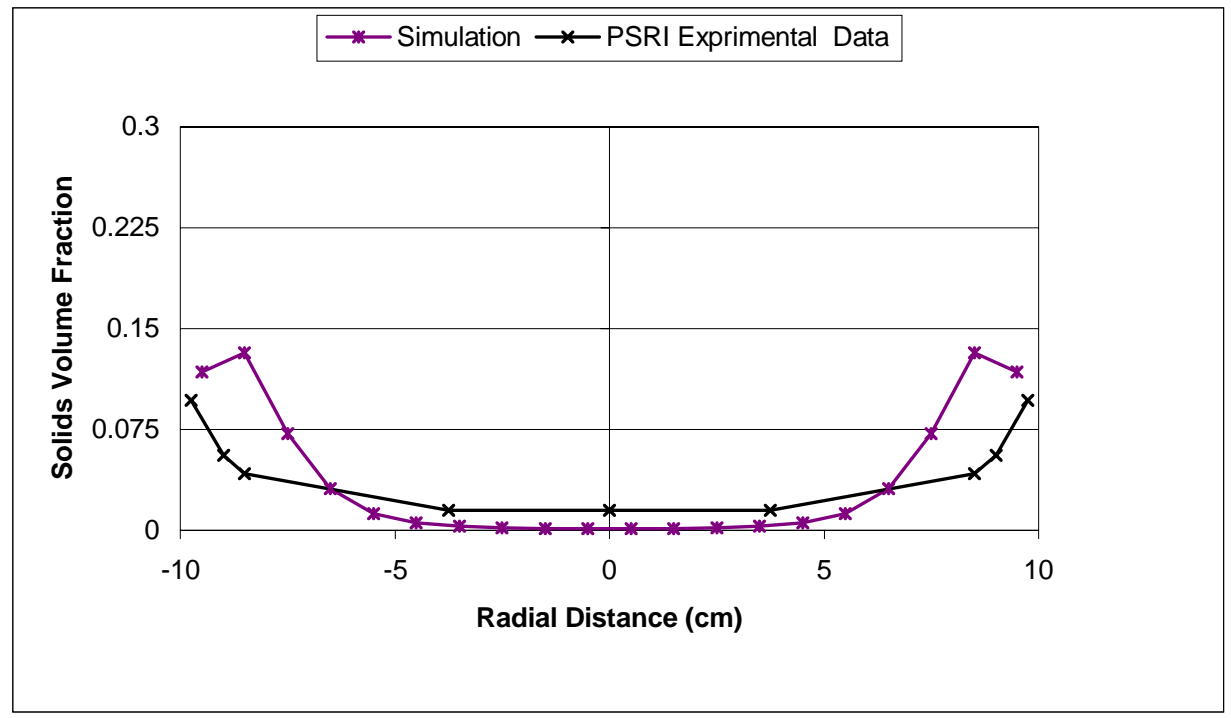

Figure 11. Radial Profile of Solid Volume Fraction at $3.9 \mathrm{~m}$ in the PSRI CFB riser.[Superficial Gas velocity $=\mathbf{1 1 . 0} \mathrm{m} / \mathrm{s}$; Solids feed flux $=489.0 \mathrm{Kg} / \mathrm{m}^{2} . \mathrm{s}$ ] 
Again here there is still larger under prediction in the center and the downflow at the wall does not match. This indicates that the model has limitations when the superficial velocity is high.

\subsection{IIT riser}

The main parameters of this system are shown in Table III. In this system, the carrier gas is air, with constant viscosity.

\section{Table III. Parameters of Air/FCC System of IIT CFB Riser.}

\begin{tabular}{|l|l|}
\hline Particle Diameter (Average based on Surface Area) & $95.13 \mu \mathrm{m}$ \\
Gasticle Density & $1654.0 \mathrm{~kg} / \mathrm{m}^{3}$ \\
Maximum Solid Volume Fraction & 0.4 \\
Riser Radius & $3.75 \mathrm{~cm}$ \\
Jet Radius & $1.905 \mathrm{~cm}$ \\
Riser Height & $6.58 \mathrm{~m}$ \\
Inflow Gas Pressure & $2.2-3.9 \mathrm{psig}$ \\
\hline & $2.5-2.8 \mathrm{psig}$ \\
Outflow Gas Pressure & $294.26 \mathrm{~K}\left(70^{\circ} \mathrm{F}\right)$ \\
\hline Riser Operating Temperature & \\
\hline
\end{tabular}

The modeling conditions of the four distinct cases are shown in Table IV and correspond to experimental conditions of Miller (1991). 
Table IV. Modeling conditions for IIT CFB riser.

\begin{tabular}{|l|c|c|c|c|}
\hline Operating conditions & $\mathbf{1}$ & $\mathbf{2}$ & $\mathbf{3}$ & $\mathbf{4}$ \\
\hline Superficial gas velocity. (m/s) & 2.89 & 2.89 & 2.89 & 2.61 \\
Solids flux. (kg/m²-s) & 20.4 & 12 & 32.8 & 20.4 \\
Solids volume fraction at the inlet & 0.006 & 0.004 & 0.008 & 0.05 \\
Inlet gas pressure. (Pa) & 123390 & 120630 & 123390 & 126146 \\
Outlet gas pressure. (Pa) & 119940 & 118561.8 & 119251.3 & 119940 \\
\hline
\end{tabular}

\subsubsection{Comparison of results}

The results for these four different cases are shown in figures 12 to 19 .

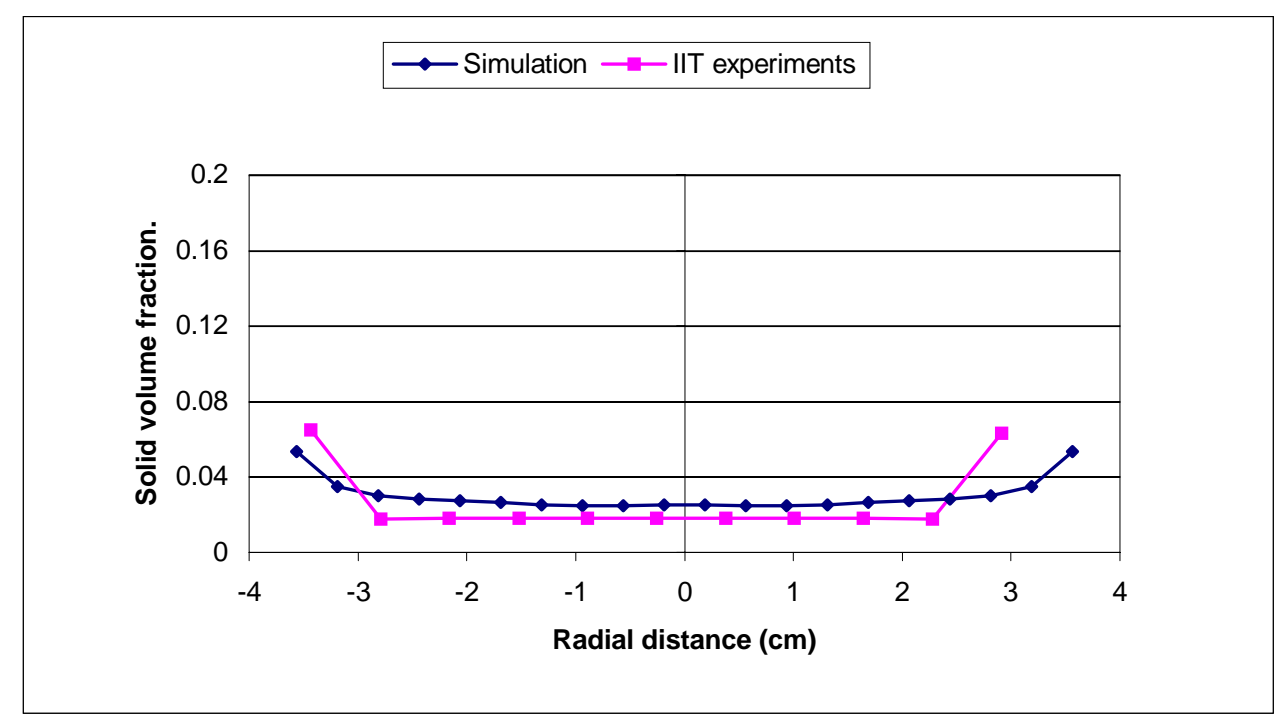

Figure 12. Radial Profile of Solid Volume Fraction at $1.86 \mathrm{~m}$ in the IIT CFB riser. [Superficial Gas velocity $=\mathbf{2 . 8 9} \mathrm{m} / \mathrm{s}$; Solids feed flux $=20.4 \mathrm{Kg} / \mathrm{m}^{2} . \mathrm{s}$ ] 


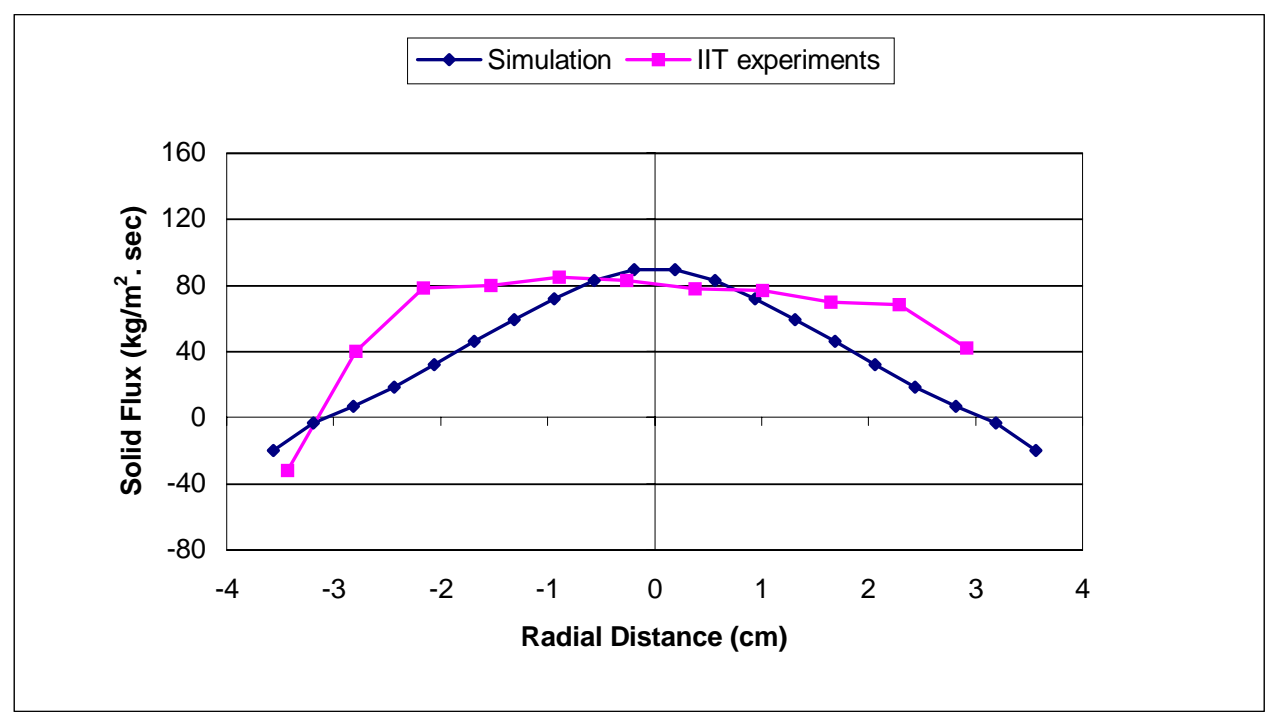

Figure 13. Radial Profile of Solid Flux at $1.86 \mathrm{~m}$ in the IIT CFB riser.[Superficial Gas velocity $=2.89 \mathrm{~m} / \mathrm{s} ;$ Solids feed flux $\left.=20.4 \mathrm{Kg} / \mathrm{m}^{2} . \mathrm{s}\right]$

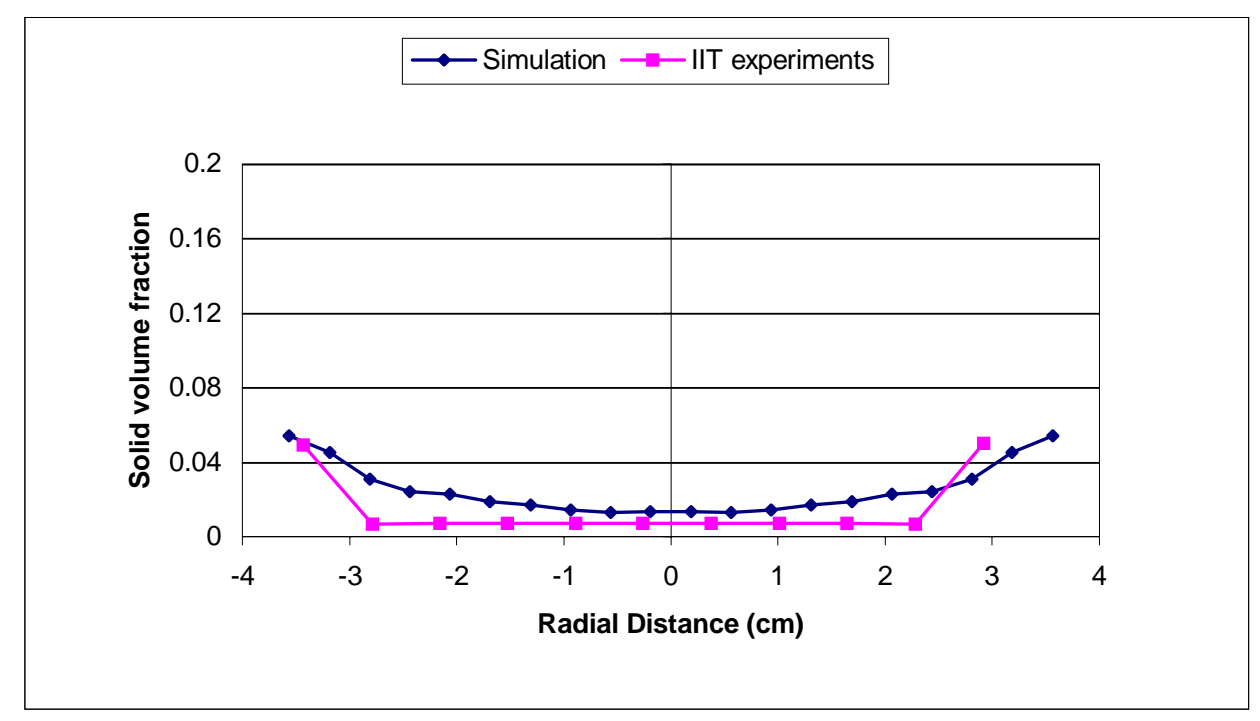

Figure 14. Radial Profile of Solid Volume Fraction at $1.86 \mathbf{m}$ in the IIT CFB riser. [Superficial Gas velocity $=2.89 \mathrm{~m} / \mathrm{s}$; Solids feed flux $=12.0 \mathrm{Kg} / \mathrm{m}^{2} . \mathrm{s}$ ] 


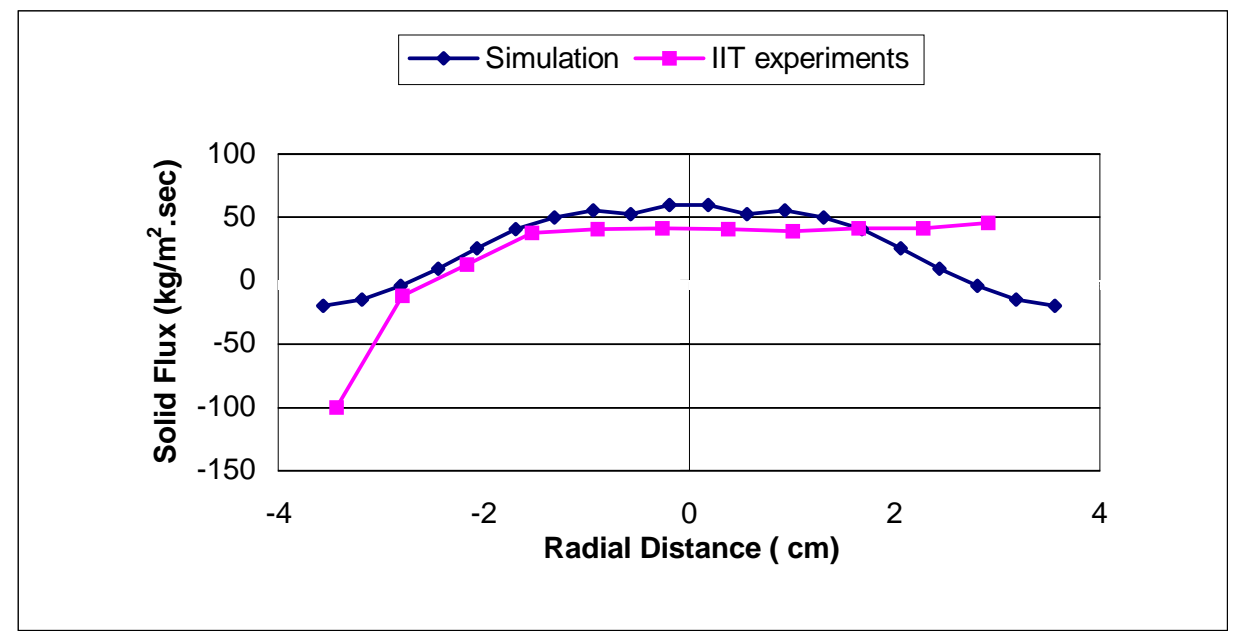

Figure 15. Radial Profile of Solid Flux at $1.86 \mathrm{~m}$ in the IIT CFB riser.[Superficial Gas velocity $=2.89 \mathrm{~m} / \mathrm{s} ;$ Solids feed flux $\left.=12.0 \mathrm{Kg} / \mathrm{m}^{2} . \mathrm{s}\right]$

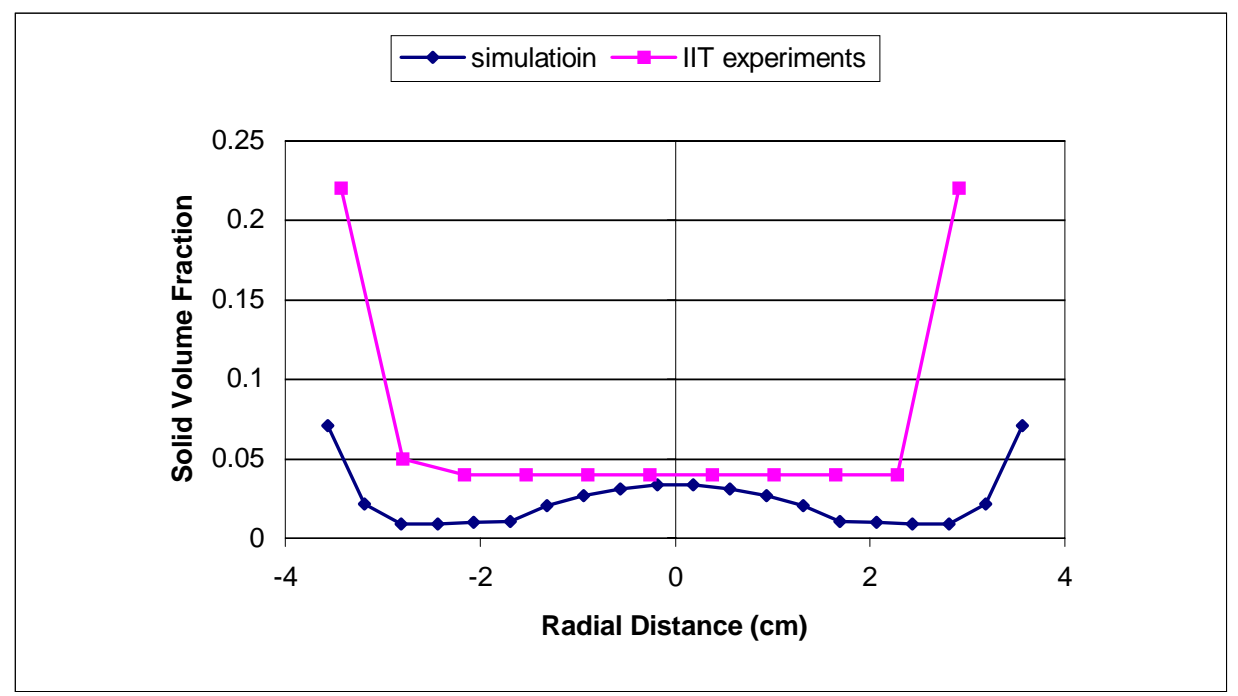

Figure 16. Radial Profile of Solid Volume Fraction at $1.86 \mathrm{~m}$ in the IIT CFB riser. [Superficial Gas velocity $=2.89 \mathrm{~m} / \mathrm{s}$; Solids feed flux $=32.8 \mathrm{Kg} / \mathrm{m}^{2} . \mathrm{s}$ ] 


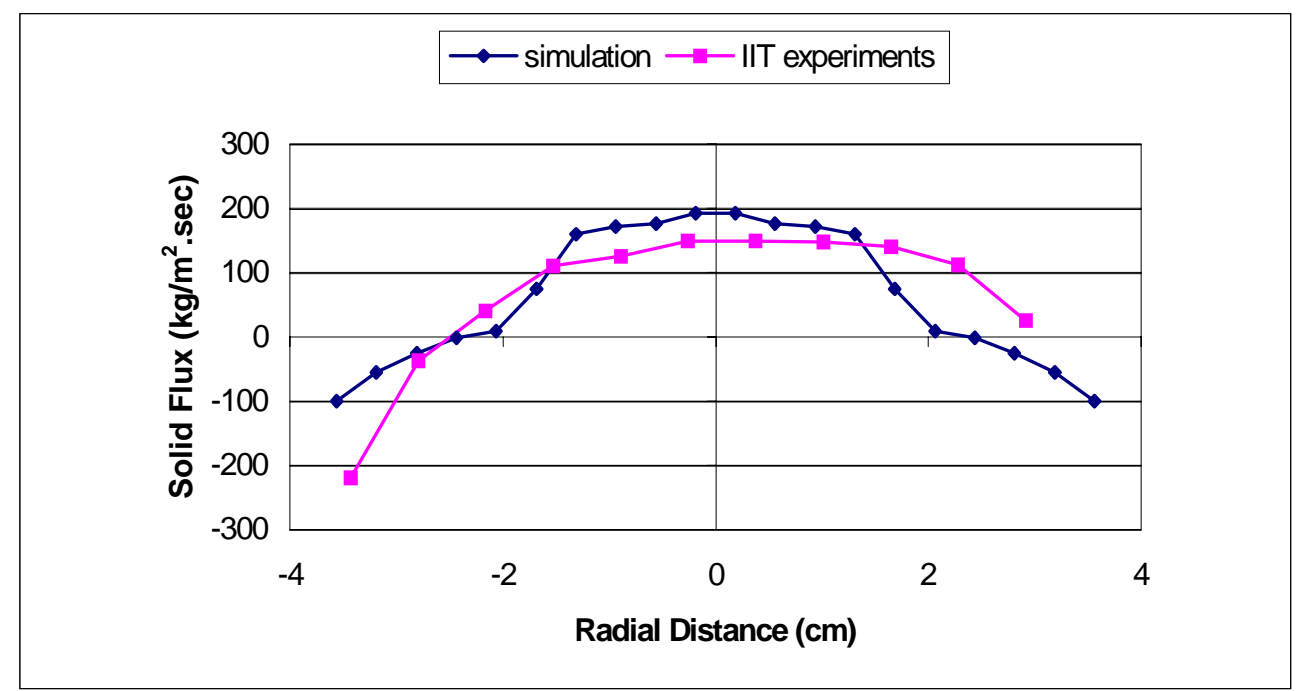

Figure 17. Radial Profile of Solid Flux at $1.86 \mathrm{~m}$ in the IIT CFB riser.[Superficial Gas velocity $=2.89 \mathrm{~m} / \mathrm{s}$; Solids feed flux $\left.=32.8 \mathrm{Kg} / \mathrm{m}^{2} . \mathrm{s}\right]$

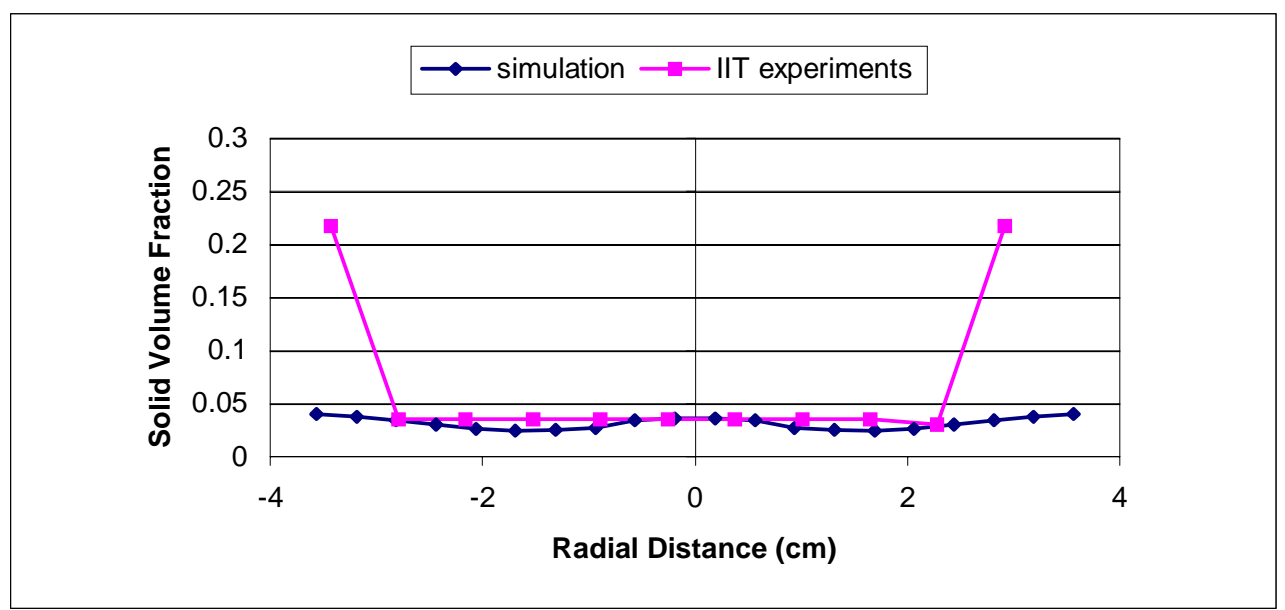

Figure 18. Radial Profile of Solid Volume Fraction at $1.86 \mathrm{~m}$ in the IIT CFB riser.[Superficial Gas velocity $=2.61 \mathrm{~m} / \mathrm{s}$; Solids feed flux $=20.4 \mathrm{Kg} / \mathrm{m}^{2} . \mathrm{s}$ ] 


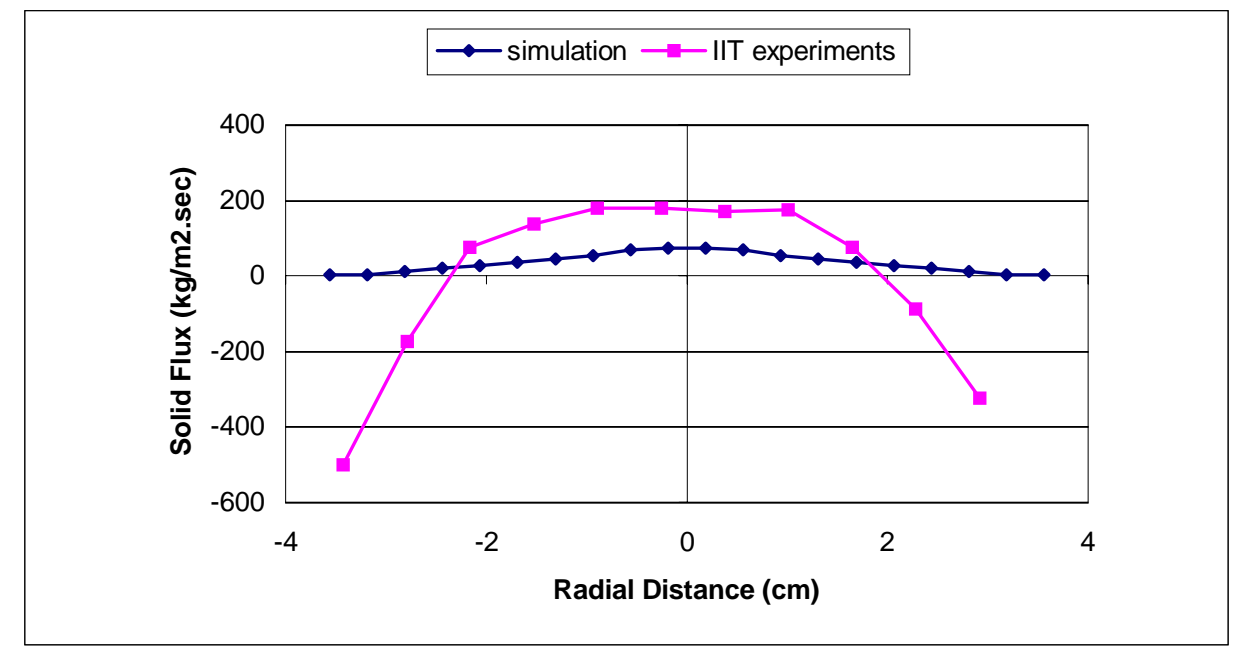

Figure 19. Radial Profile of Solid Flux at $1.86 \mathrm{~m}$ in the IIT CFB riser. [Superficial Gas velocity $=2.61 \mathrm{~m} / \mathrm{s} ;$ Solids feed flux $\left.=20.4 \mathrm{Kg} / \mathrm{m}^{2} . \mathrm{s}\right]$

As seen from the results a good match is observed for cases 1( Superficial gas velocity equals $2.89 \mathrm{~m} / \mathrm{s}$ and solids feed flux equals $20.4 \mathrm{~kg} / \mathrm{m}^{2}$-s.) and 2 ( Superficial gas velocity equals $2.89 \mathrm{~m} / \mathrm{s}$ and solids feed flux equals $12.0 \mathrm{~kg} / \mathrm{m}^{2}$-s.)as shown in Figures 12 and 14 respectively. For case 3 ( Superficial gas velocity equals $2.89 \mathrm{~m} / \mathrm{s}$ and solids feed flux equals $32.8 \mathrm{~kg} / \mathrm{m}^{2}$-s.) the flux profile follows the experimental data closely around the center as shown in Figure 17 but not around the wall. For case 4. ( Superficial gas velocity equals $2.61 \mathrm{~m} / \mathrm{s}$ and solids feed flux equals $20.4 \mathrm{~kg} / \mathrm{m}^{2}$-s.) the solids volume fraction matches the solids concentration throughout except at the wall as shown in Figure 18 but the flux prediction is not good as shown in Figure 19. These two cases (3 and 4) suggest that the same value of friction factor and the linear solids viscosity is not adequate to predict the flow profiles for all the conditions. But when the superficial velocity is low a good prediction with the experimental data is observed.

So to examine some of the reasons that would affect the flow profiles we varied 
the solids viscosity and the diameter of the particle and found that a closer match with the experimental data could be observed. But we haven't determined what viscosity relationship to be used for what flow regime.

\subsection{Effect of varying the solids viscosity and the particle diameter on flow profiles}

Solids viscosity was chosen of the form $\mu_{\mathrm{s}}=n \varepsilon_{\mathrm{s}}$, where the value of $n$ was varied to study the effects of change in viscosity on the flow profiles. Thus the effect of the value of $n$, varied from 2 to 8 is shown in figures 20 and 21 .

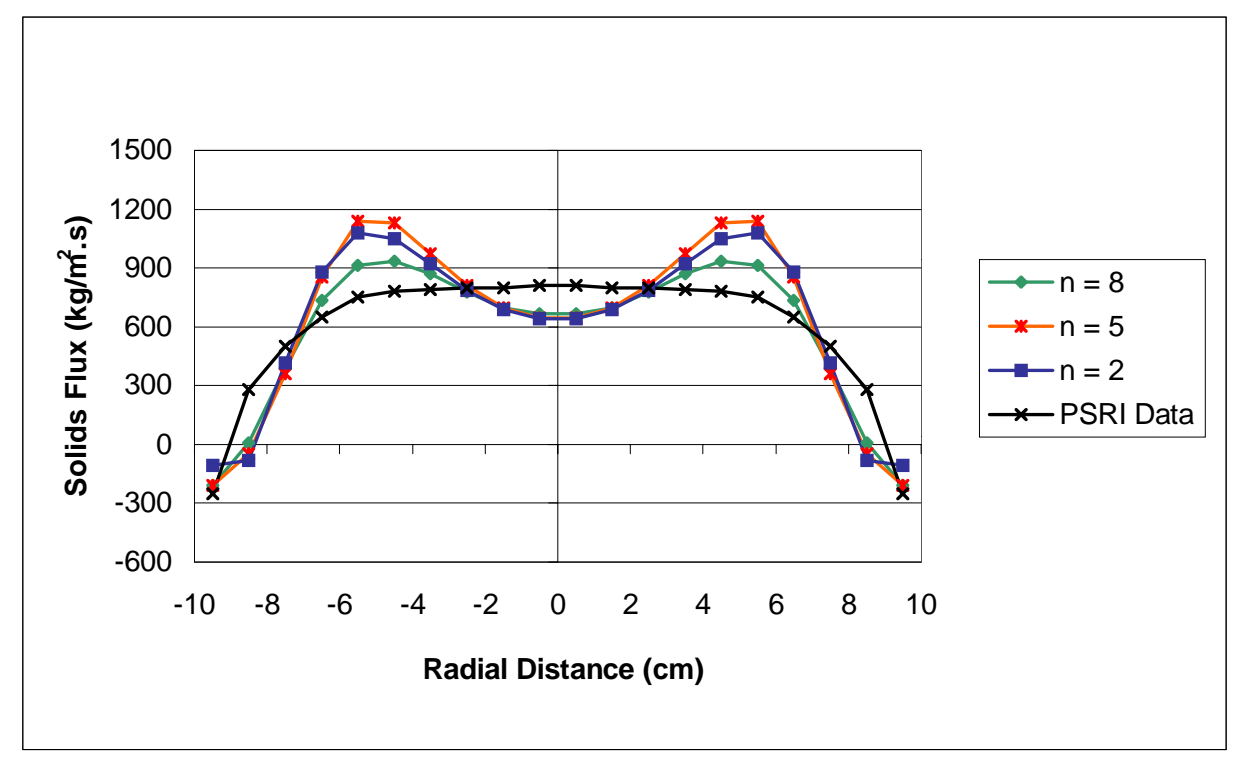

Figure 20. Effect of ' $n$ ' in $\mu_{s}=n \varepsilon_{s}$ model, gas inlet velocity $=5.2 \mathrm{~m} / \mathrm{s}$ solids inlet flux $=489 \mathrm{~kg} / \mathrm{m}^{2} . \mathrm{s}$ 


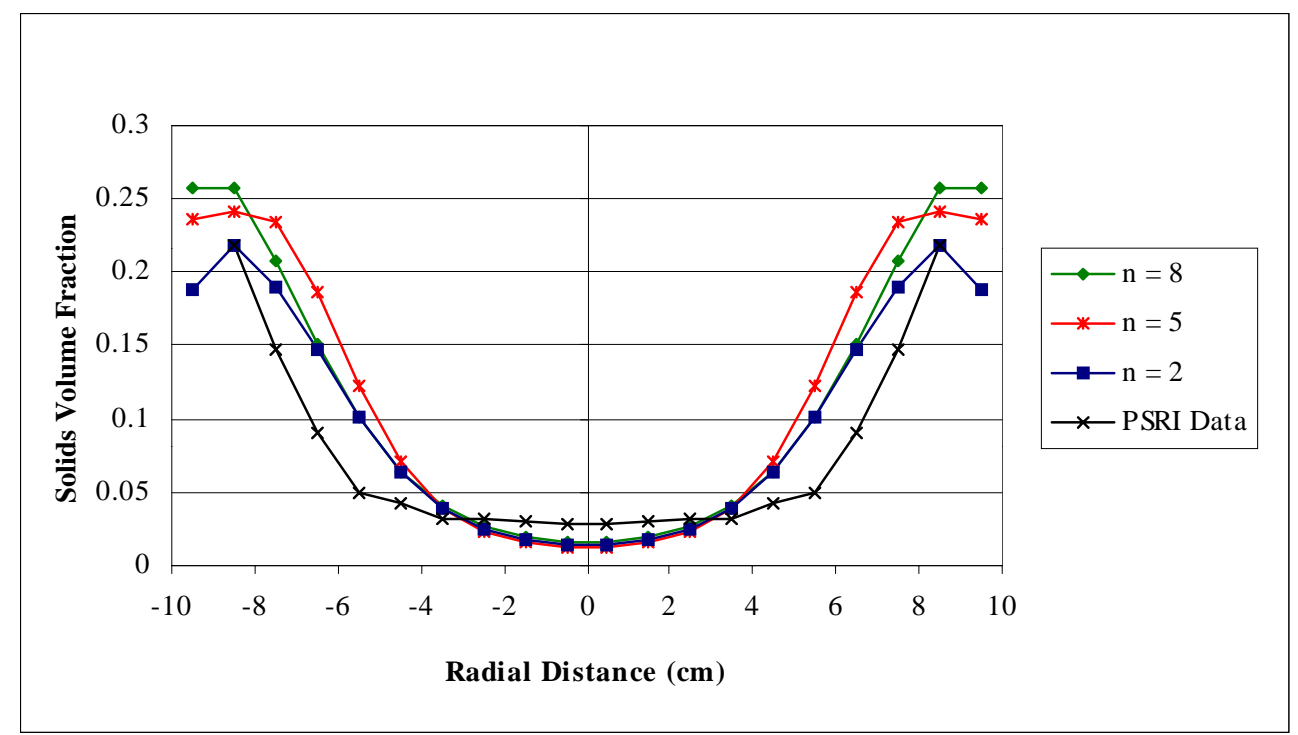

Figure 21. Effect of ' $n$ ' in $\mu_{s}=n \varepsilon_{s}$ model, gas inlet velocity $=5.2 \mathrm{~m} / \mathrm{s}$ solids inlet flux $=489 \mathrm{~kg} / \mathrm{m}^{2} \cdot \mathrm{s}$

After some time of operation of the CFB, the fines are collected and mostly heavier particles remain in the bed. Thus the effect of change in the radial flux and the solids volume fraction with the particle diameter is examined. A change in the particle diameter from 95 to $120 \mu \mathrm{m}$ resulted in the expected effects of relative lowering of fluxes (figures 22and 23). However, the basic shape of the profile did not alter. 


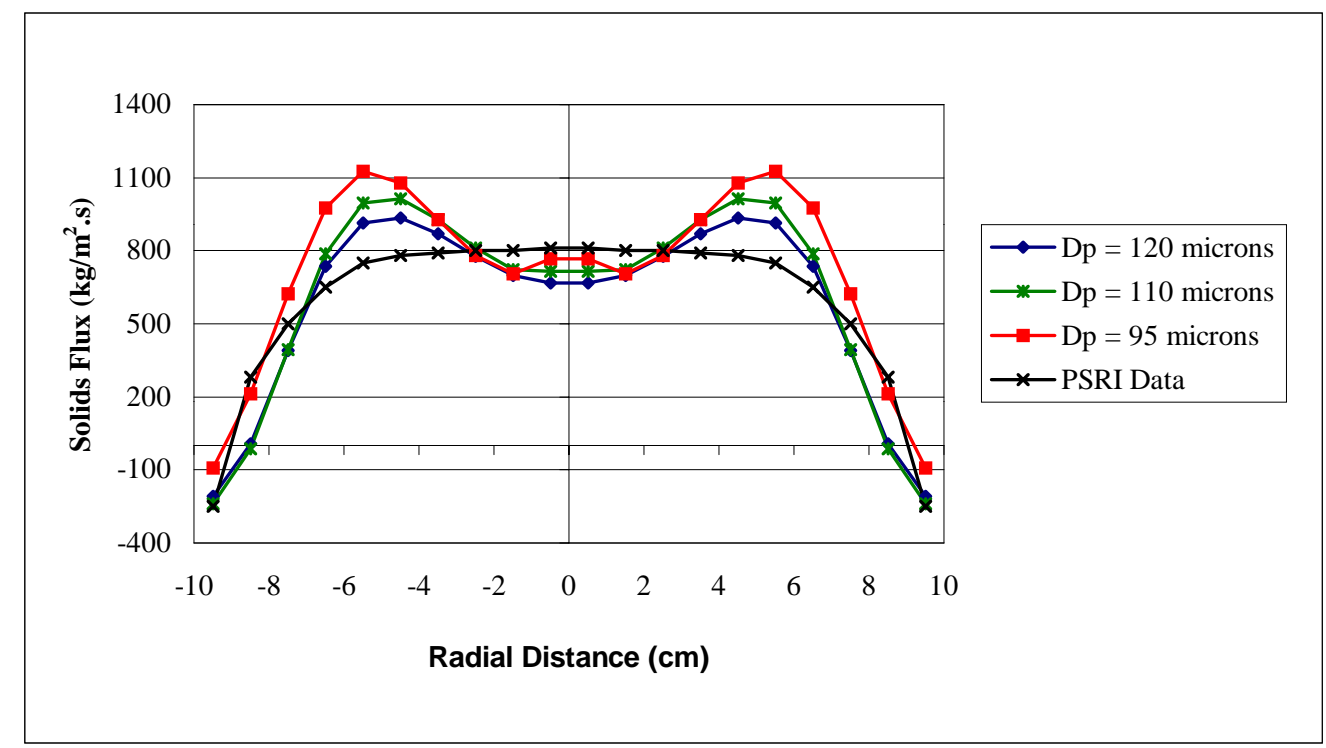

Figure 22. Effect of particle diameter. Gas inlet vel. $=5.2 \mathrm{~m} / \mathrm{s}$ solids inlet flux $=489 \mathrm{~kg} / \mathrm{m} 2 . \mathrm{s}$

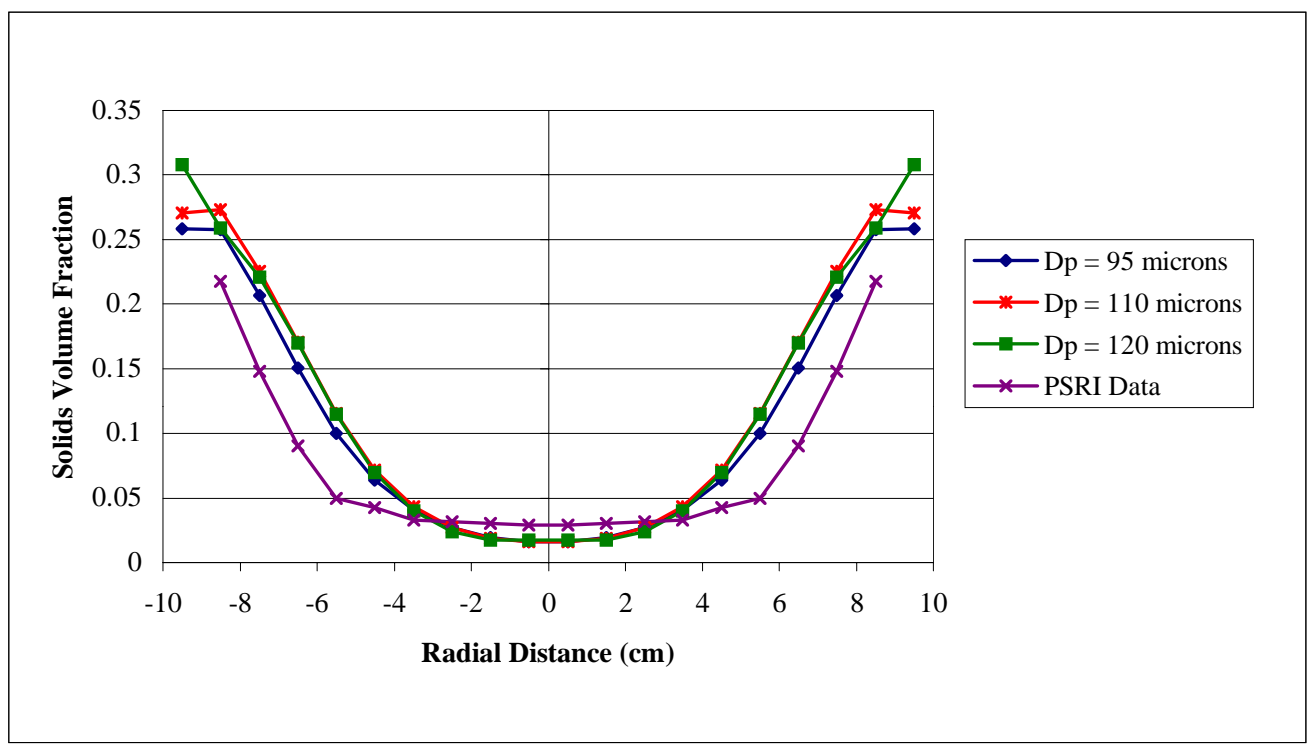

Figure 23. Effect of particle diameter. Gas inlet vel. $=5.2 \mathrm{~m} / \mathrm{s}$ solids inlet

flux $=489 \mathrm{~kg} / \mathrm{m} 2 . \mathrm{s}$ 


\section{CHAPTER V CONCLUSION}

With the reduced inlet for gas and solids, downflow of solids at the wall is observed in accordance with the experimental data. Thus modeling the actual riser as a straight pipe with reduced inlet gives a qualitative match with the experimental data. A core-annulus type of flow regime was predicted for both CFB risers, which can be described as a upflow core surrounded by a downflowing annulus. The simulation results also show that both the radial solids density and solids flux increased with decreasing superficial gas velocity, with increasing solids feed flux, and with decreasing riser height. These tendencies agree with the conclusions drawn from the experiments.

The viscosity correlation formulated from the experimental data of Miller (1991) in combination with the two phase flow model can be used in predicting the gas and solids flow patterns in CFB risers .The viscosity was a linear function of the solids volume fraction, and the shear stress was directly proportional to the shear rate.

If the solid phase was in fact a continuum in the sense of gas we could argue directly from the momentum balance that only surface forces near the wall are important. Therefore, we can obtain the relationship that shear stress is equal to the friction at the wall for the axial gas phase momentum balance. But since this is not the case, besides surface forces, additional forces are also included in the solids phase axial boundary condition. Thus solids boundary condition at the wall of the riser which was modified by using the axial momentum balance at the wall to account for the solids recirculation seems to be realistic as it can predict downflow at the wall as observed in the experiments. 
The model showed a better agreement with experimental data for the first two cases in both 7.5-cm-ID IIT riser and the 20.0-cm-ID PSRI riser respectively. Also, it is better when the superficial gas velocity is lower. The model has a limitation in predicting the flow profiles for all the conditions. One reason for this behavior could be that a different solid viscosity relationship may be required either due to change in flow regime or in the case when there is a change in the particle diameter due to fines being blown away and only course particles remaining in the bed.

The two sets of data are different in that they were obtained from unscaled CFBs of different sizes. However, the solids and the gas are the same. This study shows that numerical approaches for the design and scale-up of multiphase flow equipment is practical and accurate as a design tool. 


\section{References}

Arastoopour, H. and D. Gidaspow, "Vertical Pneumatic Conveying Using Four Hydrodynamic Models”, I\&EC Fundam., 18, 123-130 (1979).

Arastoopour, H.V. Mathiesen and B. H. Hjertager, "Experimental and Computational Study of Multiphase Gas / Particle Flow in a CFB Riser", AICHE J., 45,2503-2516, (1999).

Bader, R., J. Findlay and T. M. Knowlton, "Gas/Solid Flow Patterns in a 30.5-cm Diameter Circulating Fluidized Bed", Circulating Fluidized Bed Technol. II, P . Basu and J. F. Large, eds., Pergamon Press, 123-127 (1988).

Basu, P. and P. K. Nag, " An Investigation into Heat Transfer in Circulating Fluidized Beds", Int. J: Heat Mass Transfer, 30, 2399-2409 (1987).

Behie L. A., A.K. Mehrotra , D. M. Puchyr and N. E. Kalogerakis, "Modelling a Circulating Fluidized Bed Riser with Gas-Solids Downflow at the Wall”, Can. J: of Chem. Eng., 75, 317-328 (1997).

Berruti, F. and N. Kalogerakis, "Modeling the Internal Flow Structure of Circulating Fluidized Beds", Can. J: of Chem. Eng., 67, 1010-1014 (1989).

Berruti, F., J. Chaouki, L. Godfroy, T. S. Pugsley and G. S. Patience, "Hydrodynamics of Circulating Fluidized Bed Risers: A Review", Can. J: of Chem. Eng., 73, 579- 602 (1995).

Bolton, L. W. and J. F. Davidson, "Recirculation of Particles in Fast Fluidized Risers", Circulating Fluidized Bed Technol. II, P. Basu and J. F. Large, eds., AIChE, New York, 39-46 (1994).

Ding, J. and D. Gidaspow, "A Bubbling Fluidization Model Using Kinetic Theory of Granular Flow", AIChE J., 36, 523-538 (1990). 
Gidaspow, D., Multiphase Flow and Fluidization, Academic Press, Inc., 1994.

Gidaspow, D. and L. Huilin, “Collisional Viscosity of FCC Particles in a CFB ," AICHE, J., 42, 2503-2509, 1996.

Grace, J. R. and J. Tuot, "A Theory for Cluster Formation in Vertically Conveyed Suspensions of Intermediate density", Trans. Inst. Chem. Eng. , 57, (1979).

Grace, J. R., "High-Velocity Fluidized Bed Reactors", Chem. Eng. Sci., 45, 1953-1966, (1990).

Gu W., "Diameters of catalyst Clusters in FCC", Advanced Technol. For Fluid-particle systems, AICHE Symposium Series No. 321, Arastoopour et al., ed., 95, 42-46 New York, (1999).

Harlow, F. H. and A. A. Amsden, "Numerical Calculation of Multiphase Fluid Flow", J. of Computational Physics, 17, 19-52, (1975).

Harris, B. J. , J. F. Davison and Y. Xue, "Axial and Radial Variation of Flow in Circulating Fluidized bed Risers", Circulating Fluidized Bed Technol. IV, A. A. Avidan, ed., AIChE, New York, 103-110 (1994).

Harris, B. J. and J. F. Davison, "Modeling Options for Circulating Fluidized Beds: A Core/ Annulus Depositions Model", Circulating Fluidized Bed Technol. IV, A. A. Avidan, ed., AIChE, New York, 32-39 (1994).

Hartge, E. U., Y. Li and J. Werther, "Analysis of the local Structure of the Two-phase Flow in a Fast Fluidized Bed", Circulating Fluidized Bed Technol., P. Basu, ed., Pergamon Press, New York, 193-200 (1986).

Herbert P., L. Rehand R. Nicolai, “The ETH Experience: Experimental database and Results from Past Eight Years", Advanced Technol. For Fluid-particle systems, AICHE Symposium Series No. 321, Arastoopour et al., ed., 95, 61-64 New York, (1999). 
Horio, M., K. Morishita, 0. Tachibana and M. Murata, "Solids Distribution and Movement in Circulating Fluidized Beds", Circulating Fluidized Bed Technol. II. P.Basuano J.F.Large, eds., Pergamon Press, New York, 147-154(1988).

Knowlton, T., Geldart, D. Matsen, J. and King, D., "Comparison of CFB Hydrodynamics Model. PSRI Challenge Problem- presented at Eighth International Fluidization Conference, Tour, France , May, 1995.

Li Lu, "Computational Modeling of Gas and Solids Flow Patterns in Circulating Fluidized Bed Risers,” M.S Diss., West Virginia University, Morgantown, 1996.

Miller, A. L. and Li, Lu., "Computational Modeling of Solid Phase Flow Patterns in Circulating Fluidized Beds,”.AICHE. J., 1996.

Miller, A. L., Gidaspow, D., "Dense Vertical Gas-Solid Flow In a Pipe,” AICHE, J., 38, 1801-1815, 1992.

Miller, A.L, "Dense Vertical Gas-Solid Flow In a Pipe," PhD Diss., Illinois Institute of Technology, Chicago, 1991.

Nakamura, K. and C. E., Capes, "Vertical Pneumatic Conveying: A Theoretical Study od Uniform and Annular Particle Models", Can. J: of Chem. Eng, 51, 39-46 (1973).

O`Brian T. J. and M. Syamlal, "Particle Cluster Effects in Numerical Simulation in Circulating Fluidized Bed", Circulating Fluidized Bed Technol. IV. A.A. Avidan, ed., New York, 345-350(1994).

Ocone, R. and L. Letizia, "Multiple Steady States in Gas-Particle Flow in Vertical Flow in Vertical Ducts", submitted for publication in AIChE I. and presented at West Virginia University, 1996.

Pita, I. A. and S. Sundaresan, "Developing Flow of a Gas-Particle Mixture in a Vertical Riser", Fluid Mechanics and Transport Phenomena, 39, 541 (1993). 
Pita, I. A. and S. Sundaresan, "Gas-Solid Flow in Vertical Tubes", AIChE.J:, 37, 10091018 (1991).

Rhodes, M. I. and D. Geldart, "The Hydrodynamics of Recirculating Fluidized Beds", Circulating Fluidized Bed Technol. , P. Basu, ed., Pergamon Press, New York, 193-200 (1986).

Rhodes, M. J., X. S. Wang, H. Cheng and T. Hirama, "Similar Profiles of Solids Flux in

Circulating Fluidized Bed Risers”, Chem. Eng. Sci., 47, 1635-1643, (1992).

Richardson, I. F. and W. N. Zaki, "Sedimentation and Fluidization: Part I", Trans. Inst. Chem. Eng., 32, 35-53 (1984).

Seu-Kim, H. and H. Arastoopour, "Simulation of FCC Particles Flow Behavior in a CFB Using Modified Kinetic Theory", Can. .J: of Chem. Eng., 73, 603-611 (1995).

Sinclair, J. L. and R. Jackson, "Gas-Particle Flow in a Vertical Pipe with Particle-Particle Interactions", AIChE.J:, 35, 1473-1486 (1989).

Sinclair, J. L. and C. M. Hrenya, "Effect of Particle-Phase Turbulence in Gas-Solids Flows ", AIChE. J:, 43, 853-896 (1997).

Squires, A. M., "The Story of Fluid Catalytic Cracking: The First Circulating Fluid Bed", In Circulating Fluidized Bed Technology edited by Basu, P., Pergamon Press, 120, 1986.

Squires, A. M.; Kwauk, M.; Avidan, A. A., "Fluids Beds: At Last, Challenging Two Entrenched Practices”, Science, 230, 4732, 1329-1337, 1985.

Syamla1, M. and D. Gidaspow, "Hydrodynamics of Fluidization: Prediction of Wall to Bed Heat Transfer Coefficients", AIChE J, 31, 127-135 (1985).

Syamlal, M, "MFIX Documentation, User's Manual", 1994 
Syamlal, M., "MFIX Documentation Numerical Technique”, Draft, p.18, January 1998.

Syamlal, M., W. Rogers and T. I. O'Brien, "MFIX Documentation, Theory Guide", Technical note, DOE/METC-94/1004, 1993.

Tsuo, Y. P. and D. Gidaspow, "Computation of Flow Patterns in Circulating Fluidized Beds", AIChE .J:, 36, 885-896 (1990).

Tsuo, Y. P., "Computational of Flow Regimes in Circulating Fluidized Beds", Ph.D Thesis, Illinois Institute of Technology, Chicago (1989).

Weinstein, H.; Shao, M.; Schnitzlein and Graff R. A., "Radial Variation in Void Fraction in a Fast Fluidized Bed", Fluidization V, Proceedings of the Fifth Engineering Foundation Conference on Fluidization, Elsinore, Denmark, edited by Ostergaard, K. And Sorensen, A., 329-336, 1986.

Wang, Z. Y., Jin, Z. Q. Yu, Y Yang and D. Bai, "The Radial Distribution of Local Particle Velocity in a Dilute Circulating Fluidized Bed", Circulating Fluidized Bed Technol. Ill, P. Basu, M. Horio, and M. Hasatani, eds., Pergamon Press, New York, 201-206 (1991).

Yerushalmi, J ., D. H. Turner and A. M. Squires "The fast Fluidized Bed", Ind. Eng. Chem. Process Des. Dev.,15, 47-53, (1976

Yerushalmi, J ., "High Velocity Fluidized Beds", Ch. 7, Gas Fluidization Technol., D. Geldart, ed., Wiley, New York, 155-195 (1986). 


\section{Appendix A.}

\section{MFIX Sample Subroutines}

\section{Sample data file}

\section{mfix.dat}

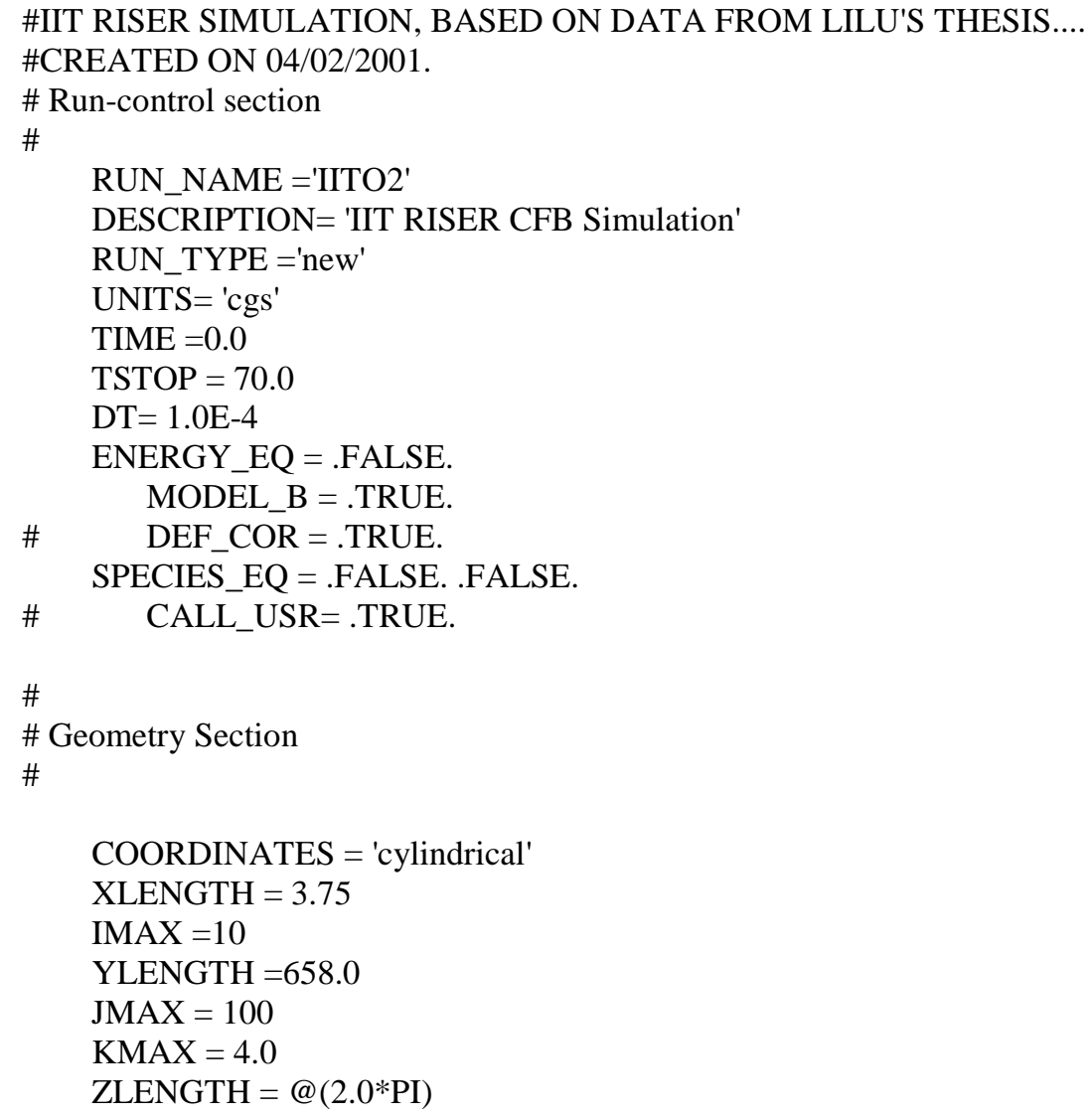


\# Solids-phase Section

\#

$$
\begin{aligned}
& \text { RO_s }=1.654 \\
& \text { D_p }=0.009513 \\
& \mathrm{e}=0.8 \\
& \quad \text { Phi }=0.0 \\
& \quad \text { EP_star }=@(1.0-1.016 / 1.654)
\end{aligned}
$$

\#

\# Initial Conditions Section

\#

IC_X_w $=0.0$

IC_X_e $=3.75$

IC_Y_s $=0.0$

IC_Y_n $=658.0$

IC_Z_b $=0.0$

IC_Z_t $=@(2.0 * \mathrm{PI})$

IC_EP_g $=0.95$

IC_U_g $=0.0$

IC_V_g = @ $(289.0 / 0.95)$

IC_W_g $=0.0$

IC_U_s $=0.0$

$\mathrm{IC}_{-} \mathrm{V}_{-} \mathrm{S}=0.0$

IC_W_s $=0.0$

IC_P_star $=0.0$

IC_T_g $=297.0$

\#

\# Boundary Conditions Section

\#

\#

$\begin{array}{lccc} & \text { Jet } & \text { Grid } & \text { Exit } \\ \text { BC_X_w } & =0.0 & 1.9 & 0.0 \\ \text { BC_X_e } & =1.9 & 3.75 & 3.75 \\ \text { BC_Y_s } & =0.0 & 0.0 & 658.0 \\ \text { BC_Y_n } & =0.0 & 0.0 & 658.0 \\ \text { BC_Z_b } & =0.0 & 0.0 & 0.0 \\ \text { BC_Z_t } & =@(2.0 * \mathrm{PI}) @(2.0 * \mathrm{PI}) @(2.0 * \mathrm{PI})\end{array}$

BC_TYPE ='MI' 'MI' 'PO'

BC_EP_g $=0.9960 .95$

BC_ROP_s $=@(1.654 * 0.004) @(1.654 * 0.05)$

BC_U_g $=0.0 \quad 0.0$

BC_V_g $=290.16 \quad 0.0$

BC_W_g $=0.0 \quad 0.0$

BC_U_s $=0.0 \quad 0.0$

BC_MASSFLOW_s $=@(1.2 * P I * 7.5 * 7.5 / 4) 0.0$

BC_W_s $=0.0 \quad 0.0$

BC_P_g $=1.20630 \mathrm{E} 6 \quad 1.20630 \mathrm{E} 6 \quad 1.185618 \mathrm{E} 6$ 
BC_T_g $=297.0 \quad 297.0 \quad 297.0$

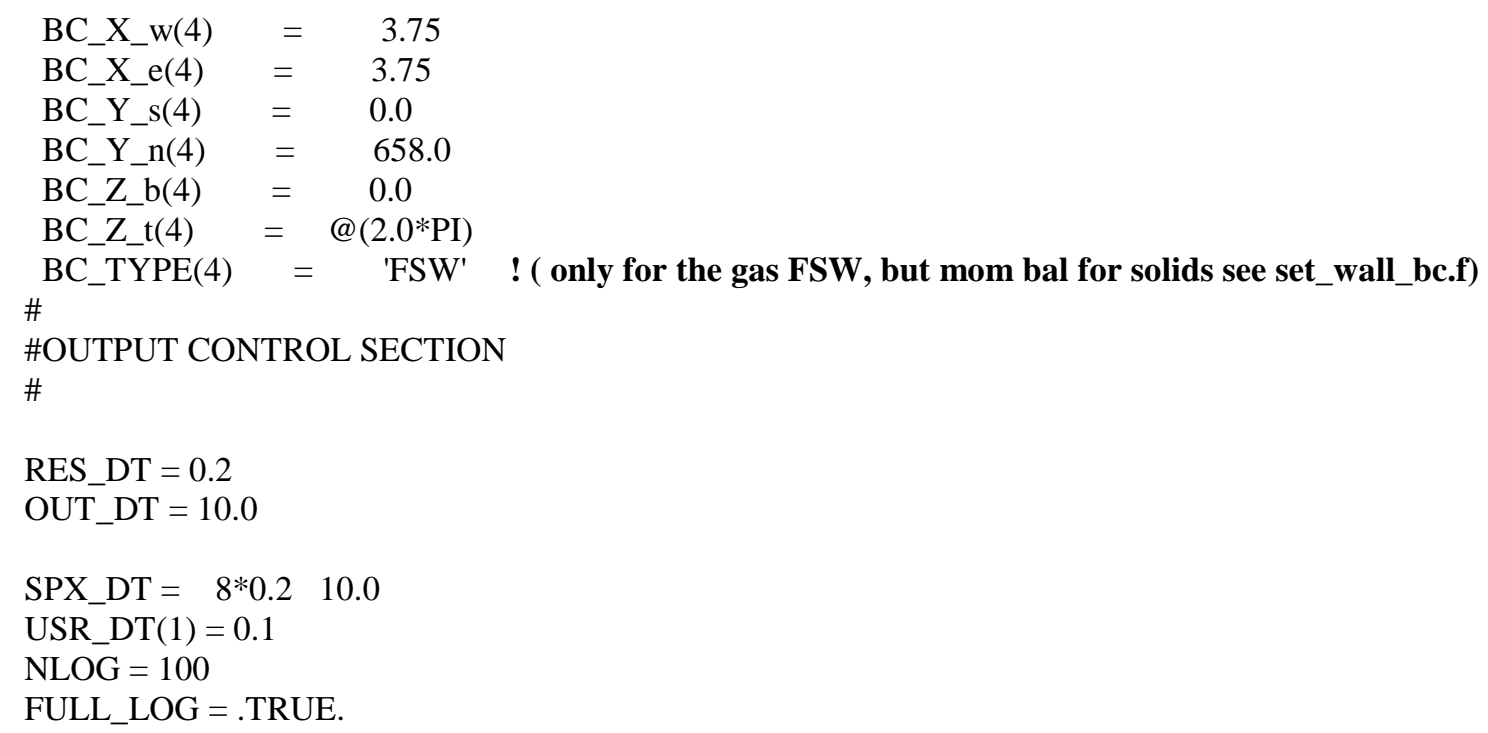




\section{Subroutine for setting solids velocity at the wall}

\section{Set_wall_bc.f}

! Module name: SET_WALL_BC(IER)

! Purpose: Set wall boundary conditions

!

! Author: M. Syamlal Date: 29-JAN-92

! Reviewer: P. Nicoletti, W. Rogers, S. Venkatesan Date: 29-JAN-92

! Revision Number: 1

! Purpose: Add calculations for mass outflow boundary condition

! Author: M. Syamlal Date: 23-OCT-92

! Reviewer: M. Syamlal Date: 11 -DEC-92

! Revision Number: 2

! Purpose:Revised for MFIX 2.0. This sub routine is different from

! old set_wall_bc.

! Author: M. Syamlal

Date: 18-JUL-96

! REVISION NUMBER 3.

! Purpose: tried to use Miller's boundary from li lu's file

! Authors: neeraj and dharm Date: 1/13/2000

!

! Literature/Document References:

!

! Variables referenced: BC_DEFINED, BC_I_w, BC_I_e, BC_J_s, BC_J_n,

$! \quad$ BC_K_b, BC_K_t, BC_TYPE, TIME, DT, BC_TIME,

! BC_V_g, BC_V_gh, BC_V_gl, BC_DT_l, BC_DT_h,

! BC_PLANE, IMAX2, JMAX2, KMAX2

! Variables modified: BC_V_g, BC_TIME, I, J, K, IJK, V_g

!

! Local variables: L, IJK2, I1, I2, J1, J2, K1, K2

!

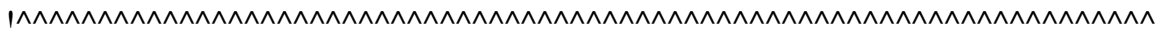

!

SUBROUTINE SET_WALL_BC(IER)

!...Translated by Pacific-Sierra Research VAST-90 2.06G5 12:17:31 $12 / 09 / 98$

!...Switches: -xf

!

! Modules

!-------------

USE param1

USE bc

USE fldvar

USE geometry

USE indices

USE physprop

USE run

USE funits

IMPLICIT NONE

INCLUDE 'function.inc' 


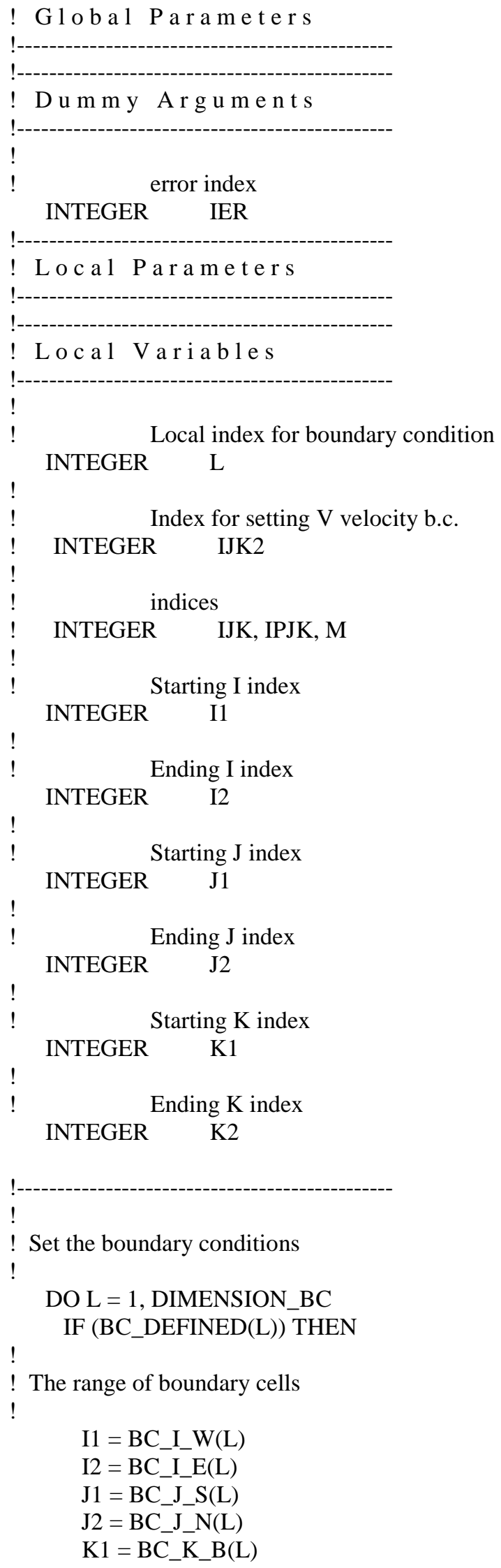




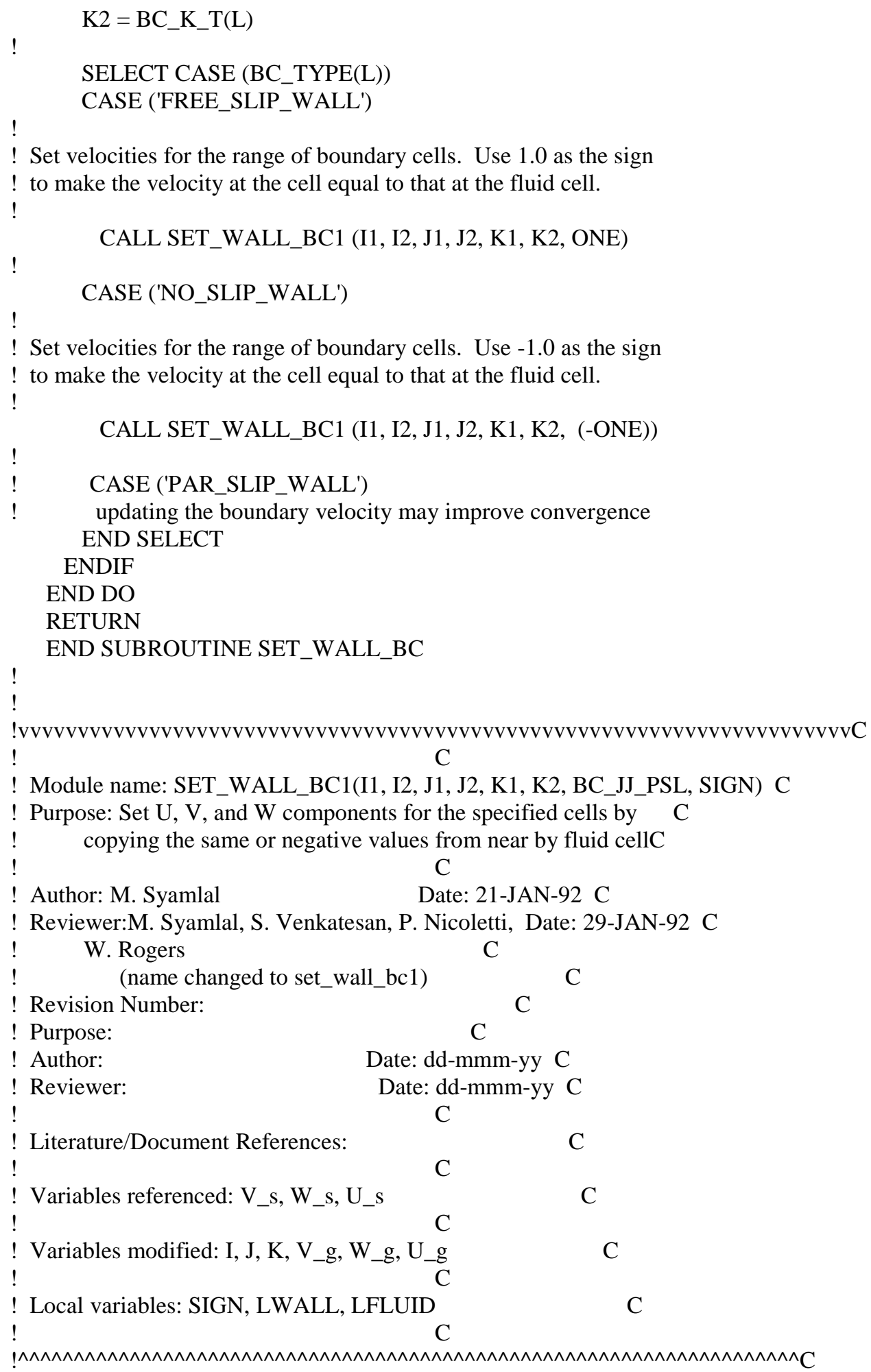

SUBROUTINE SET_WALL_BC1(I1, I2, J1, J2, K1, K2, SIGN)

!...Translated by Pacific-Sierra Research VAST-90 2.06G5 12:17:31 12/09/98

!...Switches: -xf 


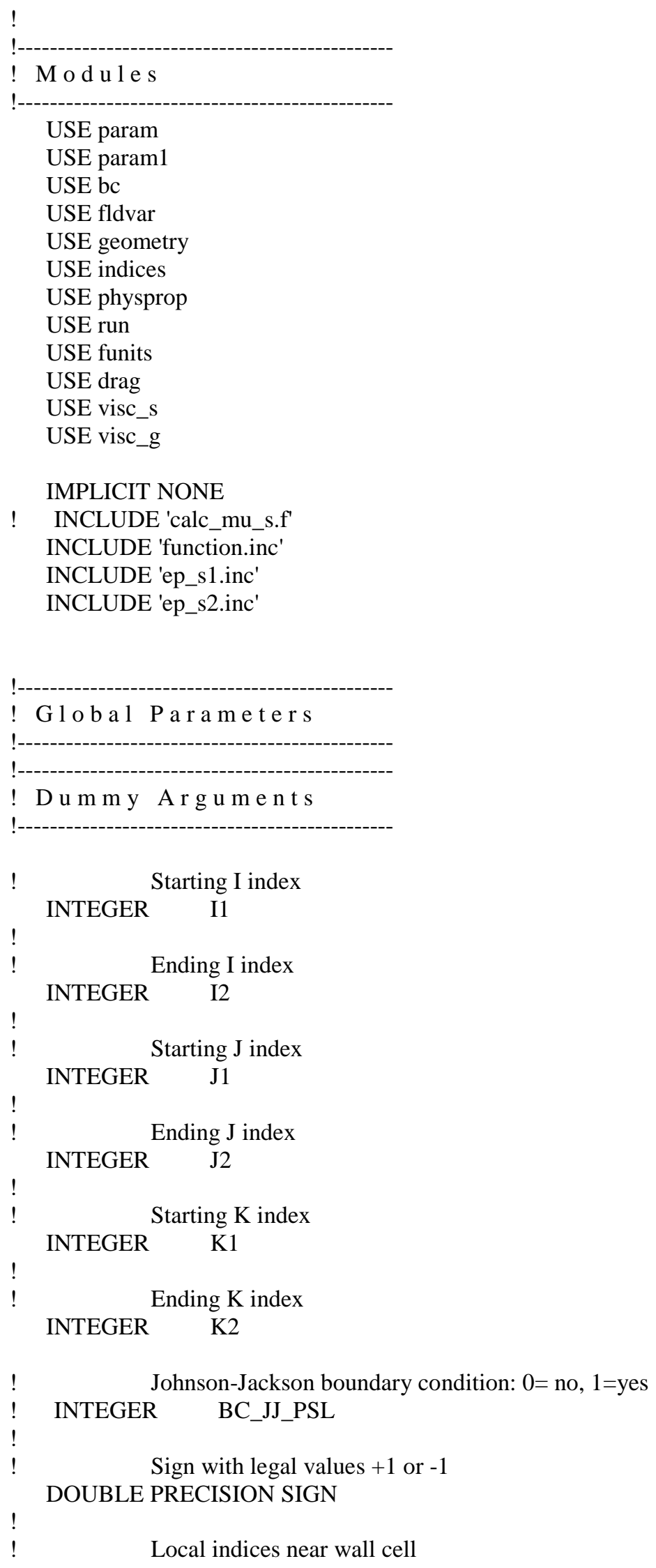




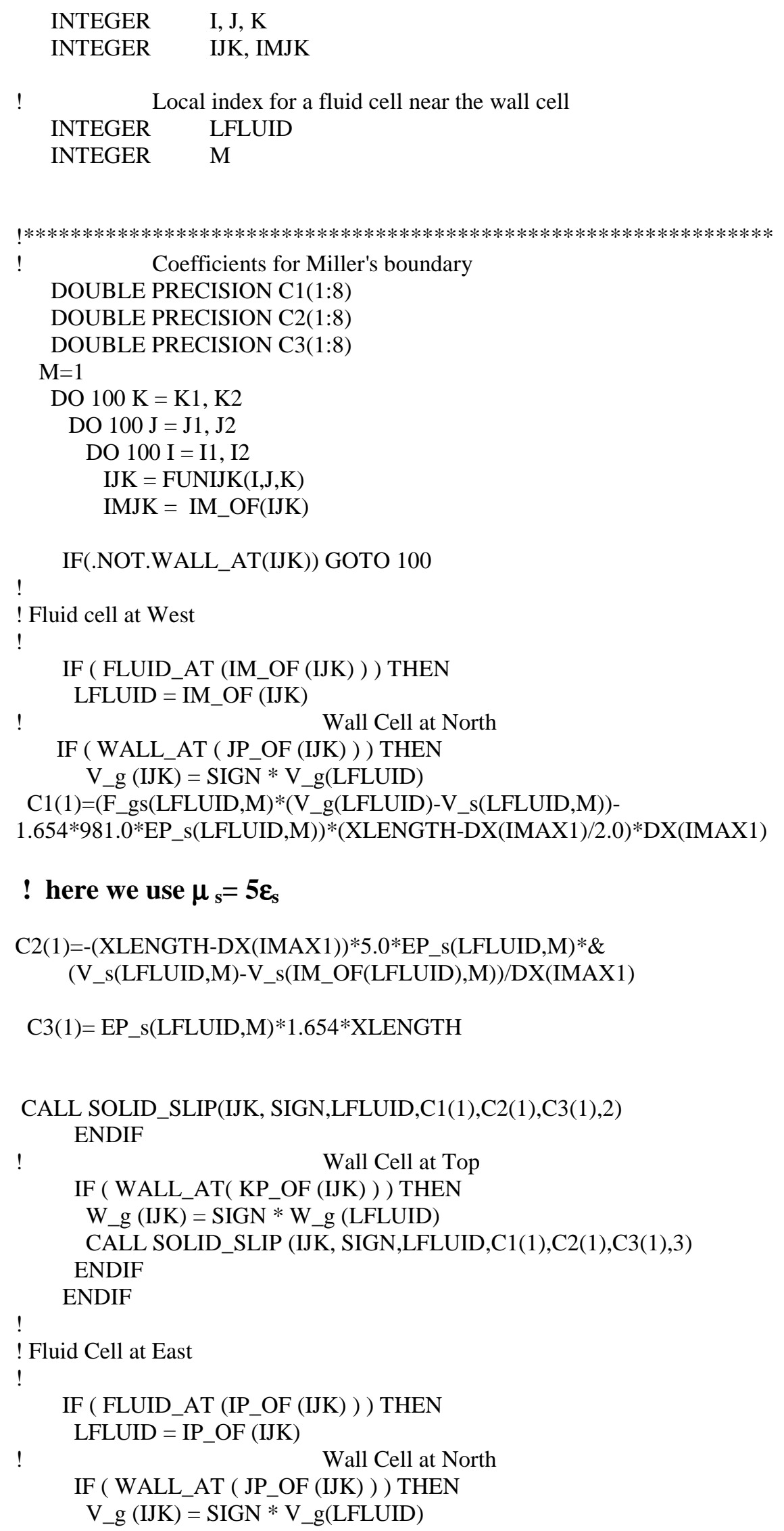


$\mathrm{C} 1(2)=\left(\mathrm{F} \_\mathrm{gs}(\right.$ LFLUID,M $) *\left(\mathrm{~V} \_\mathrm{g}(\right.$ LFLUID $)-\mathrm{V} \_\mathrm{s}($ LFLUID,M $\left.)\right)-$ $1.654 * 981.0 * \mathrm{EP} \_\mathrm{s}($ LFLUID,M) $) *(X L E N G T H-D X($ IMAX1)/2)*DX(IMAX1)

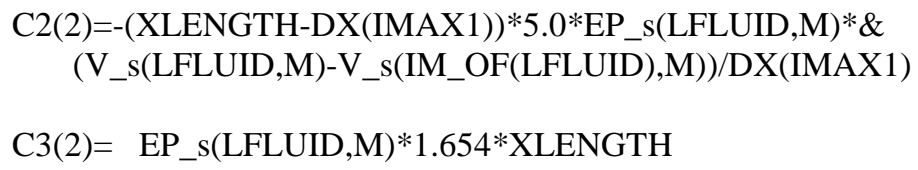


(V_s(LFLUID,M)-V_s(IM_OF(LFLUID),M))/DX(IMAX1)

$\mathrm{C} 3(4)=$ EP_s $($ LFLUID,M $) * 1.654 * X L E N G T H$

CALL SOLID_SLIP (IJK,SIGN,LFLUID,C1(4),C2(4),C3(4),1)

ENDIF

! Wall Cell at Top

IF ( WALL_AT( KP_OF (IJK) ) ) THEN

$\mathrm{W} \_\mathrm{g}(\mathrm{IJK})=\mathrm{SIGN} * \mathrm{~W} \_\mathrm{g}($ LFLUID $)$

CALL SOLID_SLIP (IJK,SIGN,LFLUID,C1(4),C2(4),C3(4),3)

ENDIF

ENDIF

!

! Fluid Cell at Bottom

!

IF ( FLUID_AT (KM_OF (IJK) ) ) THEN

LFLUID = KM_OF (IJK)

! Wall Cell at East

IF ( WALL_AT ( IP_OF (IJK) ) ) THEN

U_g (IJK) $=$ SIGN $*$ U_g (LFLUID)

$\mathrm{C} 1(5)=\left(\mathrm{F} \_\mathrm{gs}(\right.$ LFLUID,M $) *\left(\mathrm{~V}_{-} \mathrm{g}(\right.$ LFLUID $)-\mathrm{V} \_\mathrm{s}($ LFLUID,M $\left.)\right)-$

$1.654 * 981.0 *$ EP_s(LFLUID,M) $) *(X L E N G T H-D X(I M A X 1) / 2) * D X(I M A X 1)$

$\mathrm{C} 2(5)=-($ XLENGTH-DX (IMAX1) $) * 5.0 *$ EP_s(LFLUID,M $) * \&$

(V_s(LFLUID,M)-V_s(IM_OF(LFLUID),M))/DX(IMAX1)

$\mathrm{C} 3(5)=$ EP_s $($ LFLUID,M $) * 1.654 * X L E N G T H$

CALL SOLID_SLIP (IJK,SIGN,LFLUID,C1(5), C2(5),C3(5),1)

ENDIF

! Wall Cell at North

IF ( WALL_AT( JP_OF (IJK) ) ) THEN

$\mathrm{V} \_\mathrm{g}(\mathrm{IJK})=$ SIGN $* \mathrm{~V} \_\mathrm{g}$ (LFLUID)

$\mathrm{C} 1(6)=\left(\mathrm{F} \_\mathrm{gs}(\right.$ LFLUID,M $) *\left(\mathrm{~V} \_\mathrm{g}(\right.$ LFLUID $)-\mathrm{V} \_\mathrm{s}($ LFLUID,M $\left.)\right)-$

$1.654 * 981.0 *$ EP_s(LFLUID,M) $) *(X L E N G T H-D X($ IMAX1)/2)*DX(IMAX1)

$\mathrm{C} 2(6)=-(\mathrm{XLENGTH}-\mathrm{DX}(\mathrm{IMAX} 1)) * 5.0 *$ EP_s(LFLUID,M $) * \&$

(V_s(LFLUID,M)-V_s(IM_OF(LFLUID),M))/DX(IMAX1)

$\mathrm{C} 3(6)=$ EP_s(LFLUID,M $) * 1.654 * X L E N G T H$

CALL SOLID_SLIP (IJK,SIGN,LFLUID,C1(6),C2(6),C3(6),2)

ENDIF

ENDIF

!

! Fluid Cell at Top

!

IF ( FLUID_AT (KP_OF (IJK) ) ) THEN

LFLUID = KP_OF (IJK)

! Wall Cell at East

IF ( WALL_AT ( IP_OF (IJK) ) ) THEN

U_g $($ IJK $)=$ SIGN $*$ U_g $($ LFLUID $)$ 


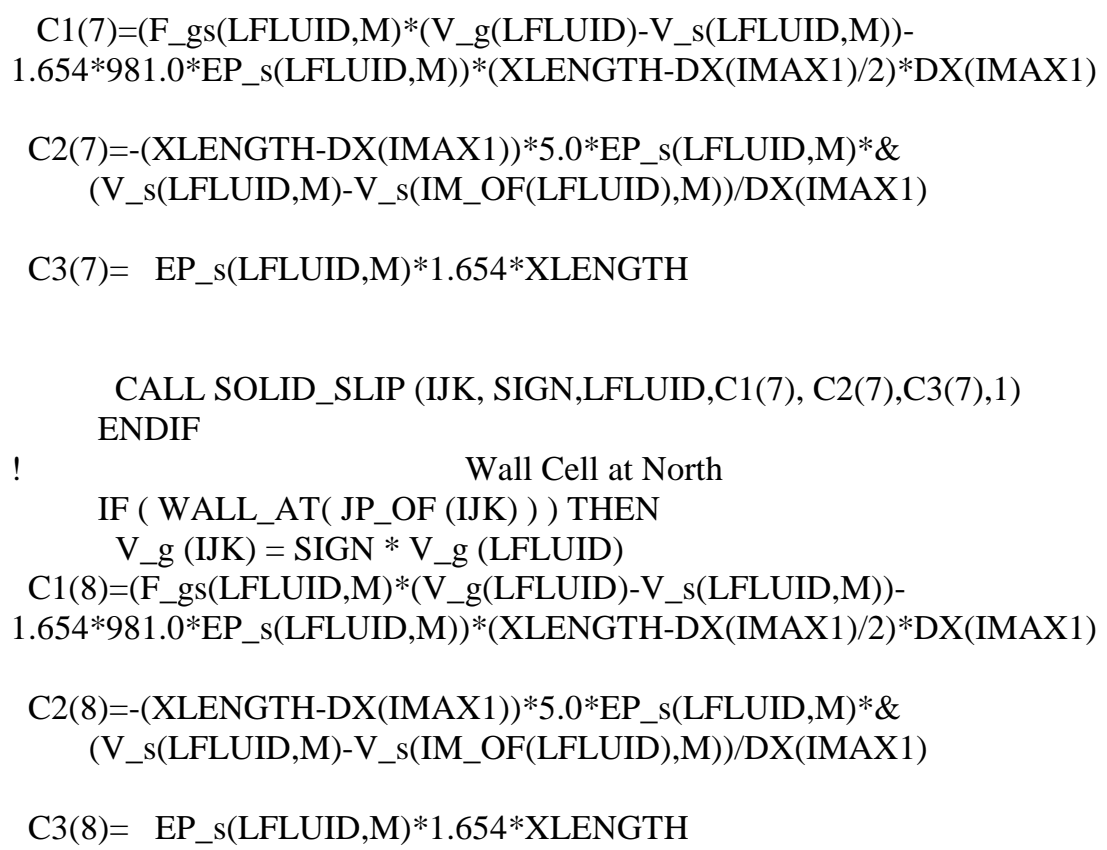


SECTION II 


\section{CHAPTER I \\ INTRODUCTION}

\subsection{Introduction to Hot Gas Desulfurization}

The removal of hydrogen sulfide to sufficiently low levels from coal derived fuel gases at elevated temperatures is crucial for the efficient and economic coal utilization in emerging and advanced power generation systems such as the integrated gasification combined cycle and the gasification molten carbonate fuel cell. In such processes the coal is gasified and the gas is cleaned (hydrogen sulfide removal) and combusted in a gas turbine. This clean up is termed as desulfurization.

Commercial desulfurization processes are based on liquid scrubbing at or below ambient temperatures resulting in considerable thermal efficiency loss and wastewater treatment. The implementation of hot gas desulfurization heavily relies on the development of regenerable sorbent materials that have high sulfur capacity and can efficiently remove hydrogen sulfide. Structural stability and good mechanical strength are also desirable features of the sorbent. Previous studies by (Jalan and Wu 1980, Grindley and Steinfeld, 1981, Flytzani et al., 1985) have investigated the potential use of zinc oxide as high temperature regenerable sorbent. The desulfurization reaction with zinc oxide as sorbent is shown below.

$\mathrm{ZnO}_{(\mathrm{s})}+\mathrm{H}_{2} \mathrm{~S}_{(\mathrm{g})} \rightarrow \mathrm{H}_{2} \mathrm{O}_{(\mathrm{g})}+\mathrm{ZnS}_{(\mathrm{s})}$

Also the use of regenerable sorbents instead of the calcium based sorbents (limestone, dolomite) for sulfur retention has recently received more attention because of the problems associated with disposal of large amount of solid wastes generated with non- 
regenerable sorbents. With the use of regenerable solvent, the amount of solid waste is minimized and the sulfur in the coal can be recovered as commercial product, such as elemental sulfur.

A major drawback of using zinc oxide is that in highly reducing atmosphere of coal-derived fuel gases, it is partially reduced to elemental zinc, which at high temperature is volatile. Consequently, sorbent loss is observed at temperatures above 600 ${ }^{0} \mathrm{C}$. Recently mixed metal oxides have been studied in an effort to improve the properties of single oxide sulfur sorbents. Lew, 1987; Flytzani-Stephanopoulos et al., 1987; Lew et al., 1990 have found that zinc oxide in association with titanium dioxide is reduced more slowly to volatile zinc than pure zinc oxide. Zinc titanate appears to be a leading sorbent for high temperature and high-pressure sulfur removal in the fluidized bed reactors (Harrison, 1995; Salo et al. 1995). The focus in this work is on the use of zinc oxide as sorbent for the sulfidation process.

In some of the previous work (Westmoreland et al, 1976; Susan Lew , Sarofim,1992 ; Flytzani-Stephanopoulos, Z. Li 1998.) experiments were carried out to determine the order of the sulfidation reaction with respect to the gas and the intrinsic rate constant with zinc oxide and zinc titanates as sorbents. The experiments were performed in thermo-gravimetric apparatus and the order of the reaction and the intrinsic rate constant were determined. It was experimentally verified that these experiments were performed in the absence of both mass transfer and pore diffusional resistances by varying the gas flow rate, quantity of sample and the particle size. In all these works the order of the reaction with respect to hydrogen sulfide was found out to be one. 


\subsection{Objective}

In all the previous works either the parameters for gas solid models for desulfurization have been described or reactor model using the fluidized bed for the sulfidation reaction have been described. In case of the fluidized bed, the sorbent has to be reloaded once all of it is spent. It has to be regenerated in another bed. If a circulating fluidized bed is used the process would become continuous and the regeneration can be carried out at the same time in another bed. With this idea hot gas desulfurization process was modeled in a circulating fluidized bed .

In this study we numerically model hot gas desulfurization in a circulating fluidized bed. The grain model is used to describe the kinetics for the gas-solid reaction since it takes into account sorbent's physical properties and is not numerically exhaustive. The parameters that affect the sulfur capture in the CFB are to be determined. A comparison is made with unreacted shrinking core model and to the results from experiments performed at NETL.

The gas solid reaction model is incorporated into MFIX (Multi phase flow with Interphase exchange) computer model (Syamlal et al., 1993). MFIX is a general-purpose hydrodynamic model that describes the chemical reactions and heat transfer in dense or dilute fluid-solids flows typically occurring in energy conversion and chemical processing reactors. It is capable of handling mass, momentum, energy and species balance for multiple phases and can incorporate user defined subroutines in it. The key area of the work is to identify the parameters that control sulfur capture and their effect on the hydrodynamics of the flow. 


\section{CHAPTER II \\ LITERATURE SURVEY}

\subsection{Introduction}

As a part of sulfur removal process development, reactor models are needed for scale up. A reliable solid conversion model together with reactor mass and energy balances can be used to predict the performance of a large-scale sulfidation reactor. Various mathematical models have been reported in the literature for gas-solid reactions. They can generally be classified as either grain models representing the structure as an assemblage of very small grains, usually spherical in shape or as pore models representing the porous solid by a collection of capillaries.

One of the earliest gas-solid reaction model described a solid with overlapping pores of uniform size randomly distributed in space ( Peterson 1957). Further refinements of the model were introduced to more closely describe the physical structure of the solid. This model was extended to include the possibility of solid product formation which changes the surface area and porosity of the solid (Cavelo and Cunningham, 1970; Ramachandran and Smith, 1977). Recently the model was expanded to describe the pore size distribution with randomly overlapping pores (Gavalas, 1980; Bhatia and Perlmutter, 1980 ; Bhatia and Perlmutter, 1983 ). More recently , an overlapping grain model with a grain size distribution was developed for gas-solid reaction (Sotirchos and $\mathrm{Yu}, 1988$ ). Some of the other models which describe the gas solid sulfidation reaction and are slight modifications of the grain model are available (Lew, 1990; Fenouil and Lynn, 1995; 
Zevenhoven et al., 1996). One of the basic models is the unreacted shrinking core model ( O’. Levenspiel).

\subsection{Gas Solid Reaction Models}

For the desulfurization reaction

$\mathrm{A}(\mathrm{g})+\mathrm{bB}(\mathrm{s}) \rightarrow \mathrm{cC}(\mathrm{g})+\mathrm{dD}(\mathrm{s})$, the gas solid models are discussed in brief below.

\subsubsection{Unreacted Shrinking Core Model}

The model was developed by Kunii and Yagi, 1955. The steps occurring are as follows: -

1. Diffusion of the gaseous reactant through the film surrounding the particle to the surface of the solid.

2. Penetration and diffusion of the reactant through the blanket of the product to the surface of unreacted core.

3. Reaction of the gaseous reactant with the solid at this reaction surface.

4. Diffusion of the gaseous product through the blanket of the solid product to the exterior surface of the solid.

5. Diffusion of the gaseous product through the film surrounding the particle to the main body of the fluid.

Steps 4 and 5 do not directly contribute to the resistance to the reaction. Thus there are three resistances, the surface reaction, diffusion through gas film, diffusion through the product layer, which are in series. 
Conversion time equations are summarized as follows*.

$$
\begin{aligned}
& \mathrm{t}_{\text {total }}=\mathrm{t}_{\text {film alone }}+\mathrm{t}_{\text {product layer alone }}+\mathrm{t}_{\text {reaction alone }} \\
& \mathrm{t}=\frac{\rho_{\mathrm{s}} \mathrm{R}}{3 \mathrm{bk} \mathrm{g}_{\mathrm{g} 0}} \mathrm{X}_{\mathrm{B}}+\frac{\rho_{\mathrm{s}} \mathrm{R}^{2}}{6 b \mathrm{D}_{\mathrm{e}} \mathrm{C}_{\mathrm{A} 0}}\left[1-3\left(1-\mathrm{X}_{\mathrm{B}}\right)^{\frac{2}{3}}+2\left(1-\mathrm{X}_{\mathrm{B}}\right)\right]+\frac{\rho_{\mathrm{s}} \mathrm{R}}{\mathrm{bkC}_{\mathrm{A} 0}}\left[1-\left(1-\mathrm{X}_{\mathrm{B}}\right)^{\frac{1}{3}}\right]
\end{aligned}
$$

where $X_{B}=1-\left(\frac{r_{c}}{R}\right)^{3} \quad r_{c}$ is the radius of the core.

The reaction rate is of the form

$$
-\mathrm{r}_{\text {solid }}=\frac{\mathrm{C}_{\mathrm{A}}}{1 / \mathrm{k}_{\mathrm{g}}+\left(\mathrm{R}-\mathrm{r}_{\mathrm{c}}\right) \mathrm{r}_{\mathrm{c}} /\left(\mathrm{r}_{\mathrm{c}} * \mathrm{D}_{\mathrm{e}}\right)+\mathrm{R}^{2} / \mathrm{r}_{\mathrm{c}}^{2} \mathrm{k}_{\mathrm{s}}}
$$

\subsubsection{The Grain Model}

In grain model (Szekely, 1976) the particle is believed to be made up of grains and the grains follow the shrinking core model, but the grain size after product formation may grow or reduce depending on the ratio of the volume occupied by one mole of the product to that of the reactant. The details of this model are discussed in the section 2.4

\subsubsection{Overlapping Grain Model}

The porous solid is simulated as an assemblage of grains randomly distributed in space . The centers of the grains are randomly placed in space with overlapping of grains permitted. If the solid product occupies more volume than a stoichiometrically equal volume of the reactant, then overlapping of the product resulting in pore closure

\footnotetext{
* Detailed model in “Chemical reaction Engineering” by O Levenspiel. Pg. 361-370 second edition
} 
occurs. In this model ( Sotirchos and Yu, 1988), the porosity and the surface area of the reaction and pore surfaces at any time are defined as:

$$
\begin{aligned}
& \varepsilon_{\mathrm{r}}=\exp \left[-\mathrm{f} \int_{\mathrm{Y}(\mathrm{t})}^{\mathrm{r}_{0, \max }} \mathrm{r}_{\mathrm{r}}^{\mathrm{F}_{\mathrm{g}}} \eta_{0}\left(\mathrm{r}_{0}\right) \mathrm{dr}_{0}\right] \\
& \varepsilon_{\mathrm{p}}=\exp \left[-\mathrm{f} \int_{\mathrm{r}_{0, \min }}^{\mathrm{r}_{0, \max }} \mathrm{r}_{\mathrm{p}}^{\mathrm{F}_{\mathrm{g}}} \eta_{0}\left(\mathrm{r}_{0}\right) \mathrm{dr}_{0}\right] \\
& \left.\mathrm{S}_{\mathrm{p}}=\mathrm{F}_{\mathrm{g}} \mathrm{f} \varepsilon_{\mathrm{p}} \exp \int_{\mathrm{r}_{0, \min }}^{\mathrm{r}_{0, \max }} \mathrm{r}_{\mathrm{p}}^{\mathrm{F}_{\mathrm{g}}-1} \eta_{0}\left(\mathrm{r}_{0}\right) \mathrm{dr} \mathrm{r}_{0}\right] \\
& \mathrm{S}_{\mathrm{r}}=\mathrm{F}_{\mathrm{g}} \exp \left[\int_{\mathrm{Y}(\mathrm{t})}^{\mathrm{r}_{0, \max }} \mathrm{r}_{\mathrm{r}}^{\mathrm{F}_{\mathrm{g}}-1} \eta_{0}\left(\mathrm{r}_{0}\right) \mathrm{dr}_{0}\right]
\end{aligned}
$$

where $\varepsilon_{\mathrm{r}}$ and $\varepsilon_{\mathrm{p}}$ are porosities of the reaction and the pore surfaces respectively. $\mathrm{S}_{\mathrm{r}}$ and $S_{p}$ are surface areas of the reaction and the pore surfaces, respectively. $r_{r}$ and $r_{p}$ are surface radius of the reaction and the pore surfaces, respectively. $F_{g}$ is the grain shape factor $($ Sphere $=3$; Cylinder $=2$; plate $=1) ; r_{0}$ is the initial grain radius $; \mathrm{f}$ is the geometric factor( Sphere $=4 \pi / 3 ;$ Cylinder $=\pi \mathrm{L}_{\mathrm{avg}} ;$ plate $\left.=2 \mathrm{~A}_{\mathrm{avg}}\right), \mathrm{L}_{\mathrm{avg}}$ and $\mathrm{A}_{\mathrm{avg}}$ are average grain length of the cylinder and average grain surface area of plate like grains, respectively; $\eta_{0}\left(r_{0}\right) d r_{0}$ is the number of grains per unit volume with radius in the initial size range of $\left[r_{0}, r_{0}+d r_{0}\right] ; r_{0, \min }$ and $r_{0, \max }$ are initial lower and upper grain radius limit; $\mathrm{Y}(\mathrm{t})$ is the lower active reactant grain radius limit. The pore surface makes up the sum of 
solid reactant and the product. The structural expressions can be incorporated into a rate expression to yield:

$$
\frac{d r_{r}}{d t}=\frac{-b k C_{A 0} / \rho_{s}}{1-\frac{k}{D_{e}} \varepsilon_{r} r_{r}^{F_{g}-1} \int_{r_{p}}^{r_{r}} \frac{d r}{\varepsilon\left(t^{\prime}\right) r^{F_{g}-1}}}
$$

$\mathrm{K}$ is the rate constant and $\mathrm{D}_{\mathrm{e}}$ is the product layer diffusivity. The change in the pore radius $r_{p}$ is related to reaction surface radius $r_{r}$ by

$$
\frac{\mathrm{dr}_{\mathrm{p}}}{\mathrm{dt}}=-\frac{\mathrm{dr} \mathrm{r}_{\mathrm{r}}}{\mathrm{dt}}\left[(\mathrm{Z}-1) \frac{\varepsilon_{\mathrm{r}} \mathrm{r}_{\mathrm{g}}^{\mathrm{F}_{\mathrm{g}}-1}}{\varepsilon_{\mathrm{p}} \mathrm{r}_{\mathrm{p}}}\right]
$$

The porosity of the solid (reactant + product) is found by

$$
\varepsilon_{\mathrm{p}}=\varepsilon_{0}-(\mathrm{Z}-1)\left(\varepsilon_{\mathrm{r}}-\varepsilon_{0}\right)
$$

The fractional conversion is calculated as

$$
\mathrm{X}=\frac{\varepsilon_{0}-\varepsilon_{\mathrm{p}}}{(\mathrm{Z}-1)\left(1-\varepsilon_{0}\right)}
$$

This model is numerically complex.

\subsection{Modeling of Hot Gas Desulfurization}

Several different desulfurization systems have been modeled with the grain model. Gibson and Harrison (1980) and Ranade and Harrison ( 1981) used the grain model to describe the $\mathrm{ZnO}-\mathrm{H}_{2} \mathrm{~S}$ reaction system. In this model the solid is described as an assemblage of non-overlapping grains reacting independently to each other . Each grain can be regarded as a shrinking non-porous reactant core. The reaction between the $\mathrm{H}_{2} \mathrm{~S}$ and $\mathrm{ZnO}$ pellets was studied in the microbalance reactor (TGA) between 375 and 
$800{ }^{\circ} \mathrm{C}$. Rapid and essentially complete reaction was observed in the temperature range of $600-700{ }^{\circ} \mathrm{C}$. Near $800{ }^{\circ} \mathrm{C}$, slow decomposition of $\mathrm{ZnO}$ with subsequent zinc vaporization led to the vapor phase reaction with $\mathrm{ZnS}$ depositing on the pellet exterior and preventing further reaction. At temperatures below $600{ }^{\circ} \mathrm{C}$ the reaction stopped well before total $\mathrm{ZnO}$ conversion was obtained. Experimental time - conversion results were compared to the predicted values obtained by applying grain model. All the grain model parameters were determined using independent measurements or using literature correlations. Good agreement between experiment and prediction was obtained in the $600-700{ }^{\circ} \mathrm{C}$ temperature range where pore diffusion provided the predominant resistance, as shown in Figure 2.1. But deviations were observed at lower temperatures and were believed due to the grain or product layer diffusion resistance.Around each grain , reaction with $\mathrm{H}_{2} \mathrm{~S}$ produces a non-porous sulfide product layer. Thus for the $\mathrm{ZnO}-\mathrm{H}_{2} \mathrm{~S}$ system poorer agreement with the constant grain model was observed (Gibson and Harrison,1980) which was later improved by incorporating the structural changes due to reaction and sintering (Ranade and Harrison, 1981).

Susan Lew, Adel Sarofim, Flytzani-Stephanopoulos, 1992 used the overlapping grain model (equations 2.2 to 2.9 with spherical particles) to describe the sulfidation of zinc oxide and zinc-titanium oxide powders at temperatures between $400-700{ }^{\circ} \mathrm{C}$ in $\mathrm{H}_{2} \mathrm{~S}-\mathrm{H}_{2}-\mathrm{N}_{2}$ gas mixtures. The resistances to the reaction were due to the surface reaction and the diffusion through the product layer. The product layer diffusion coefficient was used as a fitting parameter in the model.

Experiments of sulfidation kinetics of solids containing various $\mathrm{Zn} / \mathrm{Ti}$ atomic ratios were performed in a Cahn System 113-X thermogravimetric analyzer (TGA) 
equipped with a Cahn 2000 electrobalance, a Micricon temperature controller and a Bascon Turner data acquisition system. The TGA measured the weight gain as a function of time required for the $\mathrm{Zn}$ - $\mathrm{Ti}$ oxides sulfidation to $\mathrm{ZnS}$ and $\mathrm{TiO}_{2}$. The solids were pretreated in a vacuum oven at $90{ }^{\circ} \mathrm{C}$ to remove any adsorbed $\mathrm{H}_{2} \mathrm{O}$ before they were reacted. The mass transfer was limited by adjusting the gas flow rate. The pore diffusion was minimized by decreasing the particle size and a particle size between $90-125 \mu \mathrm{m}$ was found adequately small for all solids. The comparison between the experimental results and the results predicted by the overlapping grain model are shown in Figure 2.2 and Figure 2.3 .

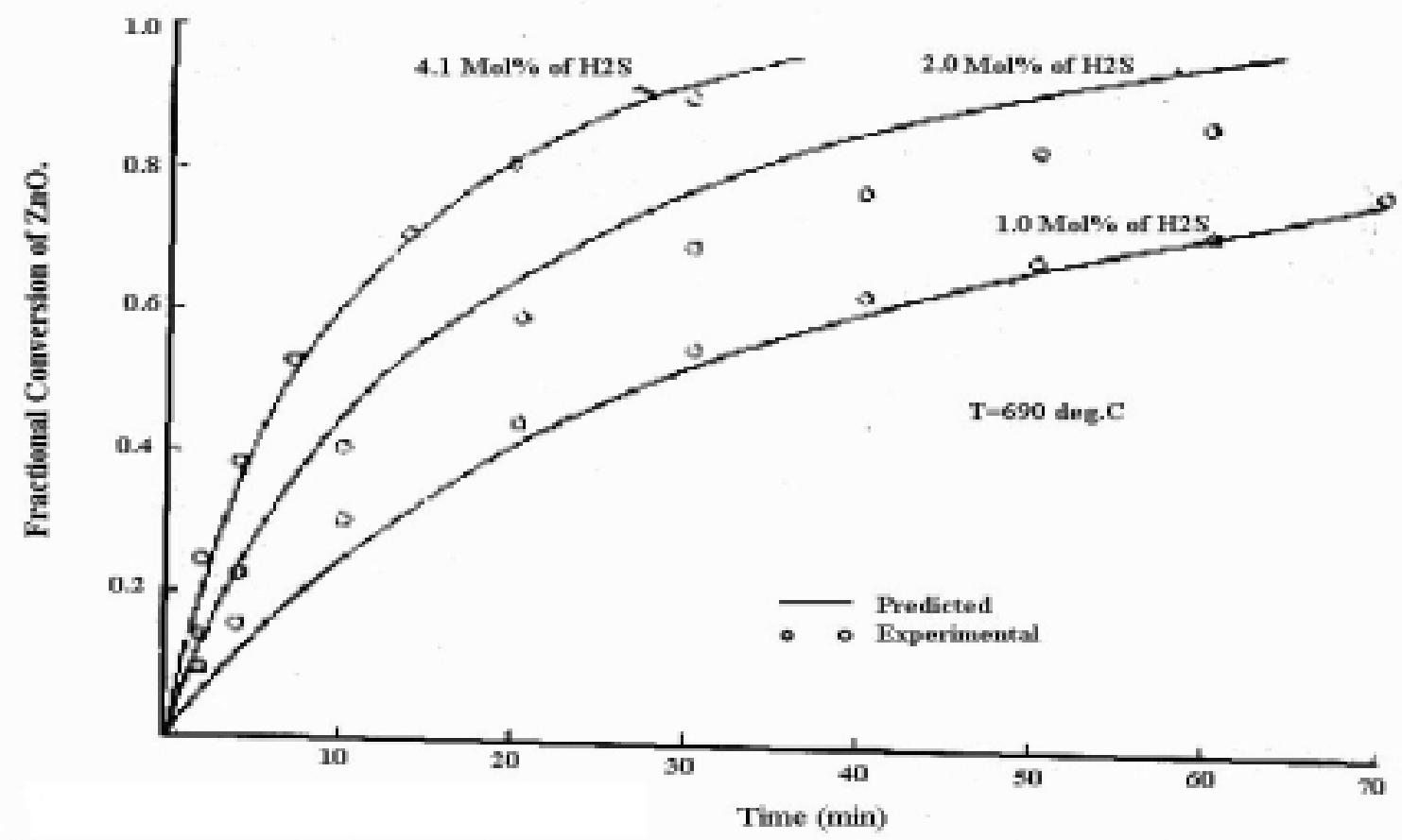

Figure 2.1 Time Conversion Data: intermediate temperature.

source :- Gibson and Harrison,1980. 


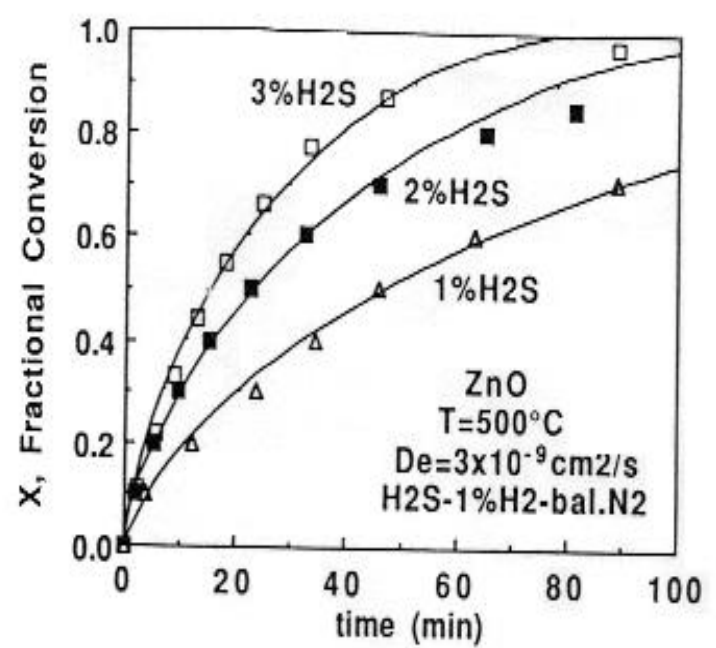

Figure 2.2 Experimental sulfidation profiles of $\mathrm{ZnO}$ at $500^{\circ} \mathrm{C}$ reacted in 1,2 and $3 \% \mathrm{H}_{2} \mathrm{~S}$ vs. calcu. lated profiles from overlapping grain model.

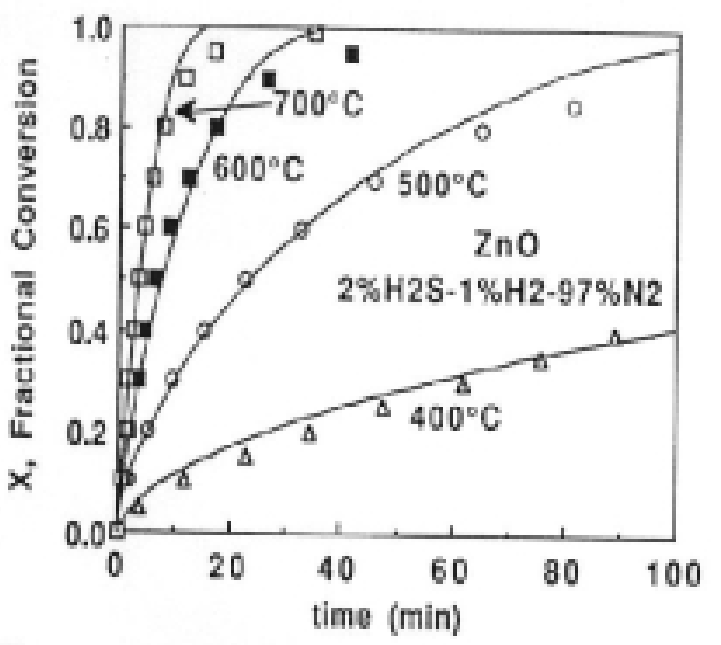

Figure 2.3 Experimental sulfidation proflles of $\mathrm{ZnO}$ at $400-700^{\circ} \mathrm{C}\left(2 \mathrm{H}_{3} \mathrm{H}_{2} \mathrm{~S} \cdot 1 \% \mathrm{H}_{2} \cdot 97 \% \mathrm{~N}_{2}\right)$ vs. calculated profiles from overlapping grain model.

source:- Susan Lew, Adel Sarofim, Flytzani-Stephanopoulos, 1992.

More recently another desulfurization system was modeled by J.T Konttinen, C. A. P. Zevenhoven and M. M. Hupa, 1997. They used the unreacted shrinking core model and the overlapping grain model for this purpose. The parameters for the models were evaluated from ambient pressure tests . The product layer diffusion coefficient was used as the fitting parameter. A method using above models with the evaluated parameters was applied to hot gas desulfurization with zinc titanate sorbents in the fluidized bed. A reasonably good fit with the experimental data was obtained.

The kinetics of the sulfidation with zinc titanate sorbent were determined using DuPont 951 TGA (Gupta and Gangwal, 1992; Mojtahedi et al., 1996) designed to handle corrosive gases. Approximately $50 \mathrm{mg}$ of the sorbent in the $100-300 \mu \mathrm{m}$ size range was used in each experiment . All experiments were conducted at 1.013 bar and sulfidation 
temperatures in the $400-600{ }^{\circ} \mathrm{C}$ range were investigated and compared with those available in the literature.

A unique high temperature and high pressure reactor system was used to evaluate candidate sorbents in cyclic sulfidation/ regeneration tests ( Abbasian et al , 1994; Mojtahedi and Abbasian , 1995a,b). The test unit includes simulated hot coal gas feed systems and a $7.5 \mathrm{~cm}$ diameter fluidized bed reactor associated with process instrumentation and control devices. In conjunction with cyclic tests the rate of sulfidation of the zinc titanate sorbents was experimentally determined in kinetic test where $15 \mathrm{~g}$ of zinc titanate was fluidized at typical process condition, $550-650{ }^{\circ} \mathrm{C}$ and $20 \mathrm{~atm}$.

The models selected to fit the experimental results were:-

1. Unreacted Shrinking core (USC) model with changing effective diffusivity. In order to account for changing internal structure of the particle, a more general version of the USC model was used, where effective diffusivity is a function of the overall particle conversion. This model has been successfully used for modeling of sulfidation with limestone and dolomite particles (Zevenhoven et al.,1995,1996).

2. The overlapping grain model (Equations 2.2 to 2.9 )

The data used for model parameter fitting included two different reactor types and pressure level ( atmospheric TGA and a pressurized fluidized bed reactor) and three different sorbents. The sulfur removal reactor operated at high pressure but the data from the ambient pressure TGA test data were included because they give the temperature dependence of the parameters. The results are summarized in Figures 2.4 to 2.6. 


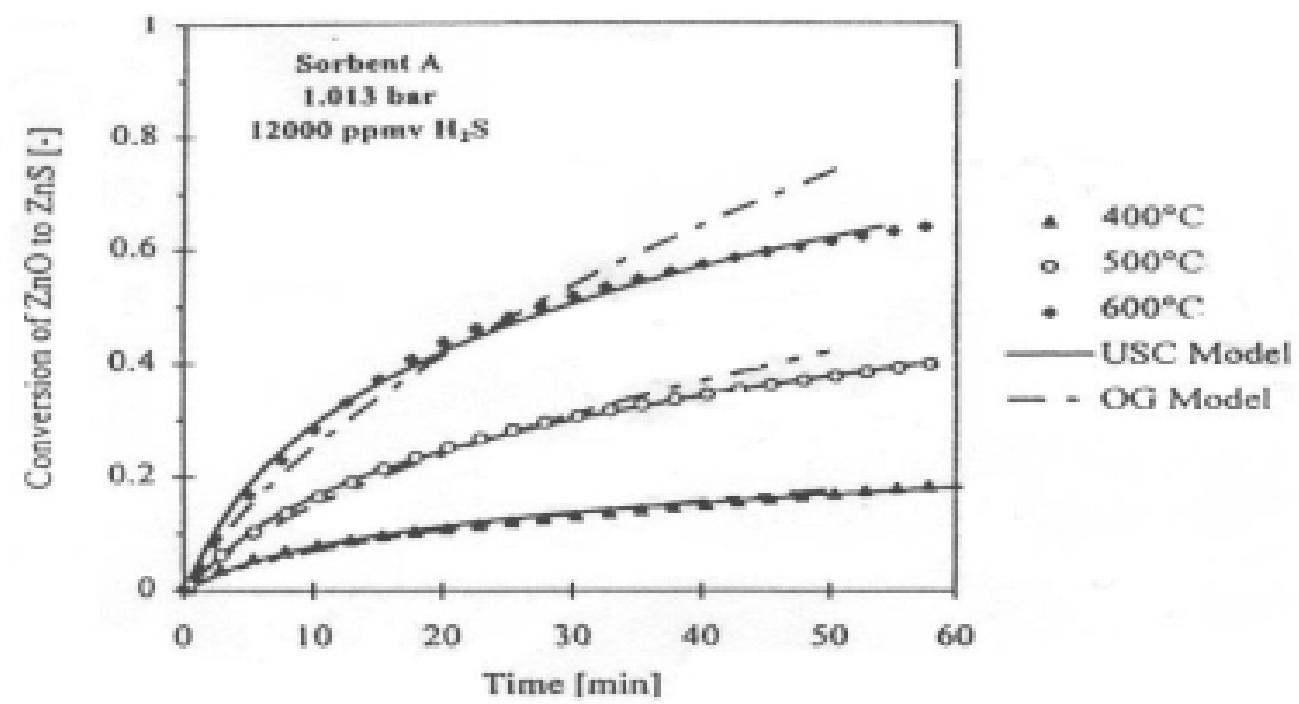

Figure 2.4 Fit of unreacted shrinking core (USC) and overlapping grain (OG) models into TGA data with sorbent A; 12000 ppmv $\mathrm{H}_{2} \mathrm{~S}$ at 400,500 , and $600{ }^{\circ} \mathrm{C}$.

Source :- J.T Konttinen, C. A. P. Zevenhoven and M. M. Hupa, 1997

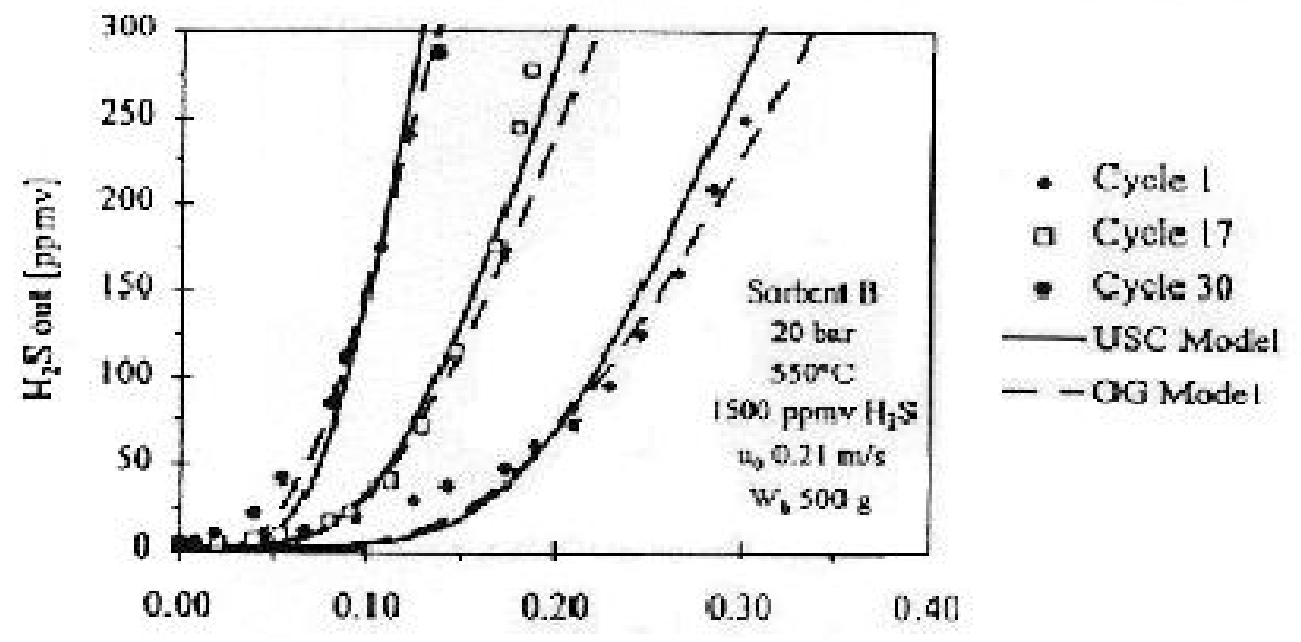

Sorhent Fractional Conversion [-]

Figure 2.5 USC and $O G$ model fits into life-cycle fluidized bed sulfidation data of sorbent $B$ at high pressure during cycles 1,17 , and $30\left(\mathrm{H}_{2} \mathrm{O}, 10 \mathrm{vol} \%\right)$.

Source :- J.T Konttinen, C. A. P. Zevenhoven and M. M. Hupa, 1997 


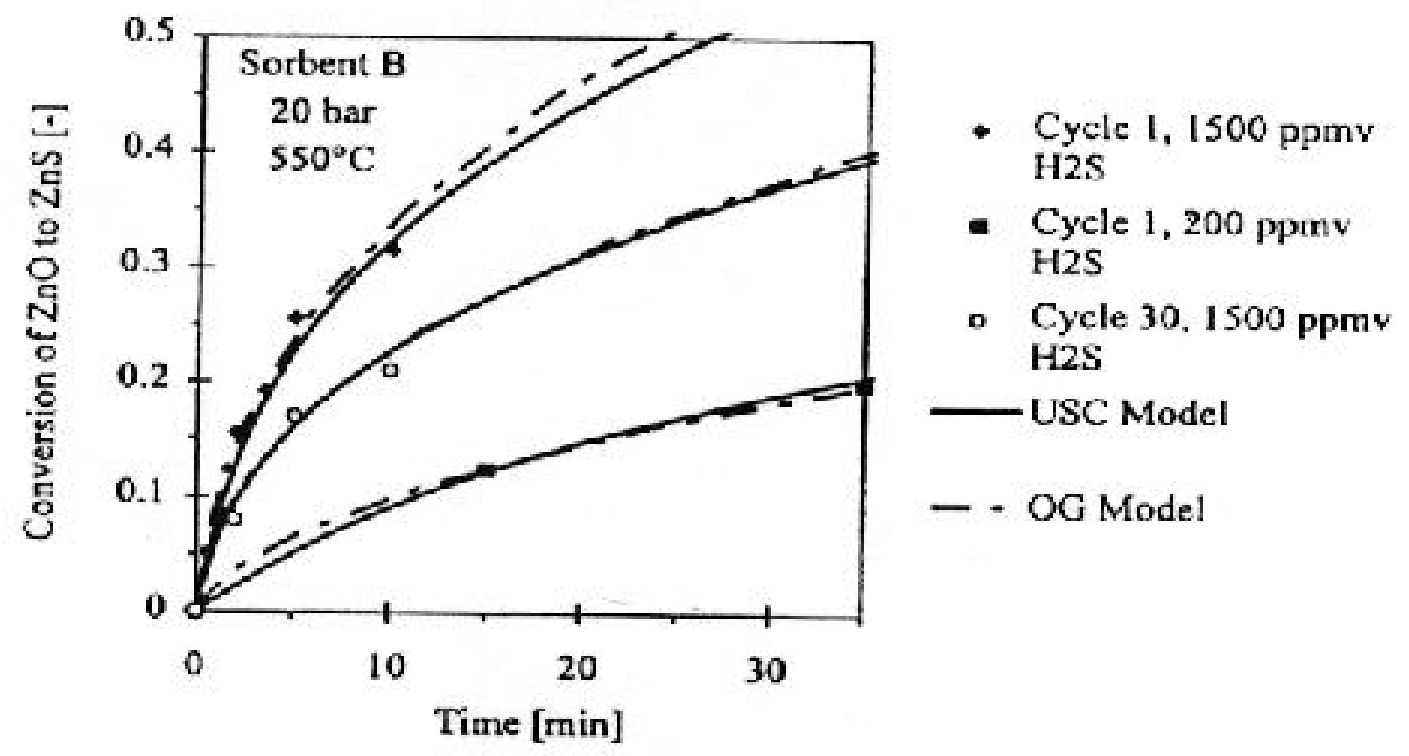

Figure 2.6 Fit of USC and OG models into solid conversion rate data produced in a fluidized bed at high pressure with sorbent $B$, 200 and 1500 ppmv $\mathrm{H}_{2} \mathrm{~S}$.

Source :- J.T Konttinen, C. A. P. Zevenhoven and M. M. Hupa, 1997

\subsection{Details of the Grain Model}

The gas-solid sulfidation reaction can be represented by the general stoichiometry $\mathrm{A}(\mathrm{g})+\mathrm{bB}(\mathrm{s}) \rightarrow \mathrm{cC}(\mathrm{g})+\mathrm{dD}(\mathrm{s})$

The solid reactant is visualized as being composed of large number of non-porous grains of regular geometry (i.e. sphere, cylinder, or plate). Each grain reacts like a shrinking core. As the reaction proceeds, the unreacted core decreases in size while maintaining its original geometric shape. Around the unreacted core, a solid product layer which may 

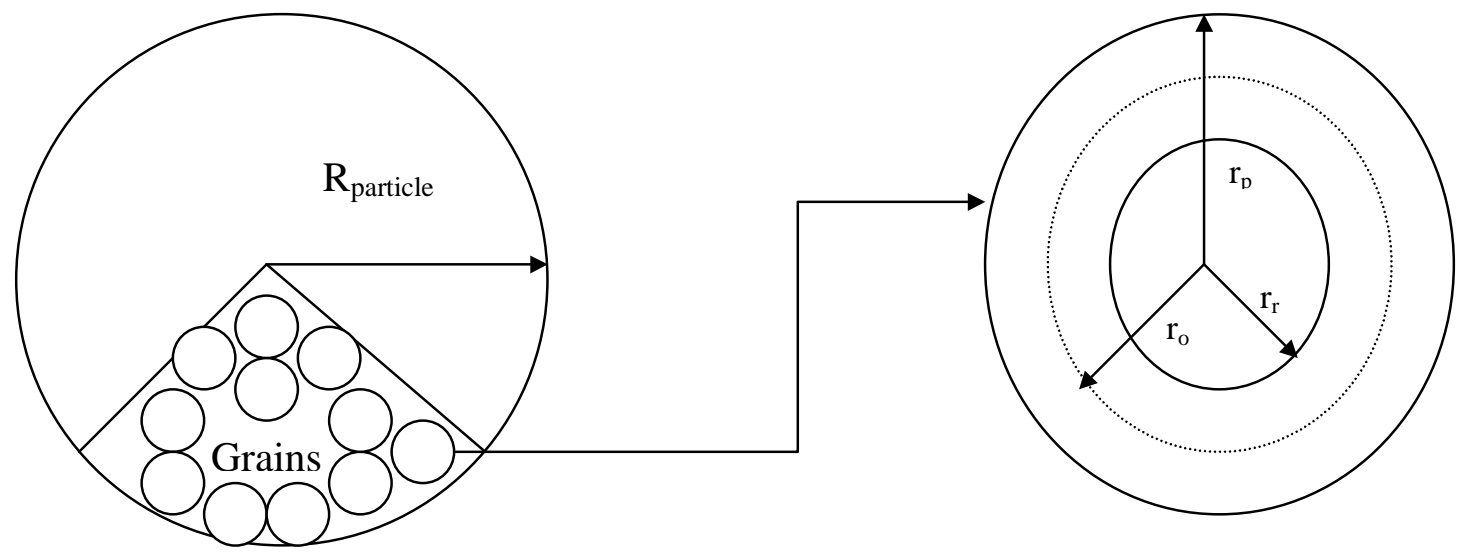

Figure 2.7 Variable size grain model.

be porous or nonporous is developed. Depending on the relative density of the solid product and the reactant, the overall size of the grain may change.

There are several resistances to the gas-solid reaction rate, such as resistances due to mass transfer, pore diffusion, product layer diffusion and chemical (surface ) reaction.

The expressions derived for the grain model (Szekely et al. 1976) are based on the assumptions of :-

\section{Isothermal Reaction}

2.First order intrinsic rate with respect to gas concentration

3. Irreversible reaction

4. Equimolar counter-diffusion

5. Pseudo steady state approximation.

6. Structural changes only due to the reaction (i.e. no sintering). 
The rate of disappearance of the reactant A by an irreversible first order surface chemical reaction is

$\mathrm{R}_{\mathrm{s}}=\mathrm{kC}_{\mathrm{AS}}$

where $R_{s}$ is the reaction rate ( moles per unit time per unit surface area ), $k$ is the heterogeneous rate constant and $\mathrm{C}_{\mathrm{AS}}$ is the concentration of the reacting gas at the surface.

Assuming equimolar counter-diffusion of the reactants and the product species, the diffusion rate through the product layer is

$$
-A_{x} D_{e} \frac{d C_{A}}{d r}=A_{x} D_{e} \frac{d C_{C}}{d r}
$$

where $A_{x}$ is the average cross-sectional diffusion area. The rate can be expressed as

$$
\mathrm{R}_{\mathrm{s}}=\frac{\mathrm{D}_{\mathrm{e}}\left(\mathrm{C}_{\mathrm{A} 0}-\mathrm{C}_{\mathrm{AS}}\right)}{\mathrm{A}_{\mathrm{r}} \int_{\mathrm{r}}^{\mathrm{r}} \frac{\mathrm{dr}}{\mathrm{A}_{\mathrm{r}, \mathrm{p}}}}
$$

where $C_{A 0}$ is the concentration of the reactant gas in the bulk, $A_{r}$ and $A_{p}$ are the reaction and the pore surface area, respectively, $r_{r}$ and $r_{p}$ is the distance from the center to the reaction and the pore surface area of the grain, respectively. With the assumption of pseudo steady state conditions, equations (2.10) and (2.12) can be combined as follows

$$
R_{s}=\frac{C_{A 0}}{\frac{1}{K}-\frac{A_{r}}{D_{e}} \int_{r_{p}}^{r_{r}} \frac{d r}{4 \pi r^{2}}}
$$

Integrating the rate expression 


$$
\frac{\mathrm{C}_{\mathrm{A} 0}}{\frac{1}{\mathrm{~K}}-\frac{\mathrm{A}_{\mathrm{r}}}{\mathrm{D}_{\mathrm{e}}} \int_{\mathrm{r}_{\mathrm{p}}}^{\mathrm{r}_{\mathrm{r}}} \frac{\mathrm{dr}}{4 \pi \mathrm{r}^{2}}}=\frac{\mathrm{C}_{\mathrm{A} 0}}{\frac{1}{\mathrm{~K}}-\frac{4 \pi \mathrm{r}_{\mathrm{r}}^{2}}{\mathrm{D}_{\mathrm{e}} 4 \pi}\left[\frac{1}{\mathrm{r}_{\mathrm{p}}}-\frac{1}{\mathrm{r}_{\mathrm{r}}}\right]}
$$

The rate of reaction of A can be expressed in terms of the rate of disappearance solid, B based on the area of the shrinking core as follows :-

$b R_{s}=-\rho_{s} \frac{d r_{r}}{d t}$

The fractional conversion $\mathrm{X}_{\mathrm{c}}$ is expressed as

$$
X_{c}=1-\left(\frac{r_{r}}{r_{0}}\right)^{3}
$$

where $r_{0}$ is the initial grain radius and $r_{r}$ is the radius of the core of the grain

$\mathrm{r}_{0}=\frac{3}{\mathrm{~A}_{0, \mathrm{~s}} \rho_{\mathrm{s}}}$

$\mathrm{A}_{0, \mathrm{~s}}$ is the initial specific surface area of the sorbent particles.

$$
\mathrm{r}_{\mathrm{p}}^{3}=\mathrm{Zr}_{0}^{3}+(1-\mathrm{Z}) \mathrm{r}_{\mathrm{r}}^{3}
$$

$r_{p}$ is the radius of the pore surface and $\mathrm{Z}$ is the ratio of molar volume of the product to that of the reactant.

Hence the rate of disappearance of solids can be written as

$$
\mathrm{R}_{\text {solids }}=\frac{\mathrm{bC}_{\mathrm{A} 0}}{\frac{1}{\mathrm{~K}}-\frac{\mathrm{r}_{\mathrm{r}}^{2}}{\mathrm{D}_{\mathrm{e}}}\left[\frac{1}{\mathrm{r}_{\mathrm{p}}}-\frac{1}{\mathrm{r}_{\mathrm{r}}}\right]}
$$


The unreacted shrinking core model considers only the external surface area of the particles as the reaction surface area. It does not take into account the change in the reaction rate due to structural changes in the sorbent particles. The grain is less complex than the overlapping grain model and is more realistic than the unreacted shrinking core model as the sulfidation rate is proportional to the reactive internal surface area of the porous particles. Hence grain model follows the real physical behavior of the sorbent in the sulfidation more closely than the unreacted shrinking core model. Also the sorbent under study has initial porosity of around 0.4 indicating it is sufficiently porous to use the grain model. The overlapping grain model is comprehensive but it was difficult to incorporate this model into MFIX since it requires numerical integration which increases computational complexity. For CFB sulfidation reactor modeling purposes, it is desirable to have a gas- solid reaction model that is complex enough to take into account the physical properties of the sorbent but is not numerically exhaustive. Hence both grain model and the shrinking core model are considered which have been successfully used for desulfurization and not the overlapping grain model. 


\section{CHAPTER III}

\section{IMPLEMENTATION OF THE GRAIN MODEL IN MFIX}

\subsection{Introduction}

The rate expression in MFIX should be based on the volume of the computational cell. Also the rate expression is based in terms of the mass of the species. The desulfurization reaction can be expressed in terms of the mass of the species as follows.

Let ' $b$ ' be the number of grams hydrogen sulfide reacted per gram of fresh sorbent reacted.

$\mathrm{b}=$ number of grams of $\mathrm{H}_{2} \underline{\mathrm{S} \text { reacted. }}$. one gram fresh sorbent.

Thus when ' $b$ ' grams of $\mathrm{H}_{2} \mathrm{~S}$ combine with one gram of zinc oxide sorbent , 18b/34 grams of $\mathrm{H}_{2} \mathrm{O}$ will be produced where 18 is the molecular weight of $\mathrm{H}_{2} \mathrm{O}$ and 34 of $\mathrm{H}_{2} \mathrm{~S}$.

Total mass of the reactants $=1+b$ and the total mass must be conserved so the amount of spent sorbent produced $=1+b-18 b / 34=(1+16 b / 34)$.

Hence the desulfurization reaction in terms of mass is

b $\mathrm{H}_{2} \mathrm{~S}+$ Fresh Sorbent $(\mathrm{ZnO}) \rightarrow(18 \mathrm{~b} / 34) \mathrm{H}_{2} \mathrm{O}+(1+16 \mathrm{~b} / 34) \operatorname{spent} \operatorname{sorbent}(\mathrm{ZnS})$.

Value of 'b' can be calculated as follows :-

34 grams (1 gmole) of hydrogen sulfide combines with 82 grams of zinc oxide (1 gmole). So for pure sorbent $b=34 / 82=0.414$ but since the sorbent has $50 \%$ purity, so $b=0.21$. 


\subsection{Rate expression for the Control Volume}

$$
\frac{\mathrm{dN}_{\mathrm{H}_{2} \mathrm{~S}}}{\mathrm{dt}}=\frac{-\mathrm{A}_{\text {surf }} \mathrm{bC}_{\mathrm{H}_{2} \mathrm{~S}}}{\frac{1}{\mathrm{~K}}-\frac{\mathrm{r}_{\mathrm{r}}^{2}}{\mathrm{D}_{\mathrm{e}}}\left[\frac{1}{\mathrm{r}_{\mathrm{p}}}-\frac{1}{\mathrm{r}_{\mathrm{r}}}\right]} *
$$

This form has to be modified according to the requirements of MFIX which uses the mass of gas per cell volume $\mathrm{M}_{\mathrm{g}}\left(\mathrm{g} / \mathrm{cm}^{3}\right)$ and the mass fraction of the solid, $\mathrm{X}_{\mathrm{s}}$. This is as shown in the following steps.

$$
\frac{\mathrm{dN}_{\mathrm{H}_{2} \mathrm{~S}}}{\mathrm{dt}}=\frac{-\left(\mathrm{A}_{\text {surf }} / \mathrm{V}_{\text {cell }}\right) \mathrm{b}\left(\mathrm{C}_{\mathrm{H}_{2} \mathrm{~S}} \mathrm{~V}_{\text {cell }}\right)}{\frac{1}{\mathrm{~K}}-\frac{\mathrm{r}_{\mathrm{r}}^{2}}{\mathrm{D}_{\mathrm{e}}}\left[\frac{1}{\mathrm{r}_{\mathrm{p}}}-\frac{1}{\mathrm{r}_{\mathrm{r}}}\right]}
$$

$A_{\text {surface }}$ is the total external area of the unreacted core of the grain in control volume.

Volume of the sorbent in computational cell $\left(\mathrm{V}_{\text {cell }}\right)=\left(1-\varepsilon_{\mathrm{g}}\right) \mathrm{V}_{\text {cell }}$

where $\varepsilon_{\mathrm{g}}$ is the volume fraction of the gas

The number of particles in control volume at any time $=\frac{\left(1-\varepsilon_{\mathrm{g}}\right) \mathrm{V}_{\text {cell }}}{\frac{4}{3} \pi \mathrm{R}^{3}}$

$\mathrm{R}$ is the radius of the particle.

Number of grains per particle $=\frac{\left(1-\varepsilon_{0}\right) * \frac{4}{3} \pi \mathrm{R}^{3}}{\frac{4}{3} \pi \mathrm{r}_{0}^{3}}$

$\varepsilon_{0}$ is the initial porosity of the sorbent particle.

\footnotetext{
* Equation is different from Equation 2.13 because the reaction is now based on mass hence term b comes in the numerator
} 
Therefore total number of grains in the control volume is given as product of equations (3.4) and (3.5).

$$
\frac{\left(1-\varepsilon_{\mathrm{g}}\right) \mathrm{V}_{\text {cell }}}{\frac{4}{3} \pi \mathrm{R}^{3}} * \frac{\left(1-\varepsilon_{0}\right) * \frac{4}{3} \pi \mathrm{R}^{3}}{\frac{4}{3} \pi \mathrm{r}_{0}^{3}}=\frac{\left(1-\varepsilon_{\mathrm{g}}\right)\left(1-\varepsilon_{0}\right) \mathrm{V}_{\text {cell }}}{\frac{4}{3} \pi \mathrm{r}_{0}^{3}}
$$

Total surface area based on the reaction surface area of the grains in the computational cell will be the product of area of one grain and the number of grains in the control volume.

$$
\mathrm{A}_{\text {surf }}=\frac{4 \pi r_{r}^{2}\left(1-\varepsilon_{\mathrm{g}}\right)\left(1-\varepsilon_{0}\right) \mathrm{V}_{\text {cell }}}{\frac{4}{3} \pi \mathrm{r}_{0}^{3}}
$$

We are using the core surface area because the resistances in the rate expression are based on the surface area of the core.

Hence $\frac{A_{\text {surf }}}{V_{\text {cell }}}=\frac{4 \pi r_{r}^{2}\left(1-\varepsilon_{g}\right)\left(1-\varepsilon_{0}\right)}{\frac{4}{3} \pi r_{0}^{3}}$

The concentration of hydrogen sulphide in the computational cell is given as follows

$$
\mathrm{C}_{\mathrm{H}_{\mathrm{S}} \mathrm{S}}=\frac{\mathrm{N}_{\mathrm{H}_{\mathrm{s}} \mathrm{S}}}{\varepsilon_{\mathrm{g}} \mathrm{V}_{\text {cell }}}
$$

Therefore, $\mathrm{C}_{\mathrm{H}_{\mathrm{S}} \mathrm{S}} \mathrm{V}_{\text {cell }}=\frac{\mathrm{N}_{\mathrm{H}_{\mathrm{S}} \mathrm{S}}}{\varepsilon_{\mathrm{g}}}$

hence the rate expression becomes 


$$
\frac{\mathrm{dN}_{\mathrm{H}_{2} \mathrm{~S}}}{\mathrm{dt}}=\frac{-\left(\frac{3 \mathrm{r}_{\mathrm{r}}^{2}\left(1-\varepsilon_{\mathrm{g}}\right)\left(1-\varepsilon_{0}\right)}{\mathrm{r}_{0}^{3}}\right) \mathrm{b}\left(\frac{\mathrm{N}_{\mathrm{H}_{2} \mathrm{~S}}}{\varepsilon_{\mathrm{g}}}\right)}{\frac{1}{\mathrm{~K}}-\frac{\mathrm{r}_{\mathrm{r}}^{2}}{\mathrm{D}_{\mathrm{e}}}\left[\frac{1}{\mathrm{r}_{\mathrm{p}}}-\frac{1}{\mathrm{r}_{\mathrm{r}}}\right]}
$$

The mass of fully sulfided grain is proportional to the mass of the fresh sorbent grain according to the stoichiometry.

$\mathrm{M}_{\text {spent }}=(1+16 \mathrm{~b} / 34) \mathrm{M}_{\text {fresh }}$

Also the ratio of the densities can be calculated as follows

$$
\frac{\tilde{\mathrm{n}}_{\text {spent }}}{\tilde{\mathrm{n}}_{\text {fresh }}}=\frac{\mathrm{M}_{\text {spent }} / \mathrm{V}_{\text {grain,spent }}}{\mathrm{M}_{\text {fresh }} / \mathrm{V}_{\text {grain,fresh }}}=\left(1+\frac{16 \mathrm{~b}}{34}\right) \frac{\mathrm{r}_{0}^{3}}{\mathrm{r}_{\mathrm{p}}^{3}}
$$

Mass of the unreacted core of the grain

$$
\mathrm{M}_{\text {fresh }}=4 \pi \int_{0}^{\mathrm{r}_{\mathrm{r}}} \rho_{\text {fresh }} \mathrm{r}^{2} \mathrm{dr}=\frac{4}{3} \pi \rho_{\text {fresh }} \mathrm{r}_{\mathrm{r}}^{3}
$$

At any time the total mass of the grain will be

$$
M_{\text {grain }}=4 \pi \int_{0}^{r_{r}} \rho_{\text {fresh }} r^{2} d r+4 \pi \int_{r_{r}}^{r_{p}} \rho_{\text {spent }} r^{2} d r=\frac{4}{3} \pi \rho_{\text {fresh }} r_{r}^{3}+\frac{4}{3} \pi \rho_{\text {spent }}\left(r_{p}^{3}-r_{r}^{3}\right)
$$

Therefore the mass fraction of fresh sorbent inside the grain will

$$
\mathrm{X}_{\text {fresh }}=\frac{\mathrm{M}_{\text {fresh }}}{\mathrm{M}_{\text {spent }}+\mathrm{M}_{\text {fresh }}}=\frac{\frac{4}{3} \pi \rho_{\text {fresh }} \mathrm{r}_{\mathrm{r}} \mathrm{r}^{3}}{\frac{4}{3} \pi \rho_{\text {fresh }} \mathrm{r}^{3}+\frac{4}{3} \pi \rho_{\text {spent }}\left(\mathrm{r}_{\mathrm{p}}{ }^{3}-\mathrm{r}_{\mathrm{r}}^{3}\right)}=\frac{1}{1+\frac{\rho_{\text {spent }}}{\rho_{\text {fresh }}\left(\frac{\mathrm{r}_{\mathrm{p}}{ }^{3}}{\mathrm{r}_{\mathrm{r}}^{3}}-1\right)}}
$$

This will be the same as the mass fraction of the fresh sorbent within the particle which is what MFIX keeps track of. 
Substituting equation (3.10) in (3.13)

$$
X_{\text {fresh }}=\frac{1}{1+\left(1+\frac{16 b}{4}\right)\left(\frac{r_{0}^{3}}{r_{r}^{3}}-\frac{r_{0}^{3}}{r_{p}^{3}}\right)}
$$

using equation (3.14) and (2.18) and solving for $\frac{\mathrm{r}_{\mathrm{r}}^{3}}{\mathrm{r}_{0}^{3}}$

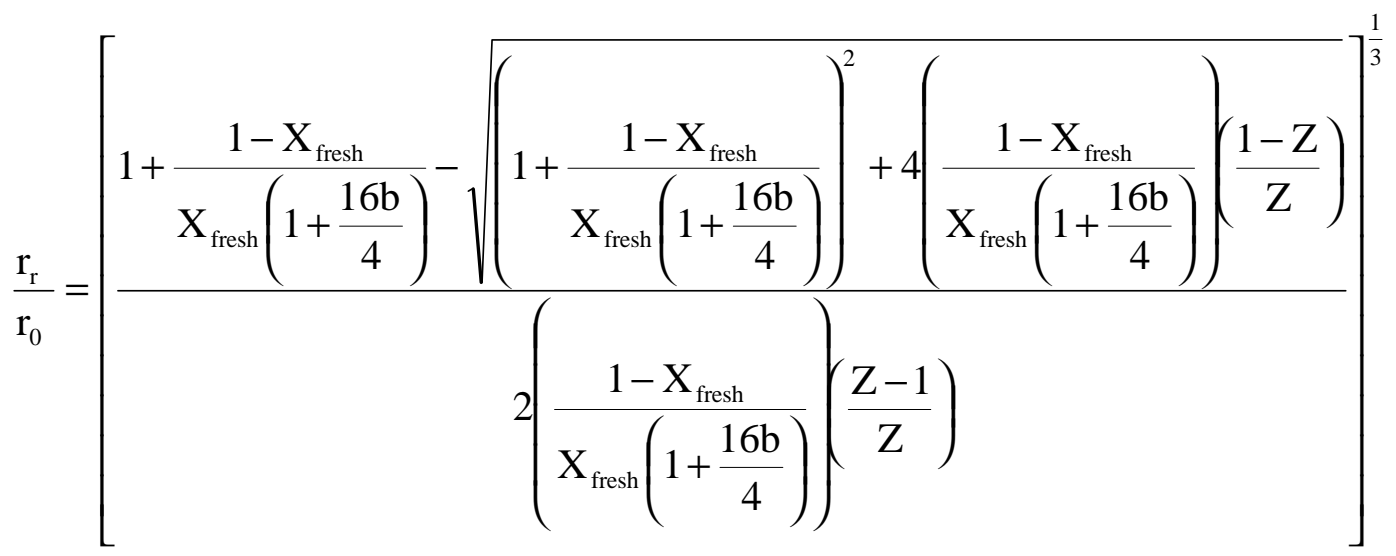

$$
\begin{aligned}
& =\mathrm{R}_{\mathrm{r}-} \mathrm{R}_{0-} \text { Ratio }
\end{aligned}
$$

Hence the denominator of the rate expression can be expressed in terms of the mass fraction of the unreacted sorbent.

Denominator of the rate expression $=\frac{1}{K}-\frac{r_{r}^{2}}{D_{e}}\left[\frac{1}{r_{p}}-\frac{1}{r_{r}}\right]=\frac{1}{K}-\frac{r_{r}}{D_{e}}\left[\frac{r_{r}}{r_{p}}-1\right]$

From equation (2.16), we have

$$
\frac{\mathrm{r}_{\mathrm{r}}}{\mathrm{r}_{0}}=\left(1-\mathrm{X}_{\mathrm{c}}\right)^{\frac{1}{3}}=\mathrm{R}_{\mathrm{r}-} \mathrm{R}_{0-} \text { Ratio }
$$

combining equations (2.18) and (3.17)

$$
\mathrm{r}_{\mathrm{p}}=\mathrm{r}_{0}\left[\mathrm{Z}+(1-\mathrm{Z})\left(1-\mathrm{X}_{\mathrm{c}}\right)\right]^{\frac{1}{3}}
$$


From equation (3.17) and (3.18) we have

$$
\begin{aligned}
& \frac{1}{K}-\frac{r_{r}}{D_{e}}\left[\frac{r_{r}}{r_{p}}-1\right]=\frac{1}{K}-\frac{r_{0}\left(1-X_{c}\right)^{\frac{1}{3}}}{D_{e}}\left[\frac{r_{0}\left(1-X_{c}\right)^{\frac{1}{3}}}{r_{0}\left[Z+(1-Z)\left(1-X_{c}\right)\right]^{\frac{1}{3}}}-1\right] \\
& =\frac{1}{K}-\frac{r_{0}}{D_{e}}\left[\left(1-X_{c}\right)^{\frac{2}{3}}\left[Z+(1-Z)\left(1-X_{c}\right)\right]^{-\frac{1}{3}}-\left(1-X_{c}\right)^{\frac{1}{3}}\right]
\end{aligned}
$$

Now we are considering the rate expression within the computational cell, so in the rate expression $\mathrm{N}_{\mathrm{H}_{2} \mathrm{~S}}$ represents the moles of $\mathrm{H}_{2} \mathrm{~S}$ in the computational cell. Multiplying both the left hand side and the right hand side of the rate expression by the molecular weight of $\mathrm{H}_{2} \mathrm{~S}$ we have from equations (3.9) and (3.19)

$$
\frac{\mathrm{dM}_{\mathrm{H}_{2} \mathrm{~S}}}{\mathrm{dt}}=\frac{-\left(\frac{3 \mathrm{~b}\left(1-\varepsilon_{\mathrm{g}}\right)\left(1-\varepsilon_{0}\right) * \mathrm{r}_{\mathrm{r}}^{2}}{\mathrm{r}_{0}^{3}}\right)\left(\frac{\mathrm{M}_{\mathrm{H}_{2} \mathrm{~S}}}{\varepsilon_{\mathrm{g}}}\right)}{\frac{1}{\mathrm{~K}}-\frac{\mathrm{r}_{0}}{\mathrm{D}_{\mathrm{e}}}\left[\left(1-\mathrm{X}_{\mathrm{c}}\right)^{\frac{2}{3}}\left[\mathrm{Z}+(1-\mathrm{Z})\left(1-\mathrm{X}_{\mathrm{c}}\right)\right]^{-\frac{1}{3}}-\left(1-\mathrm{X}_{\mathrm{c}}\right)^{\frac{1}{3}}\right]}
$$

Since MFIX does not track the mass directly, but it can track void fraction, the mass fraction of the gas and the total mass density of the gas, hence the mass of hydrogen sulfide can be expressed as follows: $M_{\mathrm{H}_{2} \mathrm{~S}}=\varepsilon_{\mathrm{g}} \mathrm{X}_{\mathrm{H}_{2} \mathrm{~S}} \rho_{\mathrm{g}}$

Substituting $\mathrm{M}_{\mathrm{H} 2 \mathrm{~S}}$ in equation (3.20)

$$
\frac{\mathrm{dM}_{\mathrm{H}_{2} \mathrm{~S}}}{\mathrm{dt}}=\frac{-\left(\frac{3 \mathrm{~b}\left(1-\varepsilon_{\mathrm{g}}\right)\left(1-\varepsilon_{0}\right) * \mathrm{r}_{\mathrm{r}}^{2}}{\mathrm{r}_{0}^{3}}\right) \mathrm{X}_{\mathrm{H}_{2} \mathrm{~S}} \rho_{\mathrm{g}}}{\frac{1}{\mathrm{~K}}-\frac{\mathrm{r}_{0}}{\mathrm{D}_{\mathrm{e}}}\left[\left(1-\mathrm{X}_{\mathrm{c}}\right)^{\frac{2}{3}}\left[\mathrm{Z}+(1-\mathrm{Z})\left(1-\mathrm{X}_{\mathrm{c}}\right)\right]^{-\frac{1}{3}}-\left(1-\mathrm{X}_{\mathrm{c}}\right)^{\frac{1}{3}}\right]}
$$


The reaction does not proceed if the partial pressure of hydrogen sulfide is less than the equilibrium value, so the rate becomes zero. To avoid this discontinuity, instead of substituting $\mathrm{M}_{\mathrm{H} 2 \mathrm{~S}}$ in the rate expression we substitute in equation (3.21) the effective mass of hydrogen sulphide per cell volume as

$$
\begin{aligned}
& \mathrm{M}_{\mathrm{H}_{2} \mathrm{~S}}=\mathrm{M}_{\mathrm{H}_{2} \mathrm{~S}}-\mathrm{M}_{\mathrm{H}_{2} \mathrm{~S}}^{\mathrm{EQLM}}
\end{aligned}
$$

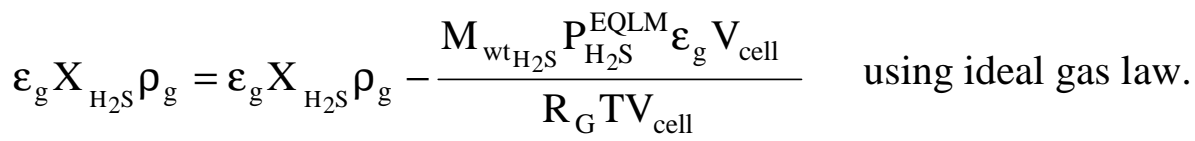

This introduces some error into rate expression but that is very small.

$$
\begin{aligned}
& \frac{\mathrm{dM}_{\mathrm{H}_{2} \mathrm{~S}}}{\mathrm{dt}}=\frac{-\left(\frac{3 \mathrm{~b}\left(1-\varepsilon_{\mathrm{g}}\right)\left(1-\varepsilon_{0}\right) * \mathrm{r}_{\mathrm{r}}^{2}}{\mathrm{r}_{0}^{3}}\right)\left(\mathrm{X}_{\mathrm{H}_{2} \mathrm{~S}} \rho_{\mathrm{g}}-\frac{\left.\mathrm{M}_{\mathrm{wt}_{\mathrm{H}_{2} \mathrm{~S}} \mathrm{P}_{\mathrm{H}_{2} \mathrm{~S}}^{\mathrm{EQLM}}}^{\mathrm{R}_{\mathrm{G}} \mathrm{T}}\right)}{\frac{1}{\mathrm{~K}}-\frac{\mathrm{r}_{0}}{\mathrm{D}_{\mathrm{e}}}\left[\left(1-\mathrm{X}_{\mathrm{c}}\right)^{\frac{2}{3}}\left[\mathrm{Z}+(1-\mathrm{Z})\left(1-\mathrm{X}_{\mathrm{c}}\right)\right]^{-\frac{1}{3}}-\left(1-\mathrm{X}_{\mathrm{c}}\right)^{\frac{1}{3}}\right]}\right.}{\mathrm{b} \frac{\mathrm{dM}_{\text {fresh sor }}}{\mathrm{dt}}=\frac{\mathrm{dM}_{\mathrm{H} 2 \mathrm{~S}}}{\mathrm{dt}}}
\end{aligned}
$$

The final form is as follows

$$
\frac{\mathrm{dM}_{\text {fresh sor }}}{\mathrm{dt}}=\frac{-3\left(\frac{\left(1-\varepsilon_{\mathrm{g}}\right)\left(1-\varepsilon_{0}\right) *\left(\mathrm{r}_{0} * \mathrm{R}_{\mathrm{r}-} \mathrm{R}_{0 \_} \text {Ratio }\right)^{2}}{\mathrm{r}_{0}^{3}}\right)\left(\mathrm{X}_{\mathrm{H}_{2} \mathrm{~S}} \varsigma_{\mathrm{g}}-\frac{\left.\mathrm{M}_{\mathrm{wt}_{\mathrm{H}_{2} \mathrm{~S}} \mathrm{P}_{\mathrm{H}_{2} \mathrm{~S}}^{\mathrm{EQLM}}}^{\mathrm{R}_{\mathrm{G}} \mathrm{T}}\right)}{\frac{1}{\mathrm{~K}}-\frac{\mathrm{r}_{0}}{\mathrm{D}_{\mathrm{e}}}\left[\left(1-\mathrm{X}_{\mathrm{c}}\right)^{\frac{2}{3}}\left[\mathrm{Z}+(1-\mathrm{Z})\left(1-\mathrm{X}_{\mathrm{c}}\right)\right]^{-\frac{1}{3}}-\left(1-\mathrm{X}_{\mathrm{c}}\right)^{\frac{1}{3}}\right]}\right.}{(3.2}
$$

where $\mathrm{X}_{\mathrm{c}}$ is as given in equation (2.16)

Gas film resistance can also be added as follows 


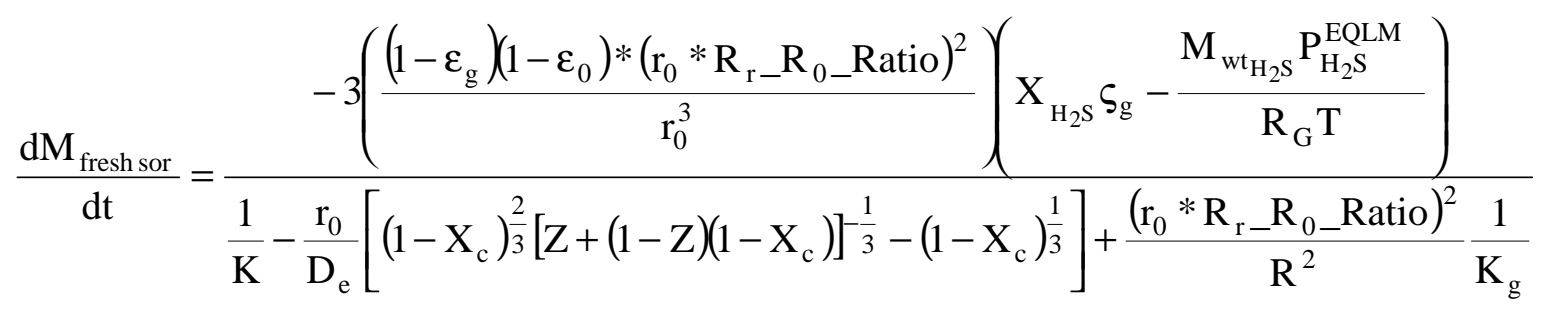

$\underline{\text { In MFIX subroutine rrates.f }{ }^{\dagger}}$

RXNA1F

$$
=\frac{3\left(\frac{\left(1-\varepsilon_{\mathrm{g}}\right)\left(1-\varepsilon_{0}\right) *\left(\mathrm{r}_{0} * \mathrm{R}_{\mathrm{r}-} \mathrm{R}_{0 \_} \text {Ratio }\right)^{2}}{\mathrm{r}_{0}^{3}}\right)\left(\mathrm{X}_{\mathrm{H}_{2} \mathrm{~S}} \varsigma_{\mathrm{g}}-\frac{\mathrm{M}_{\mathrm{wt}_{\mathrm{H}_{2} \mathrm{~S}}} \mathrm{P}_{\mathrm{H}_{2} \mathrm{~S}}^{\mathrm{EQLM}}}{\mathrm{R}_{\mathrm{G}} \mathrm{T}}\right)}{\frac{1}{\mathrm{~K}}-\frac{\mathrm{r}_{0}}{\mathrm{D}_{\mathrm{e}}}\left[\left(1-\mathrm{X}_{\mathrm{c}}\right)^{\frac{2}{3}}\left[\mathrm{Z}+(1-\mathrm{Z})\left(1-\mathrm{X}_{\mathrm{c}}\right)\right]^{-\frac{1}{3}}-\left(1-\mathrm{X}_{\mathrm{c}}\right)^{\frac{1}{3}}\right]+\frac{\left(\mathrm{r}_{0} * \mathrm{R}_{\left.\mathrm{r}-\mathrm{R}_{0-} \text { Ratio }\right)^{2}} \frac{1}{\mathrm{R}^{2}}\right.}{\mathrm{K}_{\mathrm{g}}}}
$$

The rates at which the mass of four species change are given as follows

$\frac{\mathrm{dM}_{\text {fresh sor }}}{\mathrm{dt}}=-\mathrm{RXNA1F}$

$$
\frac{\mathrm{dM}_{\mathrm{H}_{2} \mathrm{~S}}}{\mathrm{dt}}=-\mathrm{bRXNA1F}
$$

$\frac{\mathrm{dM}_{\text {spent sor }}}{\mathrm{dt}}=\left(1+\frac{16 \mathrm{~b}}{34}\right) \mathrm{RXNA} 1 \mathrm{~F}$

$$
\frac{\mathrm{dM}_{\mathrm{H}_{2} \mathrm{O}}}{\mathrm{dt}}=\frac{18 \mathrm{~b}}{34} \text { RXNA1F }
$$

\subsection{Parameters and Constants}

The expression for intrinsic chemical reaction rate is by Susan Lew, Adel Sarofim, Maria Flytzani-Stephanopoulos, " Sulfidation of Zinc Titanate and Zinc Oxide Solids.”, Ind. Eng. Chem. Res. Pg. 1890-1899, 1992.

$\mathrm{K}=1.31 \exp \left(\frac{-10300 \mathrm{cal} / \mathrm{mole}}{\mathrm{RT}}\right) \frac{\mathrm{cm}}{\mathrm{s}}$. 
Since the rate expression is based on the grains so only the product layer diffusion is considered. In most of the previous work on grain models , the product layer diffusivity is used as a fitting parameter. Based on the grain size in consideration, the product layer diffusivity expression is taken from the paper by P.V Ranade and D.P Harrison, 1981.

$\mathrm{D}_{\mathrm{e}}=0.00049 \exp (-22000 \mathrm{cal} / \mathrm{mol} / \mathrm{RT}) \mathrm{cm}^{2} / \mathrm{sec}$

To calculate the gas film diffusion coefficient, the correlation developed by D. J. Gunn, 1978 and modified by M. Syamlal, W. Rogers, and T. J O'Brian ,1993, for MFIX is used

$$
\mathrm{K}_{\mathrm{g}}=\frac{\mathrm{D}_{\mathrm{M}} \mathrm{N}_{\mathrm{sh}}}{\mathrm{d}_{\mathrm{p}}} \quad\left(\frac{\mathrm{cm}}{\mathrm{s}}\right)
$$

The expression for the Sherwood number is given as follows

$$
\begin{aligned}
& \mathrm{N}_{\mathrm{sh}}=\left(7.0-10 \varepsilon_{\mathrm{s}}+5 \varepsilon_{\mathrm{s}}{ }^{2}\left(1+\mathrm{Re}^{0.2} \mathrm{Sc}^{\frac{1}{3}}\right)+\left(1.33-2.4 \varepsilon_{\mathrm{s}}+1.2 \varepsilon_{\mathrm{s}}{ }^{2}\right) \mathrm{Re}^{0.7} \mathrm{Sc}^{\frac{1}{3}}\right. \\
& \mathrm{Sc}=\frac{\mu}{\mathrm{D}_{\mathrm{M}} \rho_{\mathrm{g}}} \text { and } \mathrm{Re}=\frac{2 \mathrm{R} \mid \mathrm{V}_{\text {sorbent }}-\mathrm{V}_{\mathrm{g}} \rho_{\mathrm{g}}}{\mu} \varepsilon_{\mathrm{s}} \text { is solids volume fraction. }
\end{aligned}
$$

Sc is the Schmidt number and Re is the Reynolds number.

\footnotetext{
${ }^{\dagger}$ subroutine attached in Appendix B.
} 


\subsection{Geometry and Operating Conditions}

The desulfurization transport reactor is a stainless steel tube which is symmetric about the axis. The inlet for the gas and the solid is from the bottom and the exit is from the top. Hot gas desulfurization has been modeled for three different reactor setups as shown in table I (personal communication, NETL, Morgantown).

The boundary conditions used for all these setups are the mass inlet at the inlet and pressure outlet at the exit. Free slip wall for both solids and gas are used. The boundary condition for energy balance is that heat flux at the wall is zero and also diffusion at the wall is set to be zero. Also with setup $\mathrm{C}$ different boundary conditions for the gas and solids have been tried out such as the solution of momentum balance at the wall. 
Table I. Reactor setup and parameters.

\begin{tabular}{|c|c|c|c|}
\hline $\begin{array}{c}\text { Reactor variables and } \\
\text { parameters }\end{array}$ & Setup A & Setup B & Setup C \\
\hline Diameter $(\mathrm{cm})$ & 2.08 & 1.696 & 0.848 \\
\hline Height $(\mathrm{cm})$ & 1155 & 855 & 855 \\
\hline Operating pressure $\left(\mathrm{N} / \mathrm{m}^{2}\right)$ & 1135606.5 & 2067850 & 2067850 \\
\hline Operating temperature $(\mathrm{K})$ & 811 & 811 & 811 \\
\hline Particle diameter $(\mu \mathrm{m})$ & 75 & 75 & 80 \\
\hline Solids mass flow rate $(\mathrm{g} / \mathrm{sec})$ & 18.9 & 1.686 & 0.63 \\
\hline Gas mass flow rate $(\mathrm{g} / \mathrm{sec})$ & 6.3 & 1.686 & 1.686 \\
\hline Solid Density $\left(\mathrm{g} / \mathrm{cm}^{3}\right)$ & 1.0 & 1.0 & 1.0 \\
\hline$\%$ Zinc in the Sorbent & 50 & $30-50$ & 50 \\
\hline Gas Viscosity (g/cm s.) & $3.17 \times 10^{-4}$ & $3.17 \times 10^{-4}$ & $3.17 \times 10^{-4}$ \\
\hline Porosity of fresh Sorbent $\varepsilon_{0}$ & 0.3 & 0.3 & 0.3 \\
\hline $\begin{array}{l}\text { Dimensionless Sorbent } \\
\text { equilibrium constant, }\end{array}$ & 71358.0 & 71358.0 & 71358.0 \\
\hline $\begin{array}{l}\text { Initial specific surface area of } \\
\text { the fresh sorbent. }\left(\mathrm{cm}^{2} / \mathrm{g}\right)\end{array}$ & $5000-10000$ & $2000-10000$ & 10000 \\
\hline \multirow[t]{3}{*}{ Inlet hot gas composition } & $\mathrm{H}_{2} \mathrm{O}-5.5 \%$ & $\mathrm{H}_{2} \mathrm{O}-5.5 \%$ & $\mathrm{H}_{2} \mathrm{O}-5.5 \%, \mathrm{H}_{2} \mathrm{~S}-0.3 \%$ \\
\hline & $\mathrm{H}_{2} \mathrm{~S}-0.03 \%$ & $\mathrm{H}_{2} \mathrm{~S}-0.03 \%$ & $\mathrm{~N}_{2}-48.5 \%, \mathrm{CO}_{2}-5.5 \%$ \\
\hline & $\mathrm{N}_{2}-94.47 \%$ & $\mathrm{~N}_{2}-94.47 \%$ & $\begin{array}{l}\mathrm{CO}-24.2 \%, \mathrm{H}_{2}-14.5 \%, \\
\mathrm{O}_{2}-1.5 \%\end{array}$ \\
\hline
\end{tabular}




\section{CHAPTER IV \\ RESULTS AND DISCUSSION}

Three different reactor setups have been modeled to determine the parameters that affect the sulfur capture. For setup A, the pressure drop across the bed was varied by adjusting the phenomenological gas/particle drag $\operatorname{law}^{\dagger}$ to account for the effect of microscale particle clustering (O'Brien, and Syamlal, 1993). Also effect of change in the sulfur capture with the change in initial specific surface area of sorbent particles was studied.

With setup B, the effect of zinc concentration in the sorbent and the initial specific surface area on sulfur capture was studied. Finally with setup $\mathbf{C}$ the effect of pressure drop on sulfur capture is determined through particle clustering, boundary condition at the wall, the solids viscosity relationship. Also a comparison is made between the grain model and the shrinking core model.

For all these setups free slip wall for solids and gas phase have been used except for setup C where some other boundary condition has been tried.

\subsection{Setup A results.}

The general trends for solid concentrations and gas and solids velocity averaged over entire reactor are shown in Figures 4.1 and 4.2 respectively with $50 \%$ zinc in the sorbent and initial specific surface area as $10 \mathrm{~m}^{2} / \mathrm{g}$. The flux profiles at three different locations are shown in Figure 4.3. All the profiles are more or less flat indicating a plug flow kind of behaviour

\footnotetext{
${ }^{\dagger}$ Refer to the summary of equations Appendix A.
} 


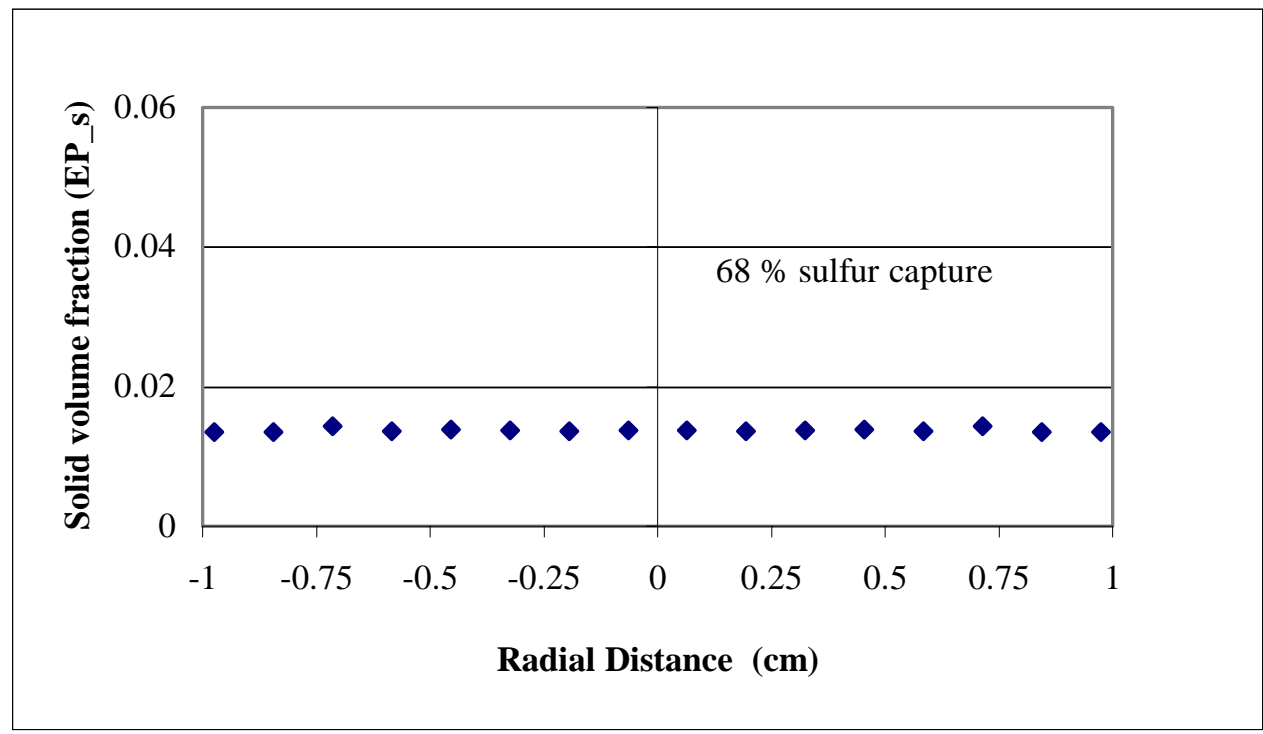

Figure 4.1. Variation of solids volume fraction with radial distance. [Setup A]

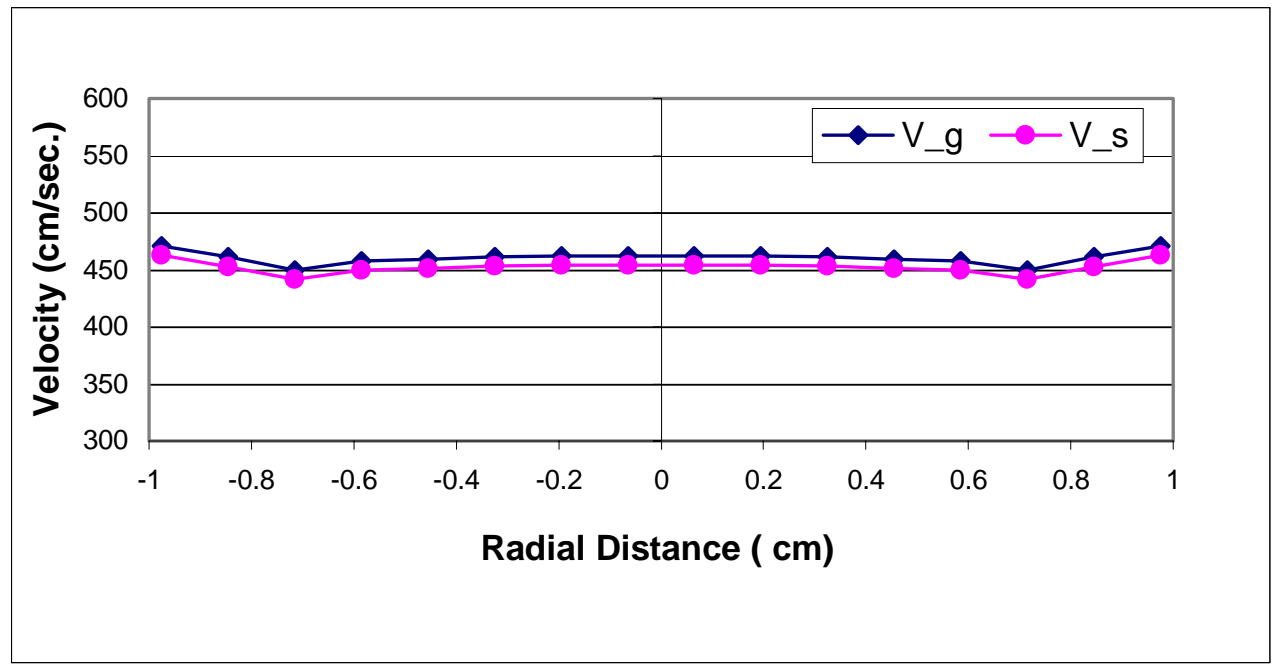

Figure 4.2. Variation of solids and gas velocity with radial distance. [Setup A] 


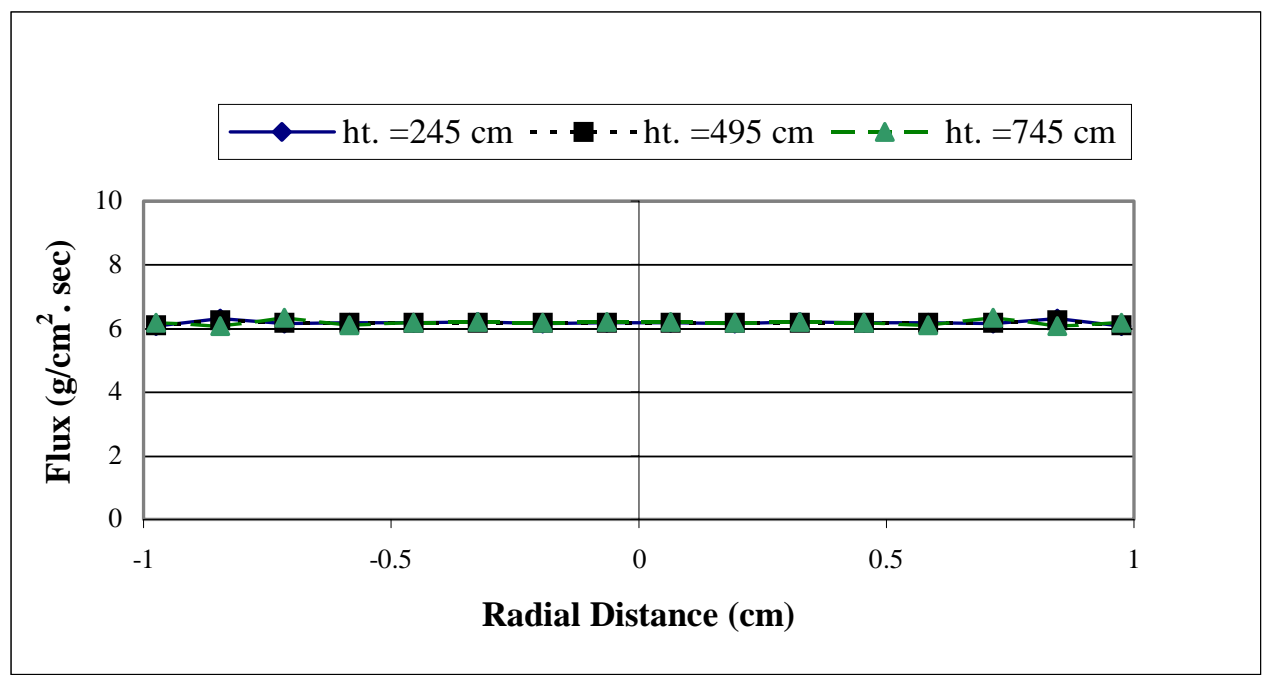

Figure 4.3. Variation of solid flux with radial distance. [Setup A]

The general trend of gas and solid velocity profiles and solids concentration profile due to clustering effect is shown in Figures 4.4 and 4.5 respectively. It is clear that the clustering largely affects the solid velocity profile and hence the sulfur capture.

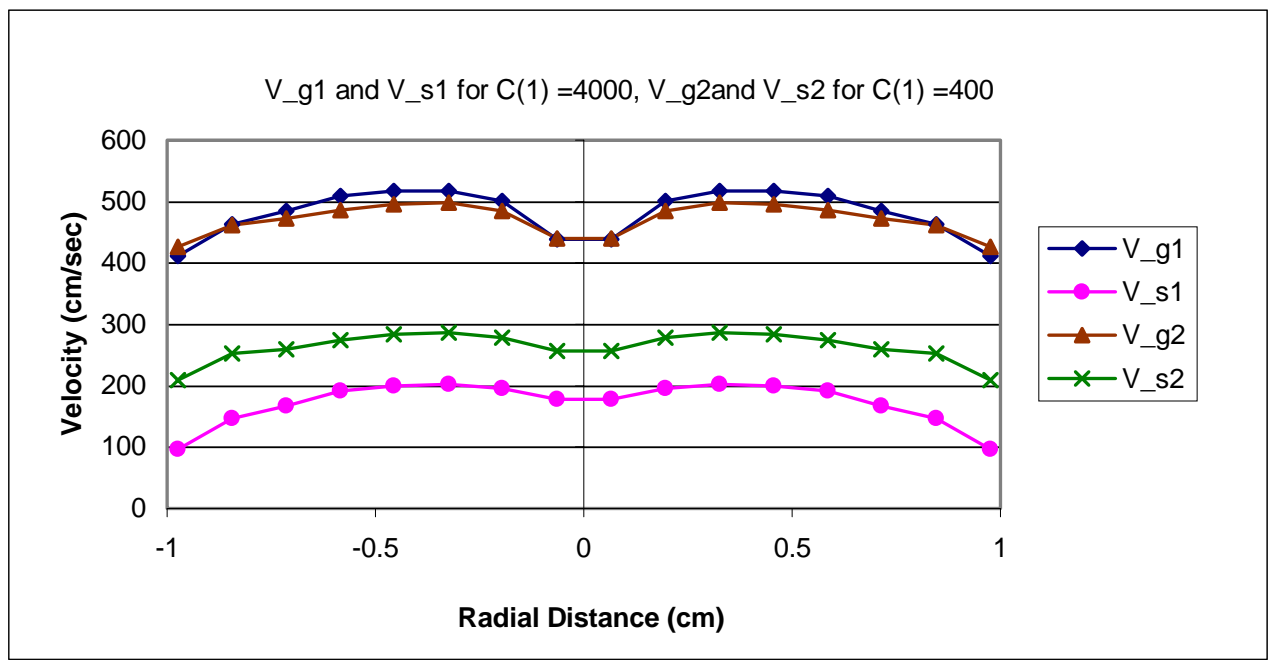

Figure 4.4. Effect of cluster correction on the radial gas and solids velocities. [Setup A] 


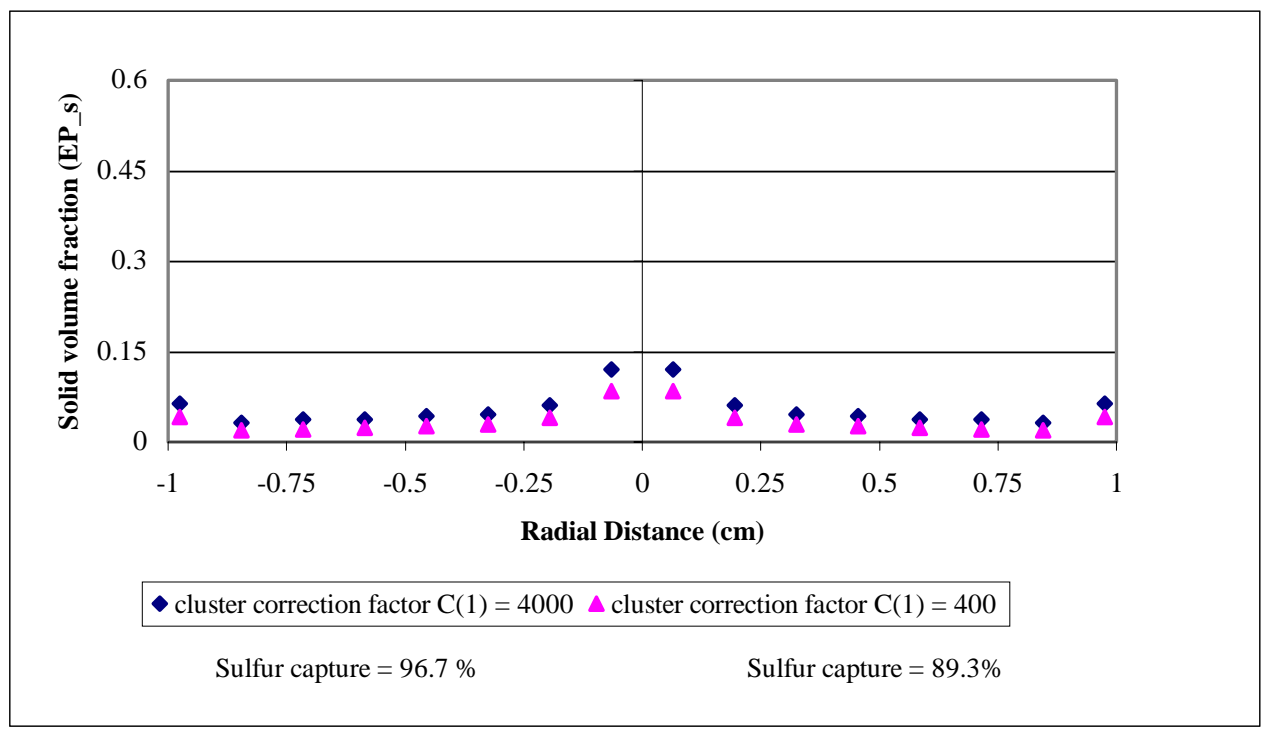

Figure 4.5. Effect of cluster correction on solids volume fraction. [Setup A]

The effect of pressure drop with sulfur capture for clustering effect is highlighted in Figure 4.6.

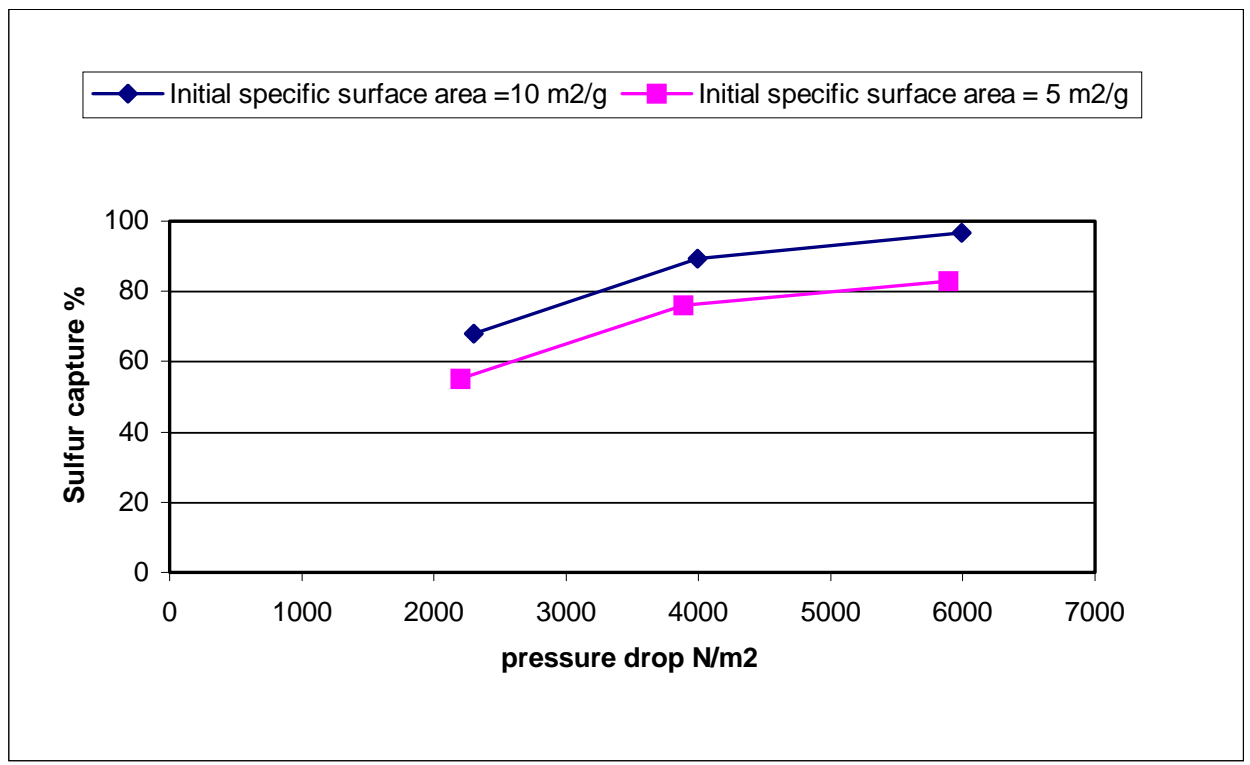

Figure 4.6. Effect of pressure drop on sulfur capture. [Setup A] 


\subsection{Setup B results}

For Setup B the effect of change in the sulfur capture with the change in initial specific surface area of sorbent particles and percentage zinc in the sorbent was studied. The pressure drop was kept constant at $1400 \mathrm{~N} / \mathrm{m}^{2}$.

\section{Effects of initial specific surface area and sorbent purity on the sulfur capture.}

The initial specific surface area determines the initial grain radius, smaller the radius greater the number of grains and hence larger sulfur capture. The initial specific surface area was varied between $2-10 \mathrm{~m}^{2} / \mathrm{g}$ and the zinc mass fraction in the sorbent was varied between 0.3 to 0.5 and corresponding sulfur capture was plotted as shown in Figure 4.7 .

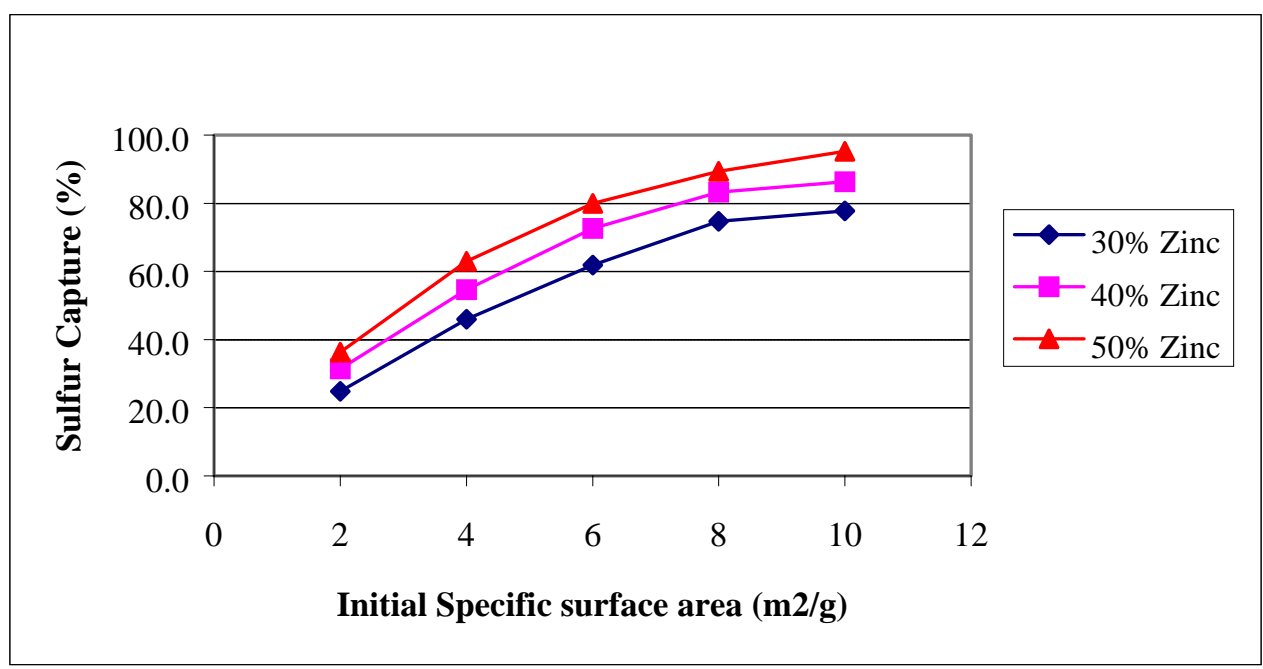

Figure 4.7. Effect of initial specific surface area and sorbent purity on the sulfur capture. [Setup B]

The solid volume fraction and the velocity profiles averaged over the entire reactor are shown in Figures 4.8 and 4.9 respectively. The solids flux profiles at three 
different heights are shown in Figure 4.10. There is not much change in the flux profiles at different heights indicating that the flow is fully developed .

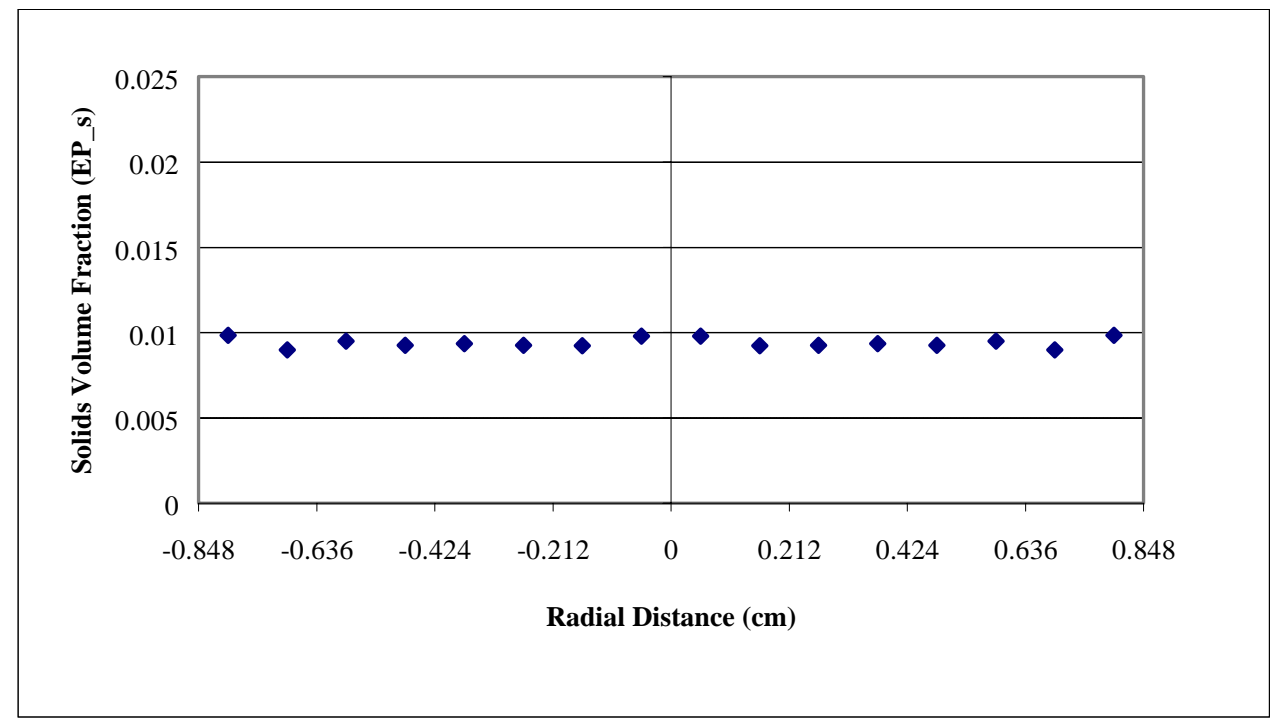

Figure 4.8. Variation of solids volume fraction with radial distance. [Setup B]

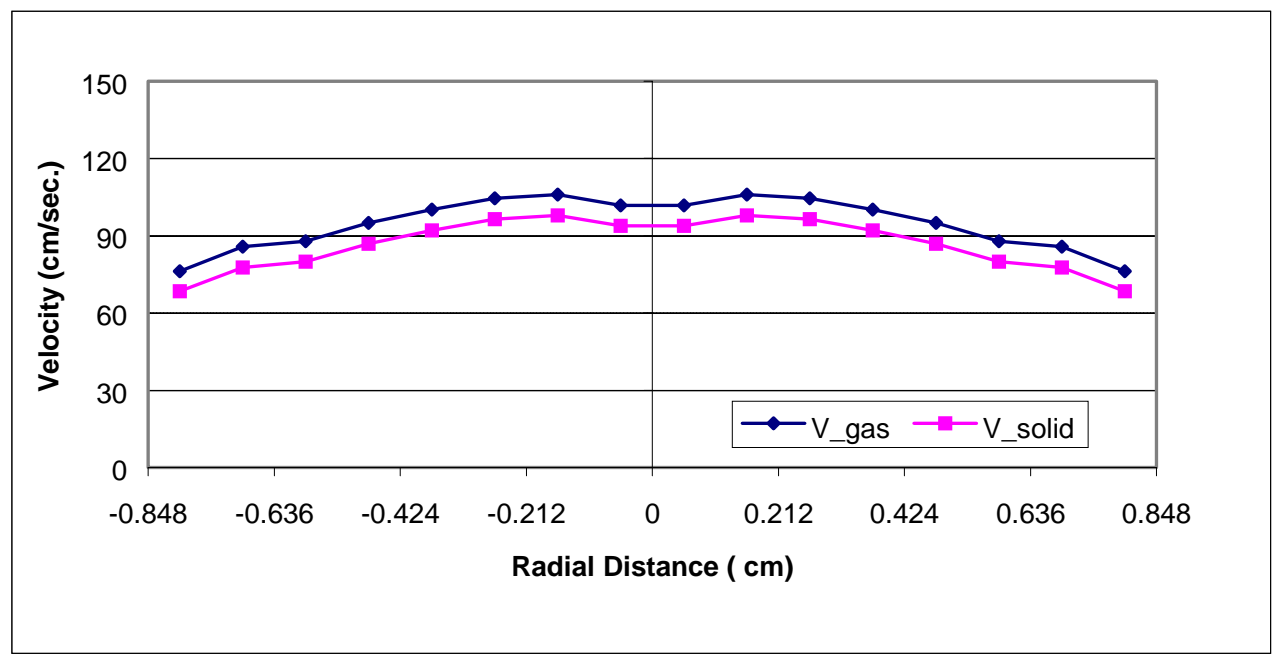

Figure 4.9. Variation of gas and solid velocity with radial distance. [Setup B] 


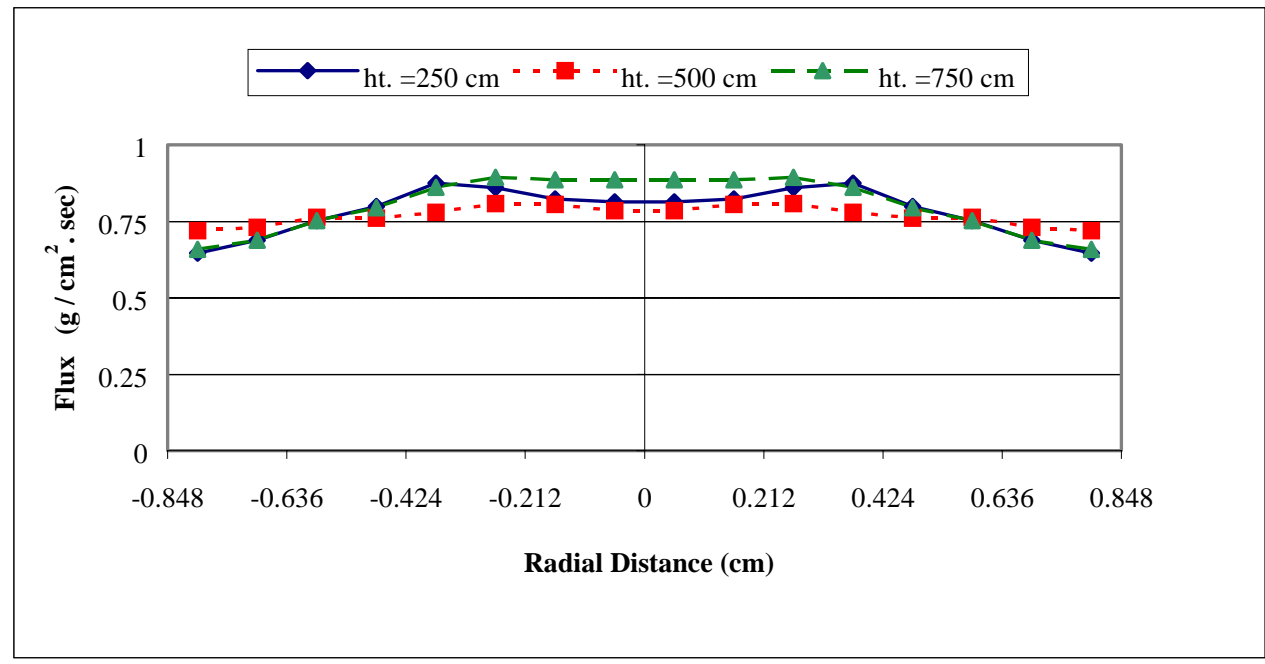

Figure 4.10. Variation of solid flux with radial distance. [Setup B] 


\subsection{Setup C results}

This is the exact setup for which experiments were performed in NETL, Morgantown whose results are yet to be released. A sulfur capture of around $90 \%$ for a pressure drop of around $4000-7000 \mathrm{~N} / \mathrm{m}^{2}$ was observed for this setup (personal communication).

With Setup $\mathbf{C}$ the pressure drop was varied by adjusting the phenomenological gas/particle drag law $w^{\ddagger}$ to account for the effect of micro-scale particle clustering (O'Brien, and Syamlal, 1993). The initial specific surface area of the sorbent was $10 \mathrm{~m}^{2} / \mathrm{g}$ and zinc mass fraction in it was 0.5 .

With this setup, the boundary condition at the wall was varied along with the solids viscosity to determine its effect on the flow profile and sulfur capture.

Also a comparison between the grain model and the shrinking core model for gassolid reaction was made with this setup.

\subsubsection{Effect of pressure drop across the reactor on the sulfur capture.}

By increasing the correction factor in the gas/particle drag law, the slip velocity can be varied which in turn causes an increase in the pressure drop. With the increase in the pressure drop, the solids concentration increases and hence the sulfur capture. This is shown in Figures 4.11,4.12 and 4.13.

\footnotetext{
$\ddagger$ Refer to the summary of equations.
} 


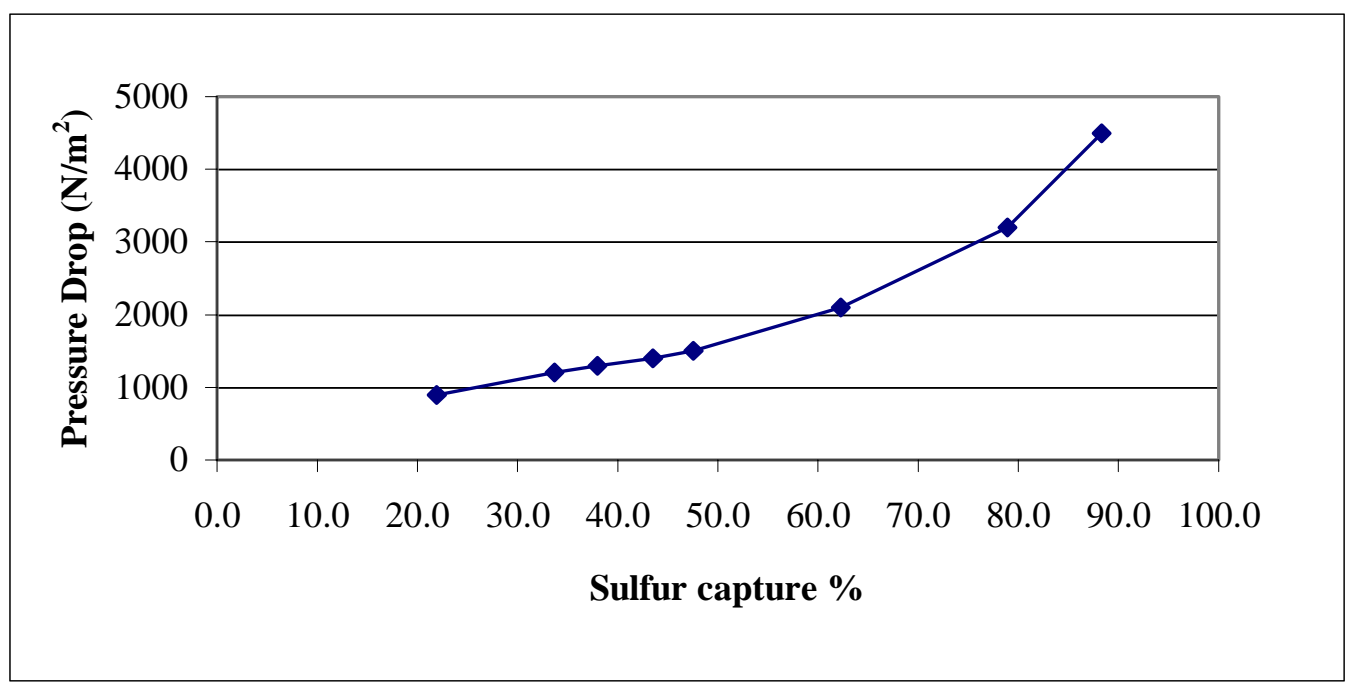

Figure 4.11. Effect of Pressure drop on sulfur capture. [Setup C]

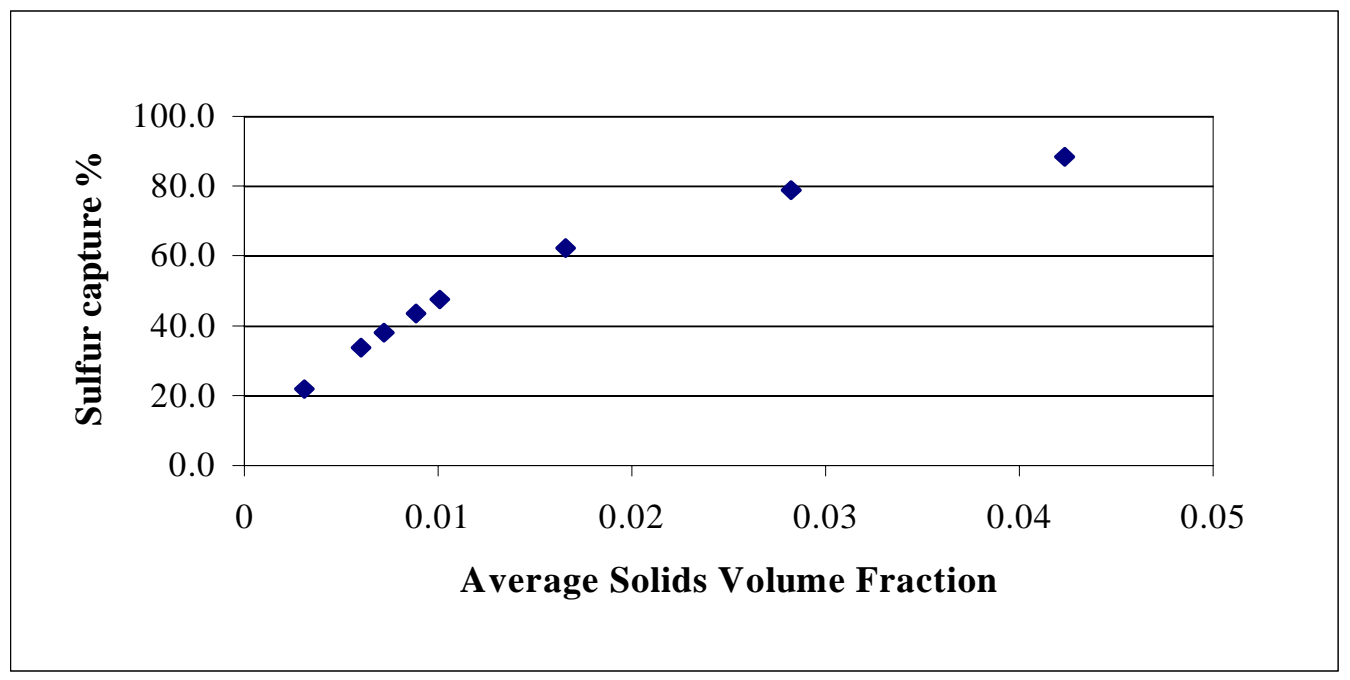

Figure 4.12. Variation of sulfur capture with solids volume fraction. [Setup C] 


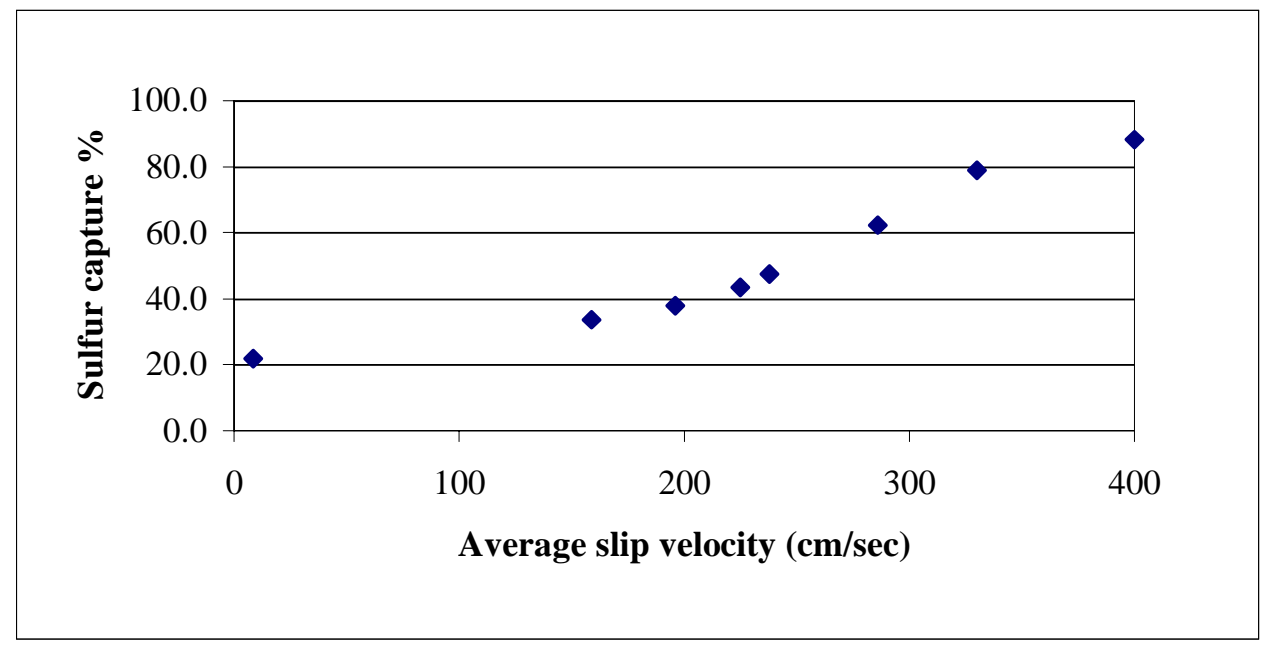

Figure 4.13.Variation of sulfur capture with slip velocity. [Setup C]

From these plots for high sulfur capture a high slip velocity is required with the average solid concentration less than $5 \%$. The solid volume fraction and the velocity profiles for a pressure drop of $1400 \mathrm{~N} / \mathrm{m}^{2}$ averaged over the entire reactor for Setup C are shown in Figures 4.14 and 4.15, respectively. The flux profiles at three different heights are shown in Figure 4.16. These profiles have been obtained by correcting the gas solid drag to account for clustering. This is the general trend of profiles for different pressure drops.

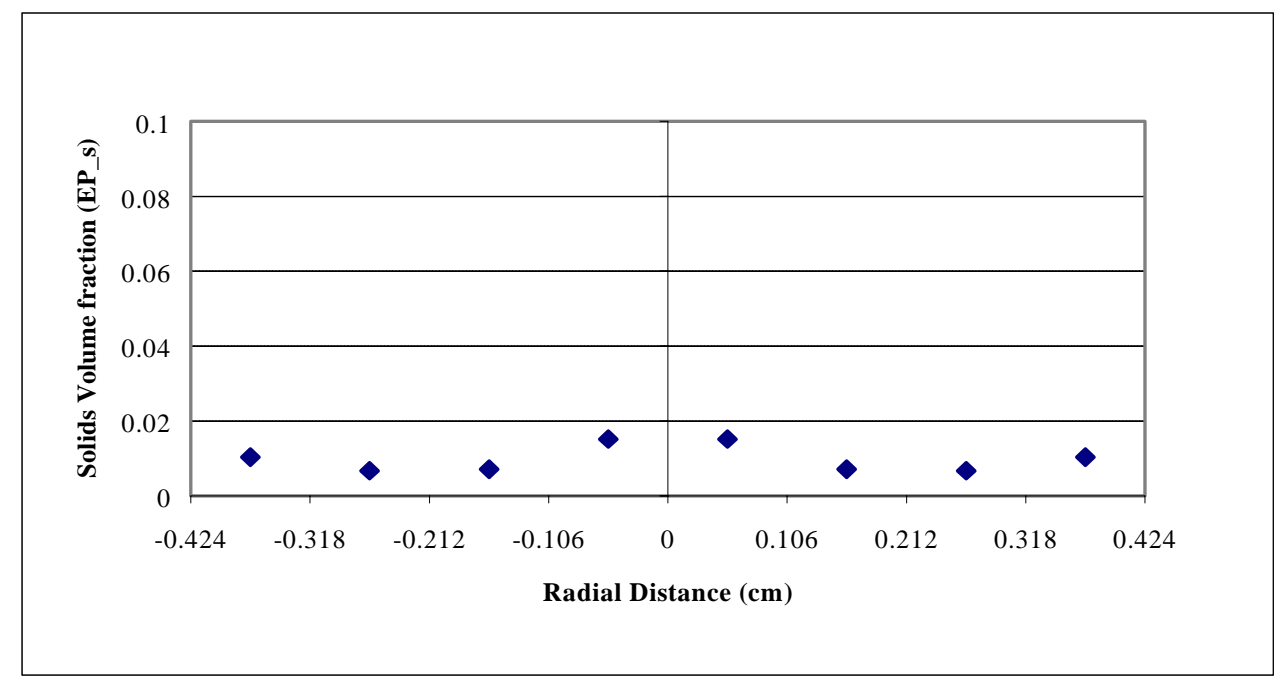

Figure 4.14. Variation of solids volume fraction with radial distance. [Setup C] 


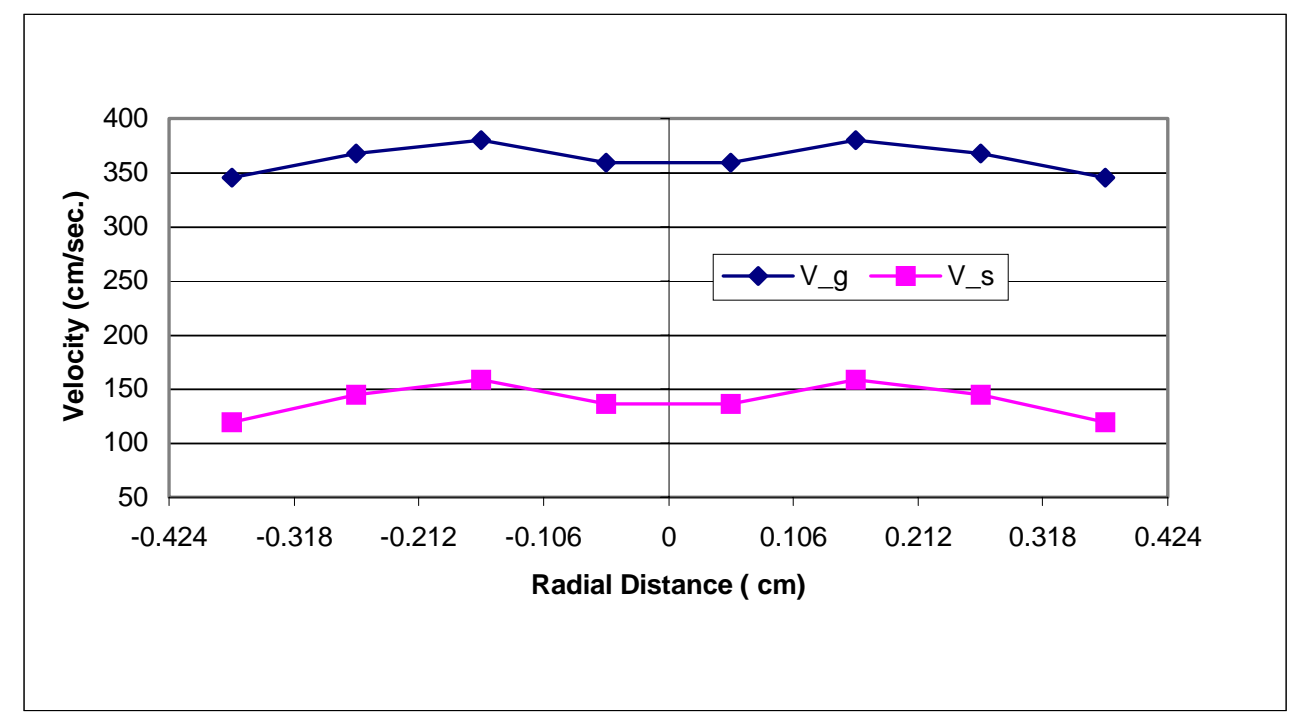

Figure 4.15. Variation of gas and solid velocity with radial distance. [Setup C]

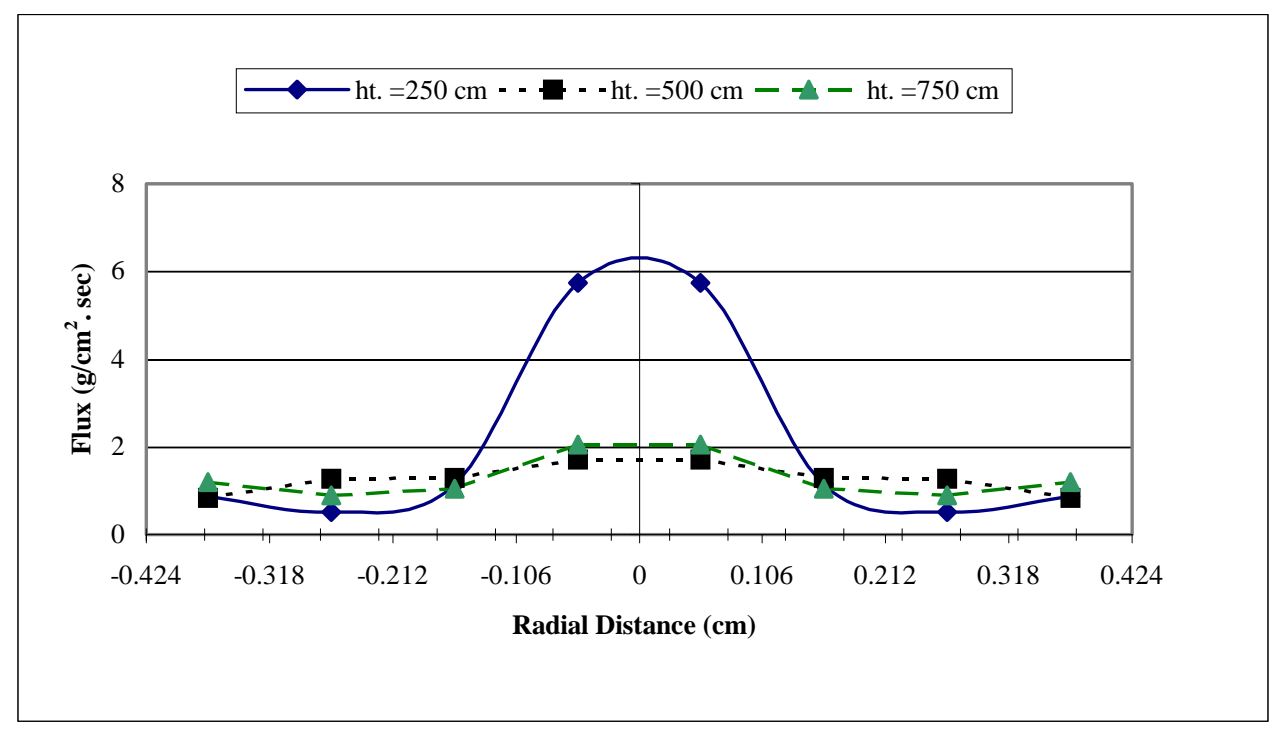

Figure 4.16. Variation of solids flux with radial distance. [Setup C]

The solids volume fraction profile shows more solids at the center and then gradual increase towards the wall. One reason could be the clustering effect is more pronounced at the center but that needs to be investigated. Also a general trend of high 
slip is observed with cluster correction. The flux profile at the inlet is sharp but with the increase in the height the profile flattens out indicating that the flow has developed .

\subsubsection{Effect of boundary condition at the wall and solids viscosity on the sulfur capture}

We believe that the flow pattern inside the CFB absorber is like core-annulus flow. Hence in the annulus region where there are minimum acceleration effects, the gas and solid phase velocities at the wall were obtained by equating the drag force with the weight of the respective phases. The results with this kind of boundary condition are shown below.

Case 1. The above mentioned boundary condition at the wall only for solids and free slip wall for the gas phase yielded the results shown in Figures 4.17 and 4.18. The algebraic expression for solids viscosity was used (Miller, 1992). The solids viscosity of the form, $\mu_{\mathrm{s}}=5.34 \varepsilon_{\mathrm{s}}$ was used.

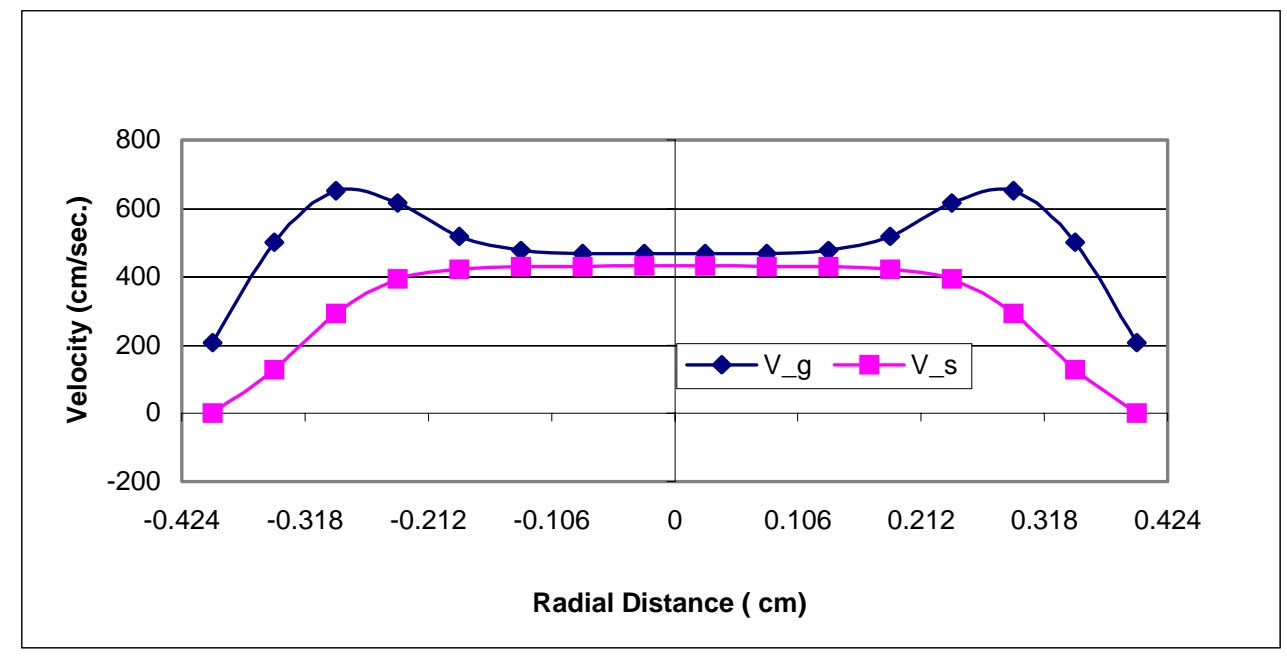

Figure 4.17. Variation of gas and solid velocity with radial distance. Effect of gas solid boundary condition. [Setup C] 


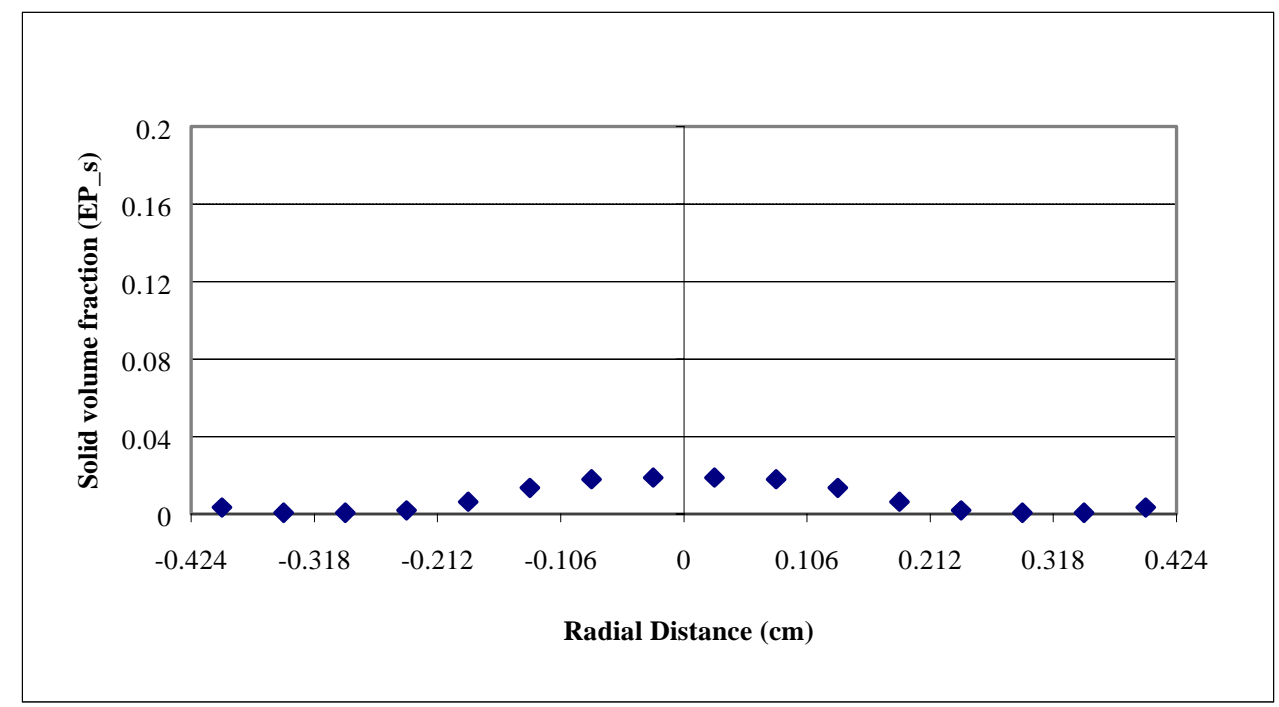

Figure 4.18. Variation of solids volume fraction with radial distance. [Setup C]

The results showed a sulfur capture of $27 \%$ and a large pressure drop of around 17200 $\mathrm{N} / \mathrm{m}^{2}$. High solids concentration at the center was predicted where minimum slip was observed.

Case 2. The above mentioned boundary condition at the wall for both solids and gas phase at wall yielded the velocity and solids concentration profiles as shown in figures 4.19 and 4.20 respectively. The algebraic model for solids viscosity was used. 


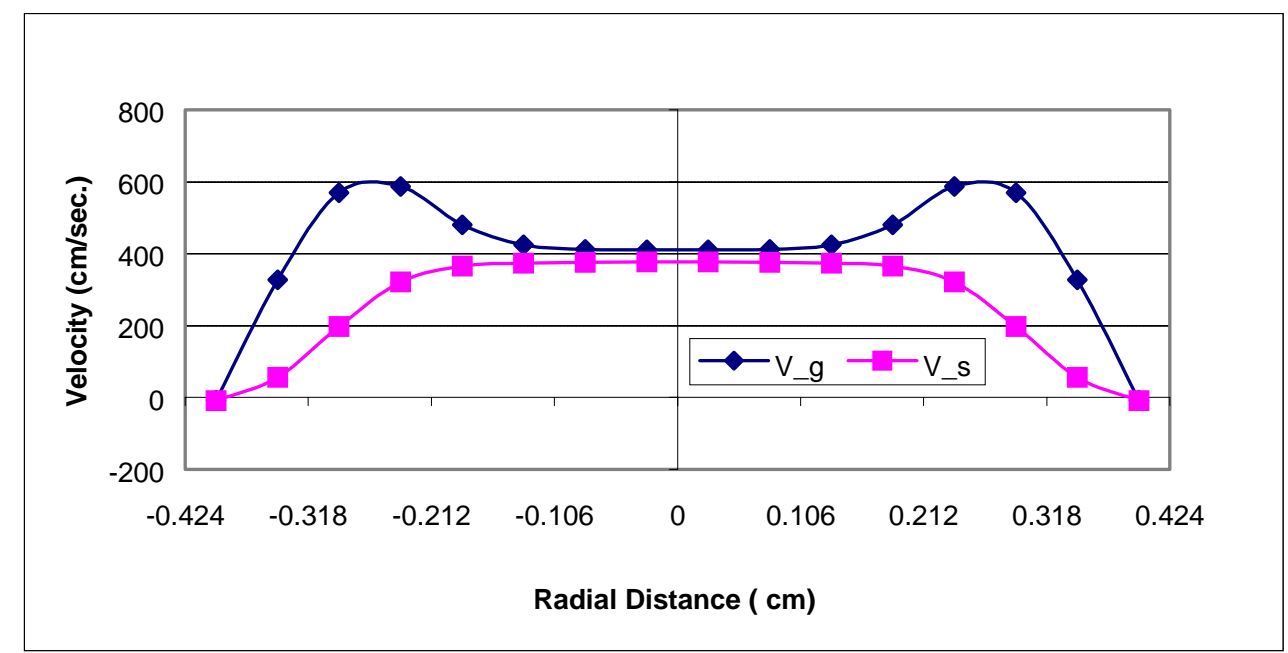

Figure 4.19. Variation of gas and solid velocity with radial distance. Effect of gassolid boundary condition. [Setup C]

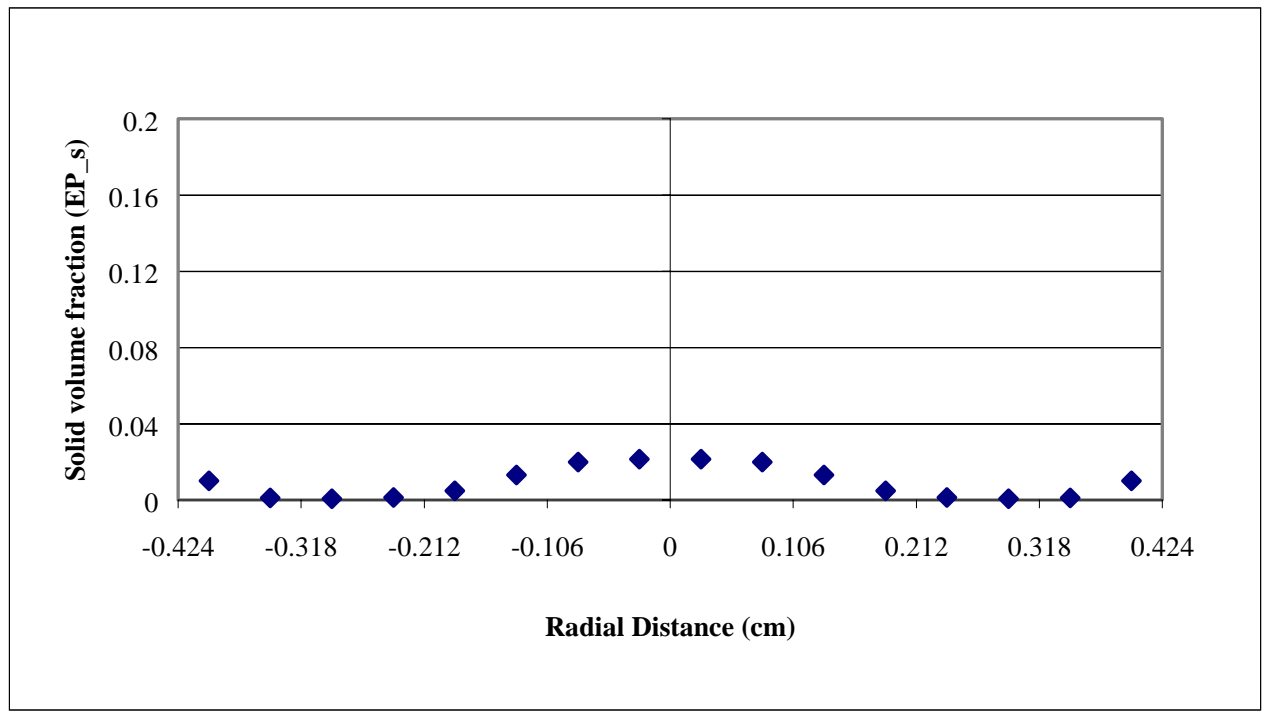

Figure 4.20. Variation of solids volume fraction with radial distance Effect of gassolid boundary condition. [Setup C]

With this $\mathrm{BC}$ the solids concentration at the wall went up as the slip velocity near the wall was reduced. A sulfur capture of around $34 \%$ was predicted with a pressure drop of $16900 \mathrm{~N} / \mathrm{m}^{2}$ which is lower than that obtained in case 1. 
Case 3. Several other boundary conditions at the wall were tried but the solids concentration at the center was always higher than that around the wall. This led us to investigate in the direction of changing the viscosity based on volume fraction and see the effect on sulfur capture. The same boundary condition as in case 2 was used and viscosity expression of the type :-

$\mu_{\mathrm{s}}=5.38 \varepsilon_{\mathrm{s}}+0.8$ if $\varepsilon_{\mathrm{s}} \leq 0.02$

$\mu_{\mathrm{s}}=5.38 \varepsilon_{\mathrm{s}}$ if $\varepsilon_{\mathrm{s}}>0.02$

was used and the results were plotted. This resulted in an expected solids concentration profile as shown in the figure 4.21 .

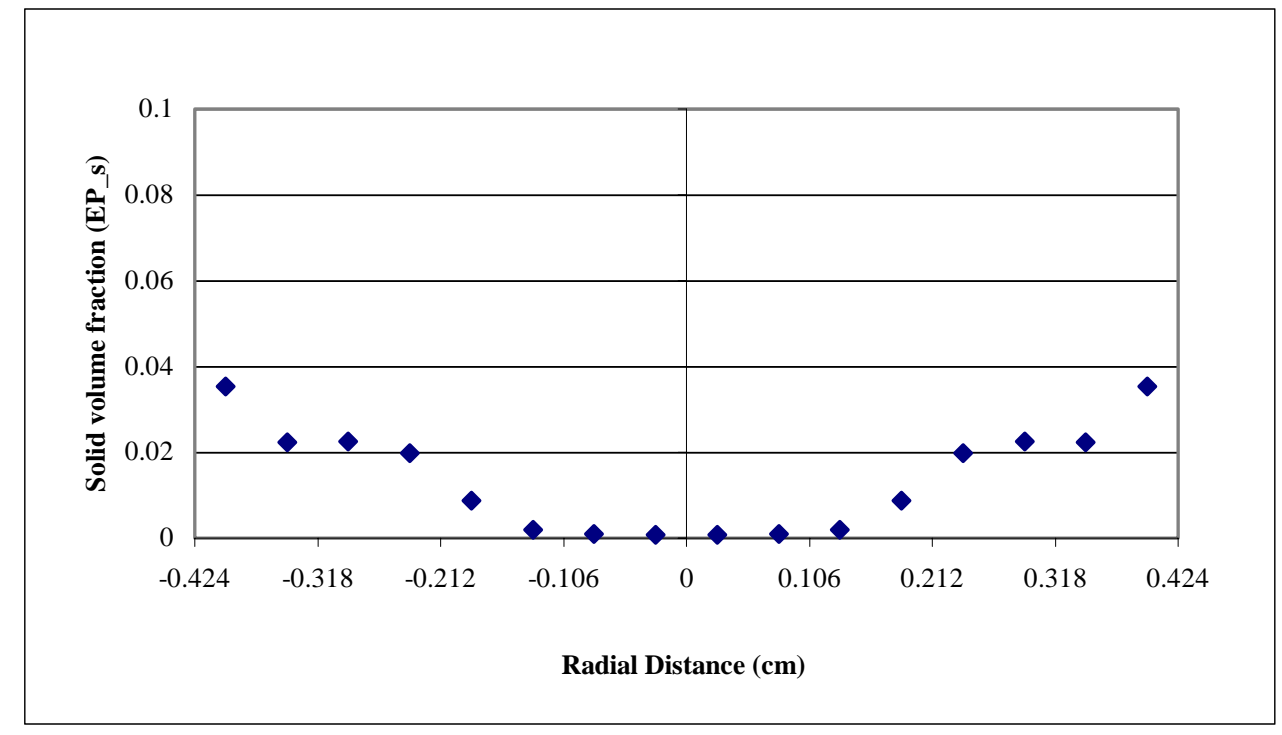

Figure 4.21. Variation of solid volume fraction with radial distance. Effect of gassolid boundary condition and solid viscosity. [Setup C]

The velocity profile (Figure 4.22) also changed from earlier cases with large slip in the center. Sulfur capture of $68 \%$ at a pressure drop of $10540 \mathrm{~N} / \mathrm{m}^{2}$ was predicted. The 
sulfur capture was doubled and the pressure drop was reduced by $40 \%$ in comparison with case 2.

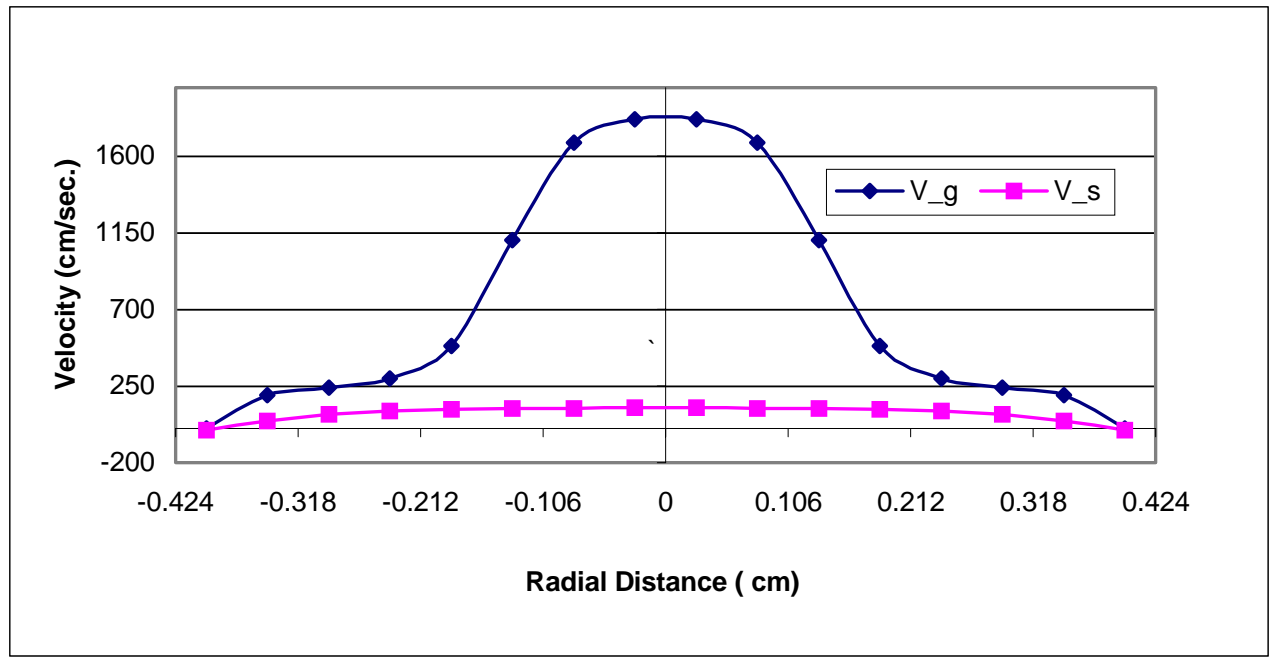

Figure 4.22. Variation of gas and solid velocity with radial distance. Effect of gas solid boundary condition and solid viscosity. [Setup C]

The boundary condition at the wall and the solid viscosity model affect the gas-solid hydrodynamics. This in turn affects the sulfur capture and the pressure drop inside the sulfidation reactor.

\subsubsection{Effect of the gas-solid reaction model on the sulfur capture.}

With setup $\mathbf{C}$ the results using unreacted shrinking core model and the grain model for gas solid reaction are shown in figures 4.23 and 4.24. The parameters used are listed earlier but the intrinsic reaction rate for unreacted shrinking core model was multiplied by a factor of 30 to account for the reaction rate based on the external surface area of the particle as the ratio of internal to external surface area of the sorbent under study was 30 . The solids volume fractions predicted for the two reaction models were more or less the same. Since the operating conditions were same only difference observed 
should be in the kinetics only which was verified from the sulfur capture for the two models. The sulfur capture for USC was around $8.4 \%$ and that for the grain model was $21.4 \%$ for the same pressure drop of around $1000 \mathrm{~N} / \mathrm{m}^{2}$ across the CFB.

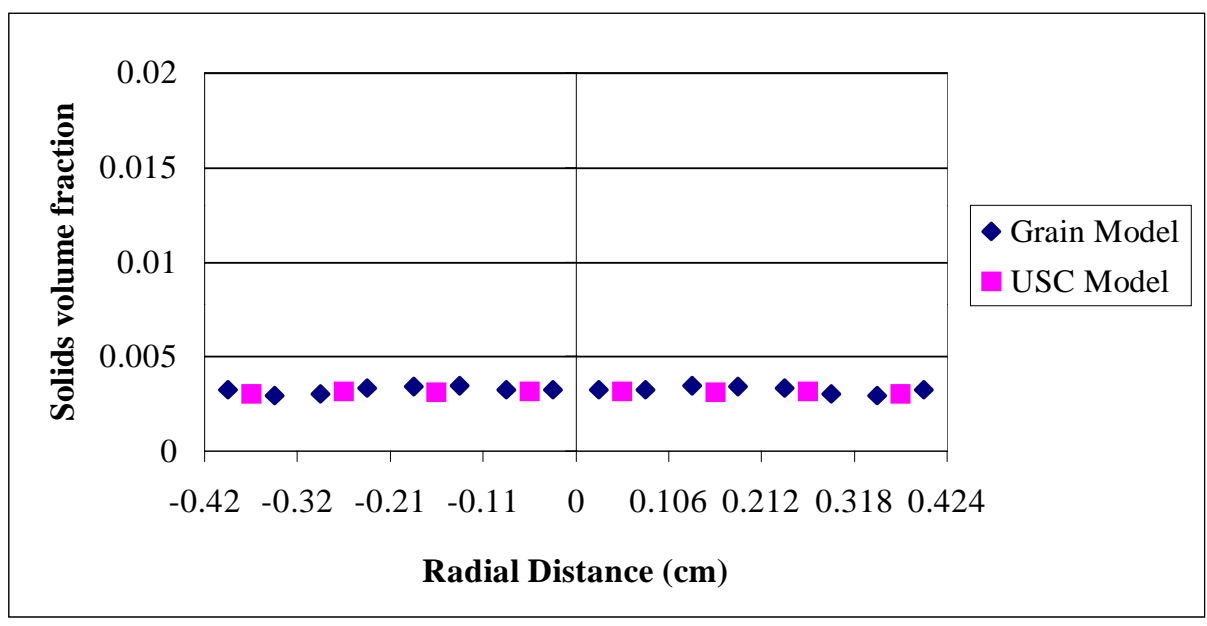

Figure 4.23. Variation of solids volume fraction with radial distance. A comparison between the grain model and the unreacted shrinking core model. [Setup C]

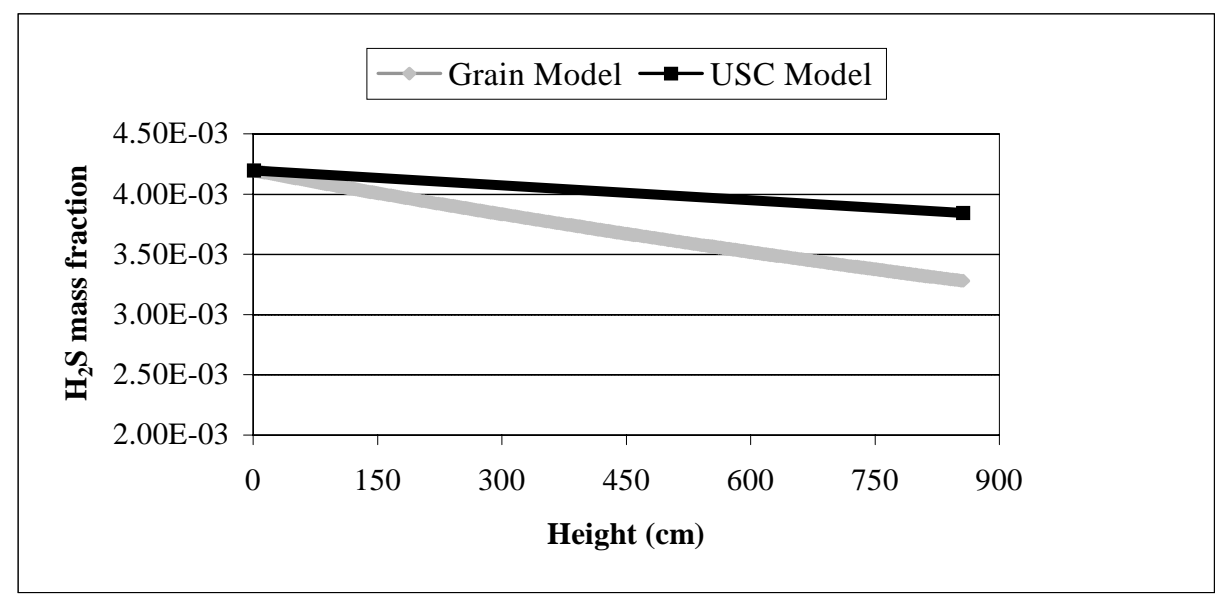

Figure 4.24. Variation of hydrogen sulfide mass fraction along the height of the CFB. A comparison between the grain model and the unreacted shrinking core model. [Setup C] 
Based on experiments performed at NETL, Morgantown, whose results are not yet released, sulfur capture of around 80-90 \% was observed for a pressure drop of 4000$7000 \mathrm{~N} / \mathrm{m}^{2}$ (personal communication). The results from cluster correction with grain model show a capture of around $80 \%$ for pressure drop of $3200 \mathrm{~N} / \mathrm{m}^{2}$. Also, the assumption of a turbulent core with pseudo steady state boundary condition at the wall gave a capture of around $70 \%$ for pressure drop of $10500 \mathrm{~N} / \mathrm{m}^{2}$. 


\section{CHAPTER V}

\section{CONCLUSION}

Grain model appears to appropriately describe the reaction kinetics the transport reactor. Although the overlapping grain model would be more comprehensive, its use is associated with numerical complexity and thus is not required for these experimental conditions. The unreacted shrinking core model appears to be inappropriate for these flow conditions as the sulfur capture efficiency obtained is lower than in the grain model for same operating conditions. Two hydrodynamic models combined with the grain model provide results close to the experimentally reported data. Based on experiments performed at NETL, Morgantown, whose results are not yet released, sulfur capture of around $80-90 \%$ was observed for a pressure drop of $4000-7000 \mathrm{~N} / \mathrm{m}^{2}$. The results from cluster correction with grain model show a capture of around $80 \%$ for pressure drop of $3200 \mathrm{~N} / \mathrm{m}^{2}$. Also, the assumption of a turbulent core with pseudo steady state boundary condition at the wall gave a capture of around $70 \%$ for pressure drop of $10500 \mathrm{~N} / \mathrm{m}^{2}$. Although the exact form of eddy viscosity that should be used is not determined, further investigation is required in that direction. The pressure drop across the bed is a critical parameter that governs sulfur capture. The first model causes an increase in pressure drop due to increase in the solids hold up, hence causing an increase in sulfur capture efficiency. The other approach causes an increase in the pressure drop due to more gas solid friction and hence causing a larger sulfur capture. With these models it was possible to predict the pressure drop and sulfur capture simultaneously with sufficient accuracy. However, in the absence of experimental data it is difficult to choose between the two models. Perhaps, the true hydrodynamic model could be a combination of these 
two models. Some of the parameters that affect sulfur capture were identified. Those parameters being the purity of the sorbent, which indicates the amount of zinc in the sorbent; the grain radius, which is dependent on the initial specific surface area and most importantly the pressure drop. Although the grain radius and the zinc concentration in the sorbent were obvious parameters but they affect the sulfur capture by a large extent. For the grain model the increase in the initial specific surface area of the sorbent causes almost a linear increase in the sulfur capture. 


\section{References}

Bhatia. S.K.; Perlmutter, D.D. "A Random Pore Model for Fluid-Solid Reactions", 1. Isothermal. Kinetic Control. A.I.Ch.E. J.1980. 26, 379-386.

Bhatia. S.K.; Perlmutter, D.D. Unified Treatment of Structural Effects in Fluid-Solid Reactions. A.I.Ch.E. J. 1983.29. 2S1-289.

Cave1o. A.; Cunningham. RE. "Kinetics of Gas-Solid Reactions. Influence of Surface Area and Effective Diffusivity Profiles.” J. Catal . 1970. .17, 1.9.

Edward B., "Report on Shrinking core model for hot as desulfurization using sorbents", FETC, September 1999.

Flytzani-Stephanopoulos, M; Z. Li. "Kinetics of Sulfidation Reaction Between $\mathrm{H}_{2} \mathrm{~S}$ and Bulk Oxide Sorbents." NATO ASI Series vol. G 42, edited by Atimay and Harrison Springer-Verlag Berlin Heidelberg 1998.

Flytzani-Stephanopoulos, M.; Gavalas, G. R.; Jothimurugesan, K.; Lew, S.; Sharma, P. K.; Bagajewicz, M. J.; Patrick, V. "Detailed Studies of Novel Regenerable Sorbents for High-Temperature Coal-Gas Desulfurization" ; Final Report DOE/MC/22193-2582, October 1987.

Flytzani-Stephanopoulos, M.; Gavalas, G. R.; Tamhankar, S. S.; Sharma, P. K. "Novel Sorbents for High-Temperature Regenerative $\mathrm{H}_{2} \mathrm{~S}$ Removal" ; Final Report DOE/MC/20417-1898, October 1985.

Gavalas, G.R. "A Random Capillary Model with Application to Char Gasification at Chemically Controlled Rates”. A.I.Ch.E. .J.1980, 26.577-585.

Gibson, J.B.; Harrison, D. P. “The Reaction Between Hydrogen Sulfide and Spherical Pellets of Zinc Oxide.”; Ind. Eng. Chem. Process Des. Dev. vol. 19 pp. 231-237, 1980.

Grindley, T.; Steinfeld, G. "Development and Testing of Regenerable Hot Coal Gas Desulfurization on Sorbents" ; Final Report DOE/ MC/16545-1125, October 1981. 
Gunn, D. J. "Transfer of Heat or Mass to Particles in Fixed and Fluidized beds," International Journal of Heat and Mass Transfer. 21:467-476, 1978,

Gupta, R. P.; and Gangwal, S.K. "Enhanced durability of Desulfurization Sorbents for fluidized bed applications”. Topical report, Research Triangle Institute, 1992.

Harrison, D. "Control of Gaseous Contaminants in IGCC Processes", An Overview. In The twelth Annual International Pittsburgh Coal Conference, Pittsburgh, PA, September 11-15, 1995; 1995; pp 1047-1052.

Jalan, V.; Wu, D. "High Temperature Desulfurization of Fuel Gases for Molten Carbonate Fuel Cell Power Plants". Paper presented at the National Fuel Cell Seminar, San Diego, CA, 1980.

Konttinen, J. T.; Zevenhoven, C. A. P.; Hupa, M. M. "Hot Gas Desulfurization with Zinc Titanate Sorbents in a Fluidized Bed" 1. Determination of Sorbent Particle Conversion Rate Model Parameters . lnd. Eng. Chem. Res. 1997, 36, 2332-2339.

Konttinen, J. T.; Zevenhoven, C. A. P.; Hupa, M. M. "Hot Gas Desulfurization with Zinc Titanate Sorbents in a Fluidized Bed" 2. Reactor Model lnd. Eng. Chem. Res. $1997,36,2340-2345$.

Kunii, D.; Levenspiel, 0. "Fluidization Engineering", 2nd ed.; Butterworth-Heinemann: Boston, 1991.

Levenspiel, 0. "Chemical Reaction Engineering"; John Wiley \& Sons: New York, 1972.

Lew, S. "High-Temperature Regenerative $\mathrm{H}_{2} \mathrm{~S}$ Removal by ZnO-TiO2 Systems". M.S. Thesis, Massachusetts Institute of Technology, Cambridge, 1987.

Lew, S. "The Reduction and Sulfidation of Zinc Titanate and Zinc Oxide Solids". Ph.D. Dissertation, Massachusetts Institute of Technology, Cambridge, 1990. 
Lew, S.; Sarofim, F.; Flytzani-Stephanopoulos, M. "Modeling of the Sulfidation of Zinc Titanium Oxide Sorbents with Hydrogen Sulfide ". A.I.C.H.E Journal 1992, 38, No. 8 pp.1161-1169.

Lew, S.; Sarofim, F.; Flytzani-Stephanopoulos, M. "The Sulfidation of Zinc Titanate and Zinc Oxide Solids”. Ind. Eng. Chem. Res. 1992, 31, 1890-1899.

Mojtahedi, W.; Abbasian, J. " $\mathrm{H}_{2} \mathrm{~S}$ Removal from Coal Gas at Elevated Temperature and Pressure in Fluidized Bed with Zinc Titanate Sorbents. 1. Cyclic Tests”. Energy Fuels 1995a, 9 (3), 429-434

Mojtahedi, W.; Abbasian, J. " $\mathrm{H}_{2} \mathrm{~S}$ Removal from Coal Gas at Elevated Temperature and Pressure in Fluidized Bed with Zinc Titanate Sorbents. 2. Sorbent Durability." Energy Fuels 1995b, 9 (5), 782-787

Mojtahedi, W.; Salo, K.; Abbasian, J. "Desulfurization of hot coal gas in fluidized bed with regenerable zinc titanate sorbents.” Fuel Process. Technol. 1994, 37, 53-65.

Mojtahedi, W.; Konttinen, J.; Gangwal, S. "Sulfidation-Regeneration Kinetics of Zinc Titanate Sorbents. In High Temperature Gas Cleaning"; Schmidt, E., Gang, P., Pilz, T., Dittler, A., Eds.; G.Braun Printconsult GmbH: Karlsruhe, Germany, September 1996; pp $557-568$

O'Brien, T.J.; and M. Syamlal, "Particle cluster effects in the numerical simulation of a circulating fluidized bed," in Circulating Fluidized Bed Technology IV, ed. A. Avidan, Proceedings of the Fourth International Conference on Circulating Fluidized Beds, August, 1993.

"Perry`s Chemical Engineering Handbook". 6 th edition D.W green and J.O. Maloney editors. McGraw-Hill, 1984, pp. 3-181.

Peterson, E.E. “Reaction of Porous Solids”. A.I.Ch.E. J. 1957. 3, 443-448. 
Ranade, P. V.; Harrison, D. P. "The Variable Property Grain Model Applied to the Zinc Oxide - Hydrogen Sulfide Reaction.” Chem. Eng. Sci. vol. 36 pp.1079-1089, 1981.

Ramachandran. P,A.; Smith, J.M.; “A Single-Pore Model for Gas-Solid Non-Catalytic Reactions”. A.I.Ch.E. J. 1977,23. 353-361..

Salo, K.; Hokajiirvi, R. "Development of New Generation IGCC”. In Eleventh Annual International Pittsburgh Coal Conference, Pittsburgh, PA, September 12-16, 1994; 1994.

Salo, K.; Konttinen, J.; Ghazanfari, R.; Feher, G.; Lehtovaara, A.; Mojtahedi, W. "Pilot Scale Experiments on IGCC Hot Gas Cleanup". In Proceedings of the Advanced CoalFired Power Systems '95 Review Meeting, Volume 1, June 1995; U.S. Department of Energy, Morgantown Energy Technology Center: Morgantown, WY,1995.

Sotirchos. S. V.; Yu. H.C. “Overlapping Grain Model for Gas-Solid Reactions with Solid Product”. lnd. Eng. Chem. Res. 1988, 27. 836-845.

Syamlal, M.; Rogers, W.; O’Brian, T. J, “ MFIX Documentation Theory Guide, Technical Note," DOE/METC-94/1004, December 1993,

Szekely, J.; Evans J. W. Sohn, H.Y.,Gas solid reactions, academic Press , New York , 1976.

Westmorland, P.R.; Harrison, D.P. Evaluation of Candidate Solids for High- Temperature Desulfurization of Low Btu Gases. Environ. Sci. Technol. 1976, 10, 659-660.

Zevenhoven, C.A.P.; Yrjas, K.P.; Hupa, M.M. "Hydrogen Sulfide Capture by Limestone and Dolomite at Elevated Pressure. 2. Sorbent Particle Conversion Modeling." Ind. Eng. Chem. Res. 1996, 35 (3), 943-949.

Zevenhoven, C.A.P.; Yrjas, K.P.; Hupa, M.M. "How does sorbent particle structure influence sulphur capture under PFBC conditions ?" Proceedings of the $13^{\text {th }}$ International Conference on Fluidized Bed Combustion, Orlando, FL, 1995; ASME: Fairfield, NJ, 1995; pp 1381-1392. 


\section{Appendix A.}

\section{Summary of Equations :}

\section{Desulfurization reaction:}

$\mathrm{bH}_{2} \mathrm{~S}+$ fresh sorbent $(\mathrm{ZnO}) \rightarrow(18 \mathrm{~b} / 34) \mathrm{H} 2 \mathrm{O}+(1+16 \mathrm{~b} / 34)$ spent sorbent $(\mathrm{ZnS})$.

$\mathrm{b}=$ grams of $\mathrm{H}_{2}$ S reacting per gram of fresh sorbent.

\section{Gas Continuity :}

$\frac{\partial}{\partial t}\left(\varepsilon_{g} \rho_{g}\right)+\nabla \cdot\left(\varepsilon_{g} \rho_{g} \overrightarrow{v_{g}}\right)=$ rate of production of gaseous species $=18 b R_{g} / 34-b_{g}$

$\mathrm{R}_{\mathrm{g}}$ (grain model $)=\frac{\left(\frac{3 \mathrm{r}_{\mathrm{r}}^{2}\left(1-\varepsilon_{\mathrm{g}}\right)\left(1-\varepsilon_{0}\right)}{\mathrm{r}_{0}^{3}}\right)\left(\frac{\mathrm{C}_{\mathrm{H}_{2} \mathrm{~S}}}{\varepsilon_{\mathrm{g}}}\right)}{\frac{1}{\mathrm{~K}}-\frac{\mathrm{r}_{\mathrm{r}}^{2}}{\mathrm{D}_{\mathrm{e}}}\left[\frac{1}{\mathrm{r}_{\mathrm{p}}}-\frac{1}{\mathrm{r}_{\mathrm{r}}}\right]} ; \mathrm{R}_{\mathrm{g}}(\mathrm{USC})=\frac{\left.\left(\frac{3\left(1-\varepsilon_{\mathrm{g}}\right)}{\mathrm{R}}\right) \frac{\mathrm{C}_{\mathrm{H}_{2} \mathrm{~S}}}{\varepsilon_{\mathrm{g}}}\right)}{\frac{1}{\mathrm{~K}_{\mathrm{g}}}-\frac{\mathrm{R}^{2}}{\mathrm{D}_{\text {eff }}}\left[\frac{1}{\mathrm{R}}-\frac{1}{\mathrm{r}_{\mathrm{r}}}\right]+\frac{\mathrm{R}^{2}}{\mathrm{r}_{\mathrm{r}}^{2} \mathrm{~K}}}$

$\mathrm{K}=1.31 \exp \left(\frac{-10300 \mathrm{cal} / \mathrm{mole}}{\mathrm{RT}}\right) \frac{\mathrm{cm}}{\mathrm{s}} ; \quad \mathrm{D}_{\mathrm{e}}=0.00049 \exp \left(\frac{-22000 \mathrm{cal} / \mathrm{mole}}{\mathrm{RT}}\right) \frac{\mathrm{cm}^{2}}{\mathrm{~s}}$

$\mathrm{D}_{\text {eff }}=0.001(\mathrm{~T} / 273)^{1 / 2} \frac{\mathrm{cm}^{2}}{\mathrm{~s}} ; \mathrm{K}_{\mathrm{g}}=\frac{\mathrm{D}_{\mathrm{M}^{\mathrm{N}}} \mathrm{sh}}{\mathrm{d}_{\mathrm{p}}} \frac{\mathrm{cm}}{\mathrm{s}}$

\section{Solids Continuity :}

$\frac{\partial}{\partial t}\left(\varepsilon_{S} \rho_{S}\right)+\nabla \cdot\left(\varepsilon_{S} \rho_{S} \overrightarrow{v_{S}}\right)=$ rate of production of solid species $=(1+16 b / 34) R_{g}-R_{g}$

\section{Gas momentum balance:}

$\frac{\partial}{\partial t}\left(\varepsilon_{g} \rho_{g} \overrightarrow{v_{g}}\right)+\nabla \cdot\left(\varepsilon_{g} \rho_{g} \overrightarrow{v_{g} v_{g}}\right)=-\nabla P_{g}+\nabla \cdot \overline{\overline{\tau_{g}}}+F_{g}\left(\overrightarrow{v_{s}}-\overrightarrow{v_{g}}\right)+\varepsilon_{g} \rho_{g} \vec{g}-\left(16 b R_{g} / 34\right) \overrightarrow{v_{g}}$

$\overline{\overline{\tau_{g}}}=2 \varepsilon_{g} \mu_{g} \nabla^{S} v_{g}-2 / 3 \varepsilon_{g} \mu_{g} \nabla \cdot v_{g} \stackrel{=}{I}$

$\nabla^{\mathrm{S}} \mathrm{v}_{\mathrm{g}}=\frac{1}{2}\left[\nabla \mathrm{v}_{\mathrm{g}}+\nabla \mathrm{v}_{\mathrm{g}} \mathrm{T}\right]$ 


\section{Solid momentum balance :}

$\frac{\partial}{\partial \mathrm{t}}\left(\varepsilon_{\mathrm{s}} \rho_{\mathrm{s}} \overrightarrow{\mathrm{v}_{\mathrm{s}}}\right)+\nabla \cdot\left(\varepsilon_{\mathrm{s}} \rho_{\mathrm{s}} \overrightarrow{\mathrm{v}_{\mathrm{s}}} \overrightarrow{\mathrm{v}_{\mathrm{s}}}\right)=\nabla \cdot \overline{\overline{\mathrm{S}_{\mathrm{s}}}}+\varepsilon_{\mathrm{s}} \rho_{\mathrm{s}} \overrightarrow{\mathrm{g}}-\mathrm{F}_{\mathrm{g}}\left(\overrightarrow{\mathrm{v}_{\mathrm{s}}}-\overrightarrow{\mathrm{v}_{\mathrm{g}}}\right)+(16 \mathrm{bR} \mathrm{g} / 34) \overrightarrow{\mathrm{v}_{\mathrm{s}}}$

$\overline{\overline{\mathrm{S}_{\mathrm{s}}}}=2 \mu_{\mathrm{s}} \nabla^{\mathrm{s}} \mathrm{v}_{\mathrm{s}}-2 / 3 \mu_{\mathrm{s}} \nabla \cdot \mathrm{v}_{\mathrm{s}} \overline{\overline{\mathrm{I}}} ; \mu_{\mathrm{s}}=5.34 \varepsilon_{\mathrm{s}}$ and from kinetic theory.

$\nabla^{\mathrm{s}} \mathrm{v}_{\mathrm{s}}=\frac{1}{2}\left[\nabla \mathrm{v}_{\mathrm{s}}+\nabla \mathrm{v}_{\mathrm{s}}^{\mathrm{T}}\right]$

\section{Gas species balance :}

$\frac{\partial}{\partial t}\left(\varepsilon_{g} \rho_{g} X_{g n}\right)+\nabla \cdot\left(\varepsilon_{g} \rho_{g} X_{g n} \overrightarrow{v_{g}}\right)=R_{g n}$

\section{Solids species balance :}

$\frac{\partial}{\partial \mathrm{t}}\left(\varepsilon_{\mathrm{sm}} \rho_{\mathrm{sm}} X_{\mathrm{smn}}\right)+\nabla \cdot\left(\varepsilon_{\mathrm{sm}} \rho_{\mathrm{sm}} X_{\mathrm{smn}} \overrightarrow{\mathrm{v}_{\mathrm{sm}}}\right)=\mathrm{R}_{\mathrm{smn}}$

\section{Gas solid drag :}

$$
\begin{aligned}
& \mathrm{F}_{\mathrm{g}}=\frac{3 \varepsilon_{\mathrm{s}} \rho_{\mathrm{g}}}{4 \mathrm{~V}_{\mathrm{rm}}^{2} \mathrm{~d}_{\mathrm{pm}}}\left(0.63+4.8 \sqrt{\mathrm{V}_{\mathrm{rm}} / \mathrm{Re}_{\mathrm{m}}}\right)^{2}\left|\overrightarrow{\mathrm{V}_{\mathrm{s}}}-\overrightarrow{\mathrm{v}_{\mathrm{g}}}\right| \\
& \mathrm{V}_{\mathrm{rm}}=0.5\left(\mathrm{~A}-0.06 \mathrm{Re}_{\mathrm{m}}+\sqrt{\left(0.06 \mathrm{Re}_{\mathrm{m}}\right)^{2}+0.12 \mathrm{Re}_{\mathrm{m}}(2 \mathrm{~B}-\mathrm{A})+\mathrm{A}^{2}}\right) * \\
& *\left(1.0+\mathrm{C}(1) \exp \left(-0.005\left(\operatorname{Re}_{\mathrm{m}}-5.0\right)^{2}-90.0\left(\varepsilon_{\mathrm{g}}-0.92\right)^{2}\right) \operatorname{Re}_{\mathrm{m}}\left(1-\varepsilon_{\mathrm{g}}\right)\right)
\end{aligned}
$$

Where $\mathbf{C}(\mathbf{1})$ is the correction factor which accounts for clustering

$$
\mathrm{A}=\varepsilon_{\mathrm{g}}{ }^{4.14} ; \mathrm{B}=0.8 \varepsilon_{\mathrm{g}}{ }^{1.28} \text { if } \varepsilon_{\mathrm{g}} \leq 0.85 \& \mathrm{~B}=\varepsilon_{\mathrm{g}}{ }^{2.65} \text { if } \varepsilon_{\mathrm{g}}>0.85
$$




\title{
Appendix B.
}

\section{MFIX Sample Subroutines}

\author{
Sample Data File \\ mfix.dat \\ \# Run-control section \\ \# \\ RUN_NAME $=$ 'HOT GAS DESULP' \\ RUN_TYPE $=$ 'restart_1' \\ UNITS $=$ 'cgs' \\ TIME $=0.0$ \\ TSTOP $=50.0$ \\ $\mathrm{DT}=1.0 \mathrm{E}-4$ \\ ENERGY_EQ $=$.TRUE. \\ SPECIES_EQ $(0)=$. TRUE. \\ SPECIES_EQ $(1)=$.TRUE. \\ MODEL_B $=$.TRUE. \\ DISCRETIZE $=8 * 2$ \\ CALL_USR $=$.TRUE. \\ NORM_g $=5.0$ \\ NORM_s $=10.0$ \\ \# Geometry Section \\ \# \\ COORDINATES $=$ 'Cylindrical' \\ IMAX $=8$ \\ XLENGTH $=0.424$ \\ $\mathrm{JMAX}=285$ \\ YLENGTH $=855.0$ \\ $\mathrm{KMAX}=4$ \\ ZLENGTH $=@(2.0 * \mathrm{PI})$ \\ \# NO_K $=$.TRUE. \\ \# Gas-phase Section \\ \# \\ $\operatorname{NMAX}(0)=3$ \\ MW_g $(1)=28.0$ \\ MW_g(2)=18.0 \\ MW_g(3) $=34.0$ \\ MU_g0 $=3.17 \mathrm{E}-4$
}

DESCRIPTION $=$ 'RXN H2S REMOVAL' 


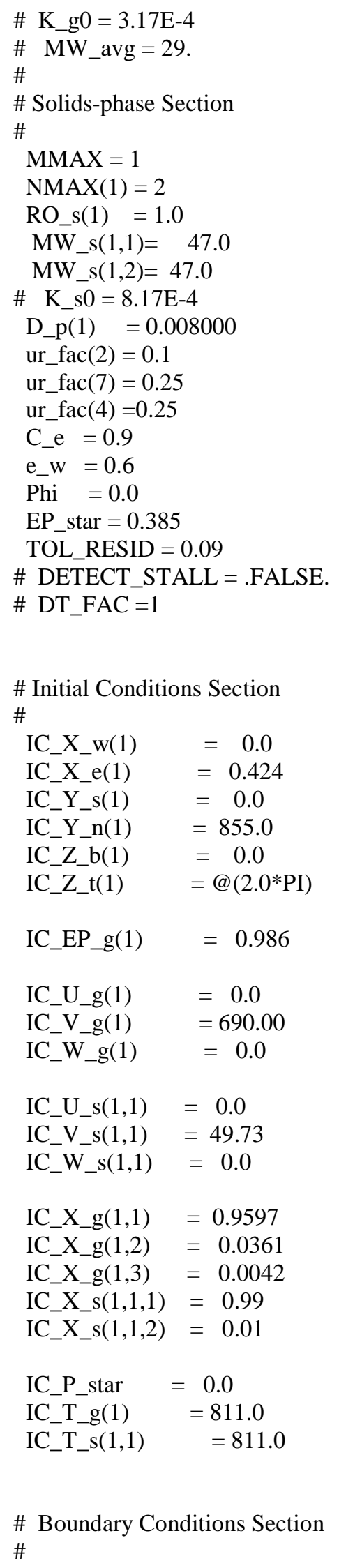




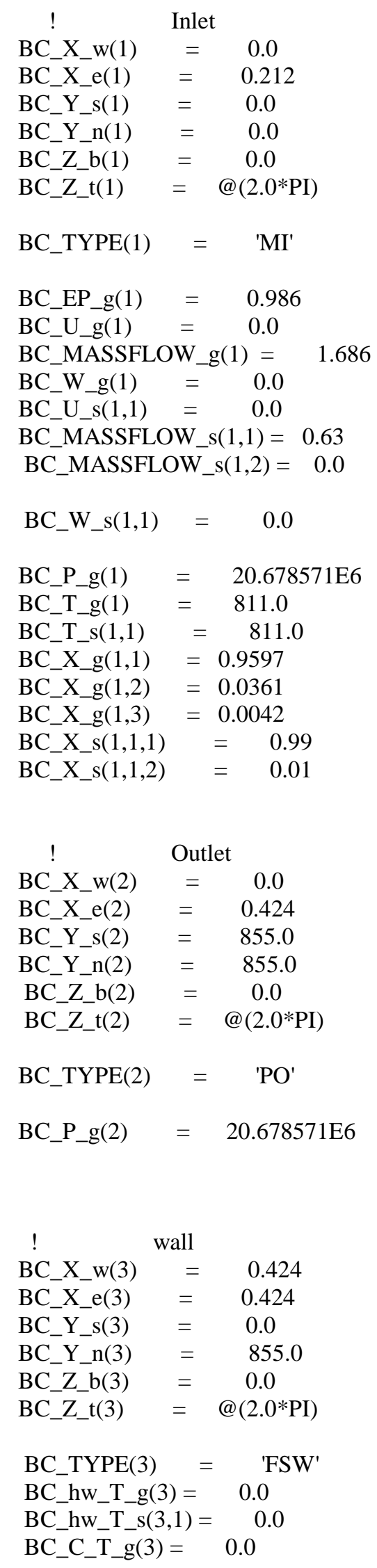




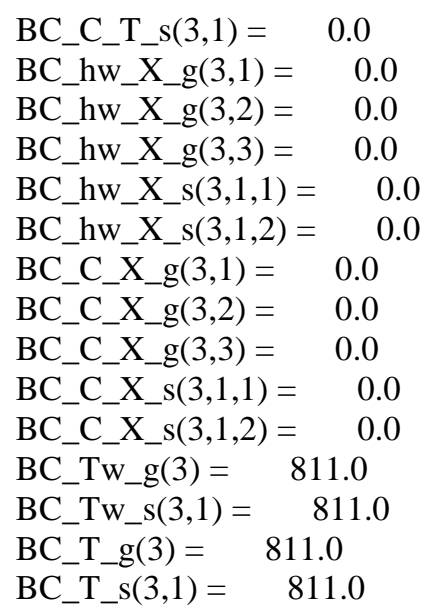

\#OUTPUT CONTROL SECTION

RES DT $=0.2$

OUT_DT $=1.0$

!

! EP_g P_g U_g U_s ROP_s T_g X_g

$! \quad$ P_star V_g V_s $\quad$ T_s1 $\quad$ X_s

! W_g W_s $\quad$ T_s2

SPX DT $=9 * 0.2$

USR_DT $(1)=0.5$

$\mathrm{NLOG}=25$

FULL_LOG $=$.TRUE. 


\section{Reaction Chemistry Subroutine rrates.f}

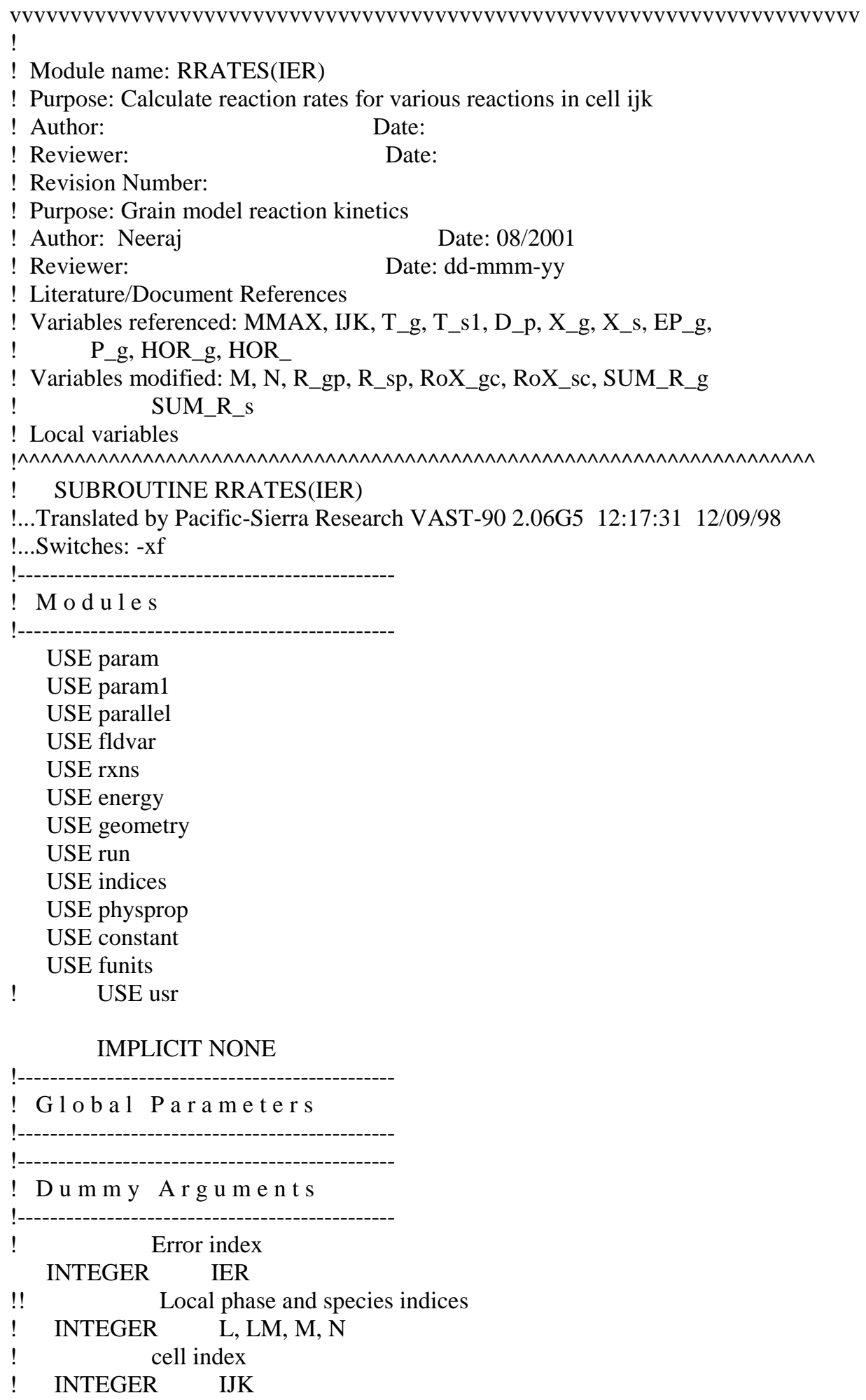

DOUBLE PRECISION R_tmp(0:MMAX, 0:MMAX) 
DOUBLE PRECISION resist,Dpl,B

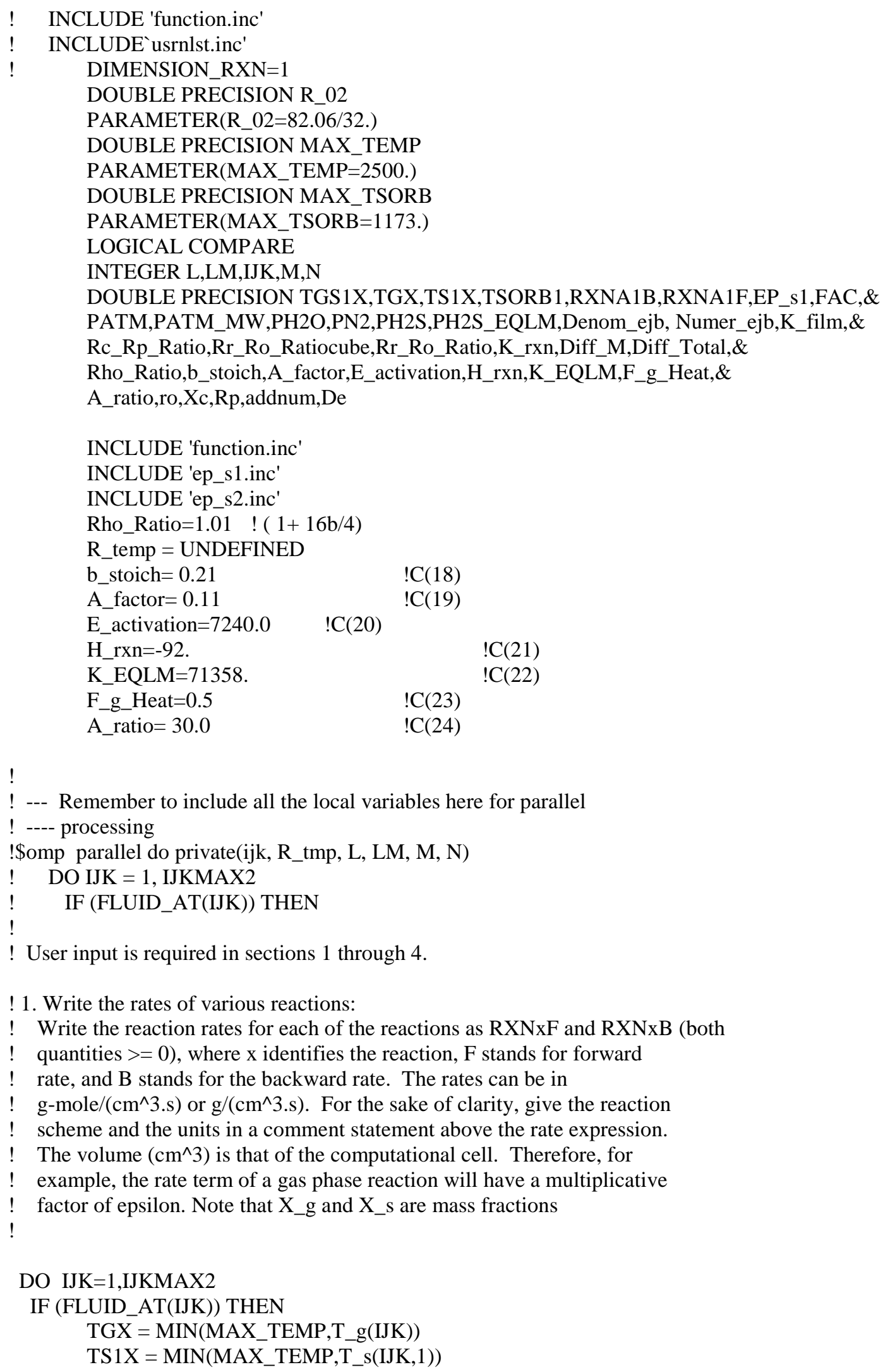

!1. Write the rates of various reactions:

! Write the reaction rates for each of the reactions as $\mathrm{RXNxF}$ and $\mathrm{RXNxB}$ (both quantities $>=0$ ), where $\mathrm{x}$ identifies the reaction, $\mathrm{F}$ stands for forward rate, and $\mathrm{B}$ stands for the backward rate. The rates can be in g-mole/( $\left.\mathrm{cm}^{\wedge} 3 . \mathrm{s}\right)$ or $\mathrm{g} /\left(\mathrm{cm}^{\wedge} 3 . \mathrm{s}\right)$. For the sake of clarity, give the reaction scheme and the units in a comment statement above the rate expression.

! The volume $\left(\mathrm{cm}^{\wedge} 3\right)$ is that of the computational cell. Therefore, for

! example, the rate term of a gas phase reaction will have a multiplicative

! factor of epsilon. Note that X_g and X_s are mass fractions

! 
TSORB1 = MIN(MAX_TSORB,T_s(IJK,1))

TGS1X=HALF*(TGX+TS1X)

!COMPUTE PARTIAL PR OF VARIOUS GASES IN ATM. P_G IN DYNES/CM^2

PATM=P_g(IJK)/1013000.

PATM_MW $=$ PATM*MW_MIX_g(IJK)

PN2=PATM_MW*X_g(IJK,1)/MW_g(1)

PH2O=PATM_MW*X_g(IJK,2)/MW_g(2)

PH2S=PATM_MW*X_g(IJK,3)/MW_g(3)

PH2S_EQLM=PH2O/K_EQLM

EP_s1=EP_s(IJK,1)

!grain model desulfurization reaction

! b H2S + sorbent_fresh -> (18b/34)H2O + (1+16b/34)Sorbent_spent $\left(\mathrm{g} / \mathrm{cm}^{\wedge} 3 . \mathrm{s}\right)$

! $\mathrm{R}=1.987 \mathrm{cal} / \mathrm{gmol} . \mathrm{K}$ or $82.06 \mathrm{~cm}^{\wedge} 3 \mathrm{~atm} / \mathrm{mol} \mathrm{K}$.

RXNA1F=ZERO

IF(PH2S.GT.PH2S_EQLM)THEN

IF(.NOT.COMPARE(EP_g(IJK),ONE))THEN

IF(X_s(IJK,1,1).GT.ZERO)THEN

Rr_Ro_Ratiocube $=$ \&

$((1.0-(1 /$ Rho_Ratio $)+(1 /($ Rho_Ratio*X_s(IJK, 1,1$)))) \&$

-SQRT((1.0-(1/Rho_Ratio)+(1/(Rho_Ratio*X_s(IJK,1,1))))**2.\&

$-1.1014 *(-(1 /$ Rho_Ratio) $+(1 /($ Rho_Ratio*X_s(IJK,1,1)))) ))\&

$/(0.5507 *(-(1 /$ Rho_Ratio) $+(1 /($ Rho_Ratio*X_s(IJK,1,1)) ))

Rr_Ro_Ratio $=($ Rr_Ro_Ratiocube $) * *(1 . / 3$. $)$

Rr_Ro_Ratio $=$ MIN $\left(\mathrm{ONE}, \mathrm{Rr} \_\right.$Ro_Ratio $)$

ELSE

Rr_Ro_Ratio $=$ ZERO

ENDIF

ELSE

Rr_Ro_Ratio $=$ ZERO

ENDIF

IF(Rr_Ro_Ratio.EQ.ZERO .OR. EP_s1.EQ.ZERO)THEN

RXNA1F=ZERO

ELSE

Diff_M $=0.16 *$ SQRT(TGX/273.)

Diff_Total $=0.09 *$ Diff_M

K_film = Diff_M*N_sh(IJK)/D_p(1)

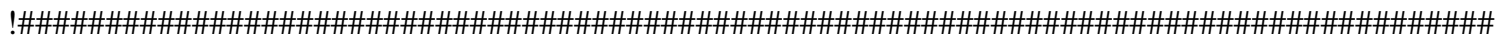
\#\#\#\#\#

!Grain model with parameters same as used in Boyles model same rxx kinetics

!Model rates based on external surface area of the particle $\mathrm{Z}=1.34$ for $\mathrm{ZnO}$

!A_ratio will definately come into play. De used from Harrison and Ranade`s model

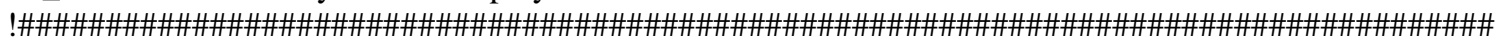

\#\#\#\#\#

! ro $=3.0 / 10.0 \mathrm{E} 4.0 * 1.0)$ from Berry approximate Ao,s= between 2 - 5E4sq.cm/g

ro $=0.300 \mathrm{e}-4$

!lews thesis and that rc/rp from mfix 
! we get the expression below-------------A

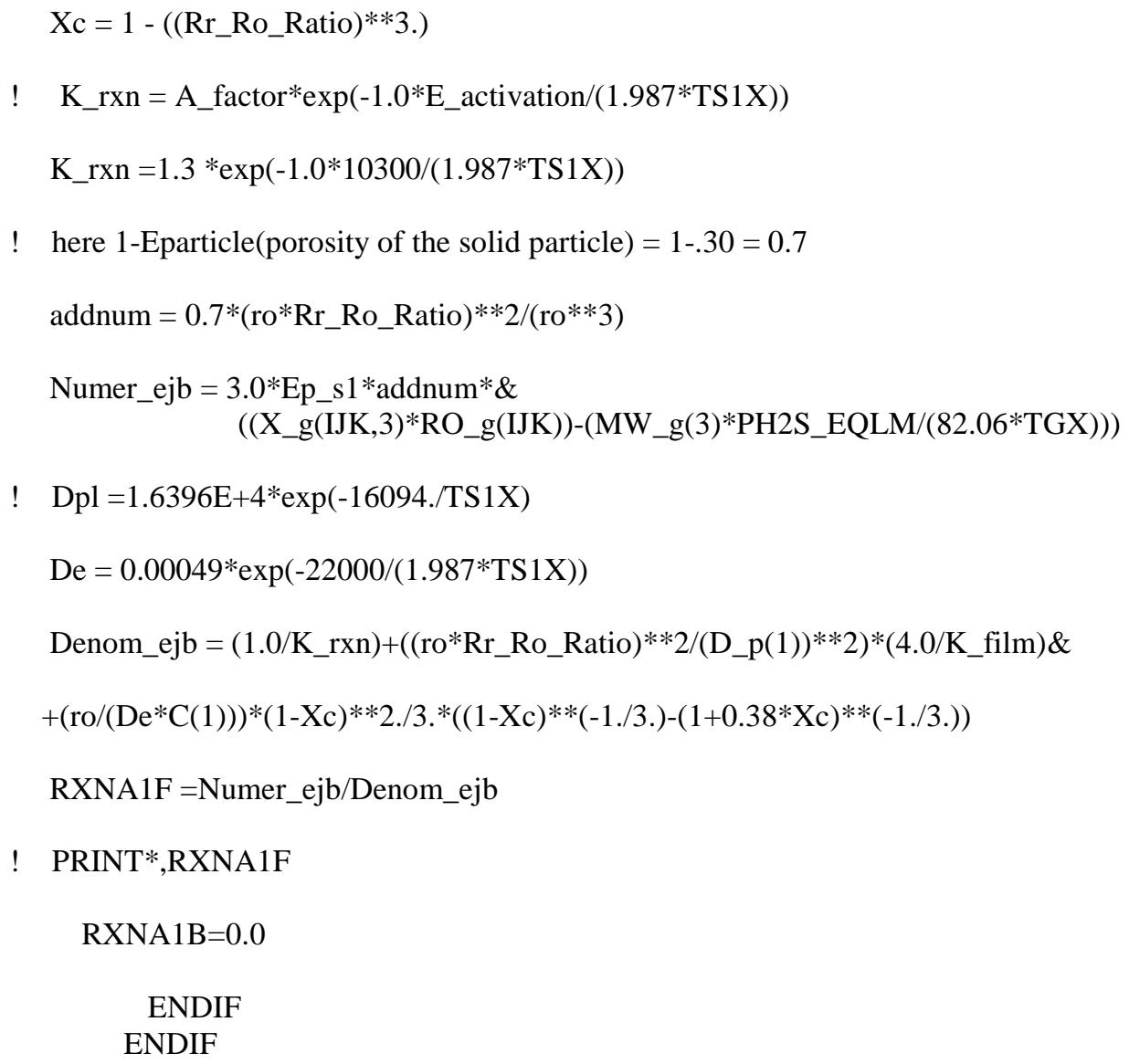


! 2. $\mathrm{H} 2 \mathrm{O}$

R_gp $(\mathrm{IJK}, 2)=18.0 *$ b_stoich*RXNA1F/34.0

RoX_gc(IJK,2)=ZERO ! Neeraj

!3. $\mathrm{H} 2 \mathrm{~S}$

IF(X_g(IJK,3).GT.ZERO)THEN

RoX_gc(IJK,3) = b_stoich*RXNA1F/X_g(IJK,3)

ELSE

ENDIF

RoX_gc $(I J K, 3)=1.0 \mathrm{e}-9$

R_gp $(I J K, 3)=$ ZERO ! Neeraj

!solids species

!1. sorbent fresh

IF(X_s(IJK,1,1).GT.ZERO)THEN

RoX_sc(IJK,1,1) = RXNA1F/X_s(IJK, 1,1)

ELSE

RoX_sc(IJK, 1,1$)=1.0 \mathrm{e}-7$

ENDIF

!2. sorbent spent

R_sp $(\mathrm{IJK}, 1,2)=(1.0+(16 *$ b_stoich/34.0) $) * \mathrm{RXNA1F}$

RoX_sc(IJK,1,2)=ZERO! Neeraj

R_sp(IJK,1,1)=ZERO! Neeraj

!333333333333333333333333333333333333333333333333333333333333333333333333333333333333333

!

!3. Determine the $\mathrm{g} /\left(\mathrm{cm}^{\wedge} 3 . \mathrm{s}\right)$ transferred from one phase to the other.

! R_tmp(To phase \#, From phase \#)

! R_temp(Rxn\#, To phase \#, From phase \#)

! e.g. R_tmp $(0,1)$ - mass generation of gas phase from solids-1,

R_tmp $(0,2)$ - mass generation of gas phase from solids-2,

$\mathrm{R}_{-} \mathrm{tmp}(1,0)$ - mass generation of solid-1 from gas $=-\mathrm{R}_{-} \mathrm{tmp}(0,1)$

R_tmp $(1,2)$ - mass generation of solid-1 from solids- 2 .

Note, for example, that if gas is generated from solids- 1 then

! R_tmp $(0,1)>0$.

! The R-phase matrix is skew-symmetric and diagonal elements are not needed.

! Only one of the two skew-symmetric elements -- e.g., R_tmp $(0,1)$ or

! R_tmp $(1,0)--$ needs to be specified.

! $\quad$ R_tmp $(0,1)=$ ZERO

!

!desulfurization reaction

R_temp $(1,0,1)=-16.0 *$ b_stoich $*$ RXNA1F $/ 34.0$ 
!

!4. Determine the heat of reactions in $\mathrm{cal} /\left(\mathrm{cm}^{\wedge} 3 . \mathrm{s}\right)$ at the

! temperature T_g or T_s1. Note that for exothermic reactions

! HOR_g (or HOR_s) will be negative. The assignment of heat of reaction

! is user defined as it depends upon the microphysics near the interface,

! which is averaged out in the multiphase flow equations. For example,

! heat of Reaction for the $\mathrm{C}+\mathrm{O} 2$ reaction is split into parts;

! $\mathrm{CO}$ formation is assigned to the solid phase and $\mathrm{CO} 2$ formation from $\mathrm{CO}$ to

! the gas phase.

!desulfurization reaction

$$
\begin{aligned}
& \text { HOR_g(IJK) }=\text { H_rxn*F_g_Heat*RXNA1F } \\
& \text { HOR_s(IJK,1) = H_rxn*(1.0-F_g_Heat }) * R X N A 1 F
\end{aligned}
$$

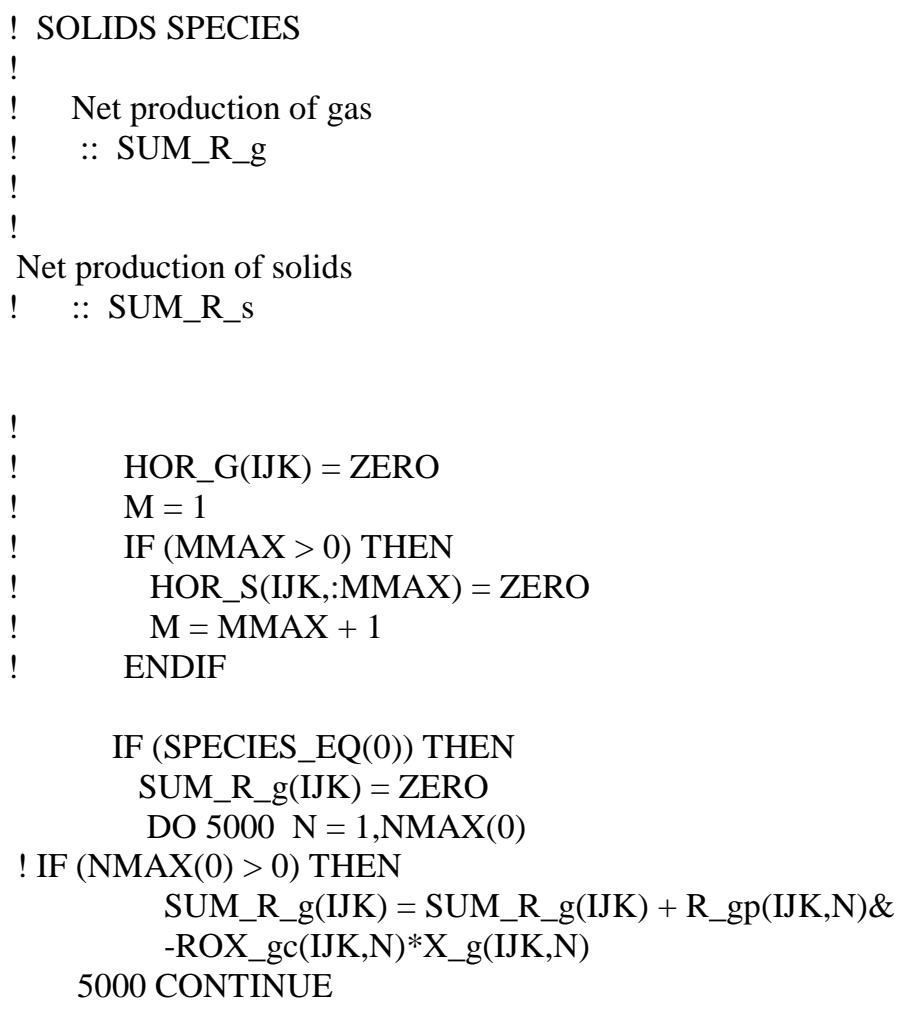

! ENDIF

ENDIF

DO $\mathrm{M}=1$, MMAX

IF (SPECIES_EQ(M)) THEN

SUM_R_s(IJK,M) = ZERO

DO $5200 \mathrm{~N}=1$, NMAX(M)

! IF (NMAX $(\mathrm{M})>0)$ THEN 


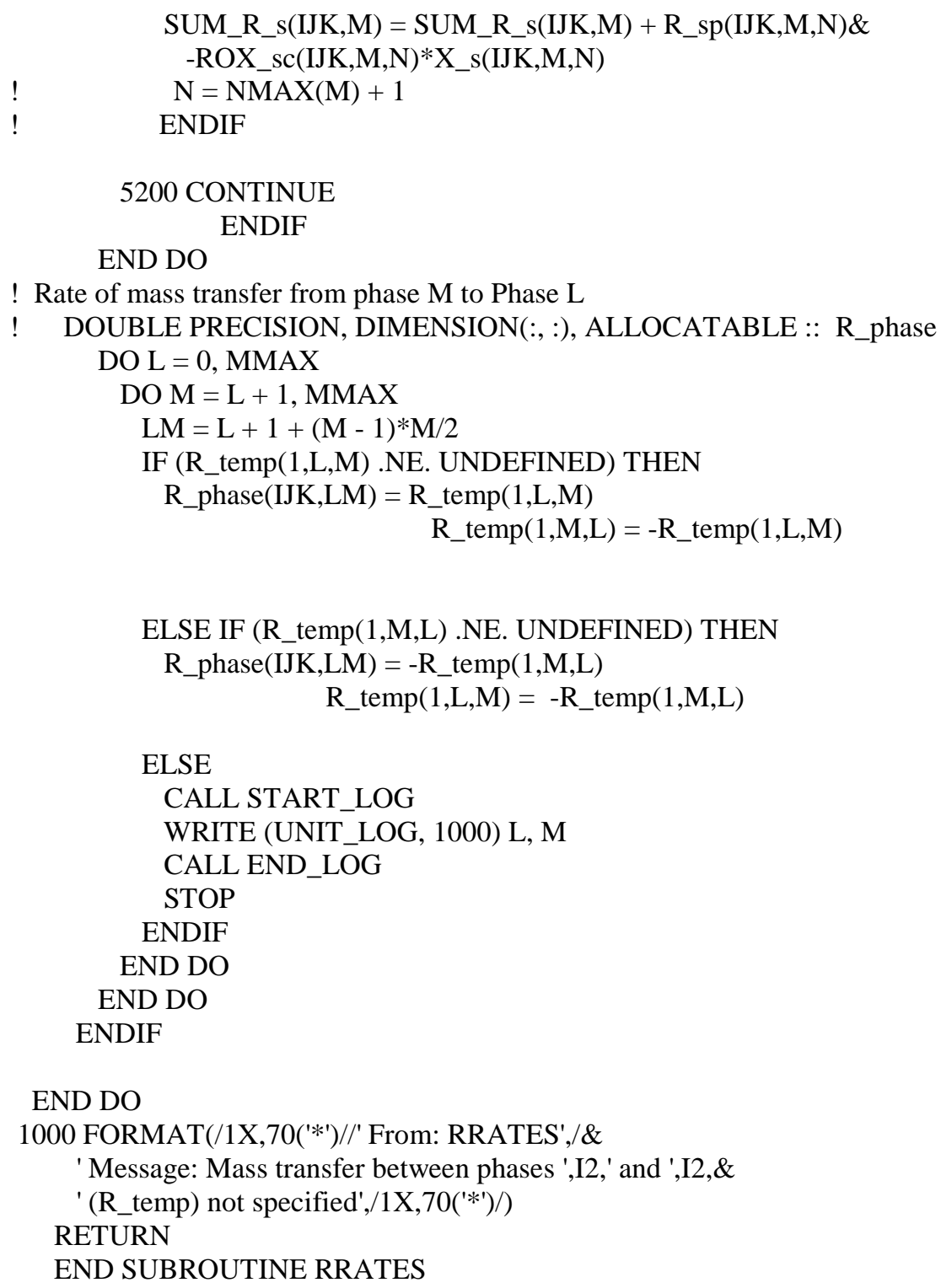

